\title{
The Effects of Tracheal Occlusion on Wnt Signaling in a Rabbit Model of Congenital Diaphragmatic Hernia
}

\author{
Martina M. Mudri, The University of Western Ontario \\ Supervisor: Bütter, Andreana, The University of Western Ontario \\ Co-Supervisor: Regnault, Timothy R.H., The University of Western Ontario \\ A thesis submitted in partial fulfillment of the requirements for the Master of Science degree in \\ Surgery \\ (C) Martina M. Mudri 2018
}

Follow this and additional works at: https://ir.lib.uwo.ca/etd

Part of the Animal Structures Commons, Congenital, Hereditary, and Neonatal Diseases and Abnormalities Commons, Musculoskeletal System Commons, Respiratory System Commons, and the Tissues Commons

\section{Recommended Citation}

Mudri, Martina M., "The Effects of Tracheal Occlusion on Wnt Signaling in a Rabbit Model of Congenital Diaphragmatic Hernia" (2018). Electronic Thesis and Dissertation Repository. 5736.

https://ir.lib.uwo.ca/etd/5736

This Dissertation/Thesis is brought to you for free and open access by Scholarship@Western. It has been accepted for inclusion in Electronic Thesis and Dissertation Repository by an authorized administrator of Scholarship@Western. For more information, please contact wlswadmin@uwo.ca. 


\section{ABSTRACT}

Purpose: Tracheal occlusion (TO) reverses pulmonary hypoplasia (PH) in congenital diaphragmatic hernia $(\mathrm{CDH})$, but its effect on epithelial-mesenchymal transition (EMT) in lung development remains poorly understood. The purpose of this study was to a) confirm the CDH rabbit model produced $\mathrm{PH}$ which was reversed by $\mathrm{TO}$ and $\mathrm{b}$ ) determine the effects of $\mathrm{CDH}+/-\mathrm{TO}$ on EMT pathways.

Methods: $\mathrm{CDH}$ was created at 23 days, $\mathrm{TO}$ at 28 days and lung collection at 31 days gestation in fetal rabbits. Lung body weight ratio (LBWR), mean terminal bronchiole density (MTBD), and expression of mRNA and micro-RNA was determined.

Results: Fifteen $\mathrm{CDH}, 15 \mathrm{CDH}+\mathrm{TO}, 6$ sham $\mathrm{CDH}$, and 15 controls were included in the study. LBWR was low in $\mathrm{CDH}$ while $\mathrm{CDH}+\mathrm{TO}$ was similar to controls. MTBD was higher in $\mathrm{CDH}$ fetuses and restored to control levels in $\mathrm{CDH}+\mathrm{TO}$. miR-33 and MKI67 were increased following $\mathrm{TO}$, while Lgl1 was decreased in $\mathrm{CDH}+\mathrm{TO}$.

Conclusion: TO reversed PH and stimulated early Wnt signaling in $\mathrm{CDH}$ fetal rabbits.

KEYWORDS: Congenital diaphragmatic hernia (CDH), tracheal occlusion (TO), epithelialmesenchymal transition (EMT), lung development, Wnt signaling, TGF- $\beta$ signaling, retinoic acid (RA) signaling, micro-RNA (miRNA) 


\section{ACKNLOWEDGEMENTS}

I would like to thank Dr. Shane Smith, who piloted this project with Dr. Andreana Bütter and established the surgical protocol for our fetal rabbit surgery.

Dr. Nancy Chan was helpful with orienting me to lung histology and teaching me how to calculate mean terminal bronchiole density.

My thanks to the Regnault lab, especially Christie Vanderboor and Ousseynou Sarr, for their teaching, supervision, and assistance with lab experiments. Cheryl Vander Tuin was invaluable as a veterinary technician and took excellent care of our pregnant rabbits in the perioperative period.

Thank you to Dr. Michael Ott and the Division of General Surgery at Western University for allowing me the opportunity to participate in the MSc in Surgery program. Dr. Abdel-Rahman Lawendy and my MSc in Surgery classmates provided constructive criticism that helped shape and clarify my research.

I am thankful to my co-supervisor, Dr. Timothy Regnault, who provided direction, encouragement, and expertise in this research project. Dr. Sarah Jones was also on my advisory committee and provided much appreciated guidance and feedback.

Finally, a very special thanks to my primary supervisor and mentor, Dr. Andreana Bütter, who has inspired, supported, guided, and believed in me. Thank you for taking me under your wing, and for giving me the opportunity to be a part of this $\mathrm{CDH}$ research project. 


\section{DEDICATION}

To my husband, Martin Prusinkiewicz, who inspires my curiosity in science. Thank you for always supporting me in everything that I do, and for all of your advice and lab tips. 


\section{TABLE OF CONTENTS}

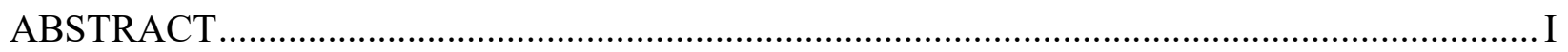

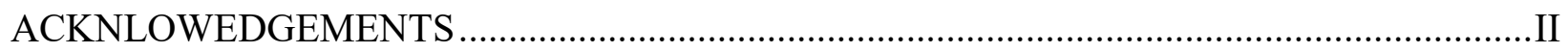

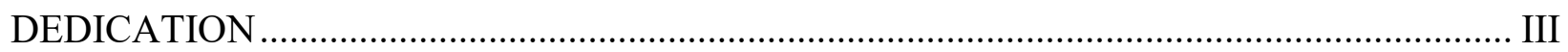

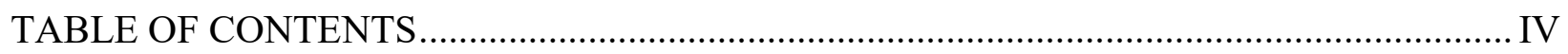

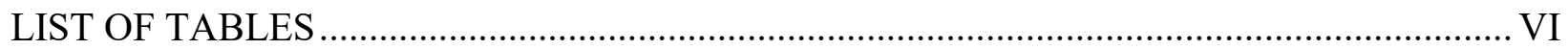

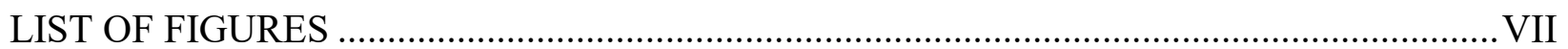

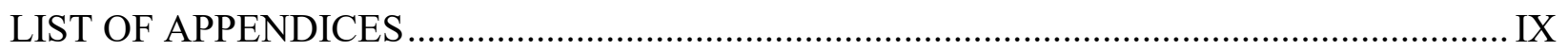

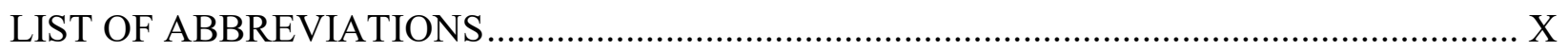

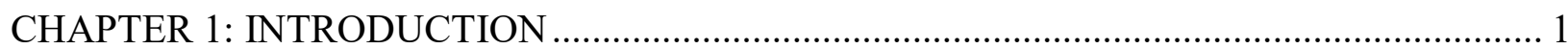

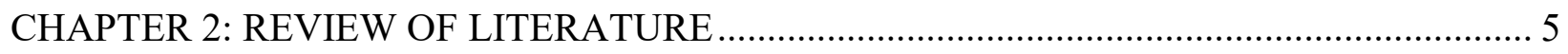

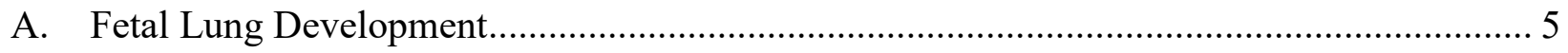

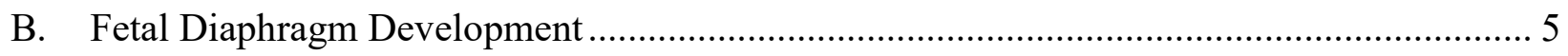

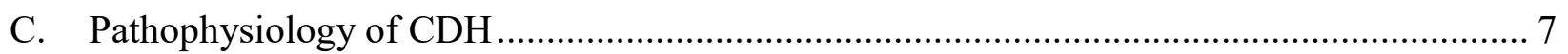

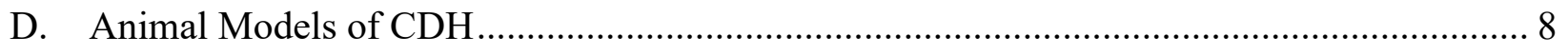

E. EMT in Lung Development and the Wnt Signaling Pathway ......................................... 10

F. The role of microRNAs in Lung Development Pathways ................................................... 15

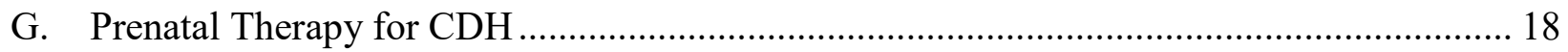

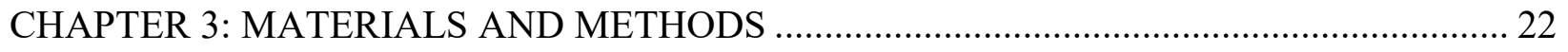

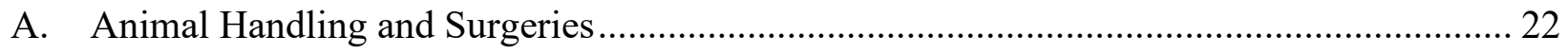




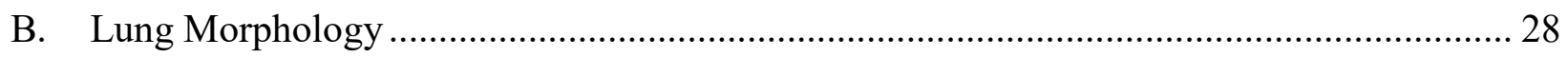

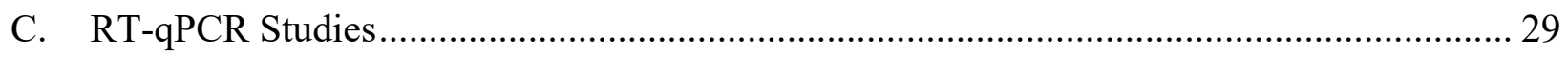

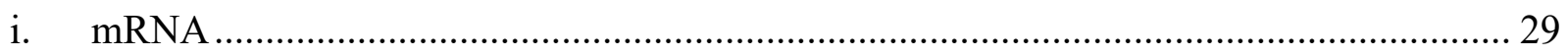

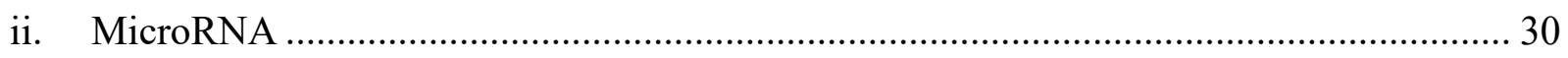

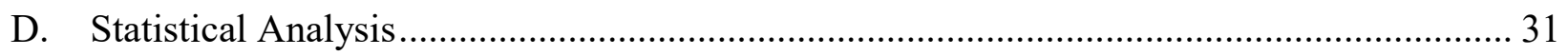

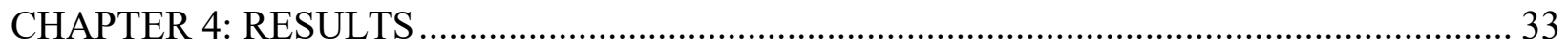

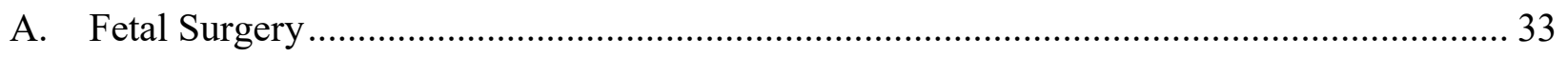

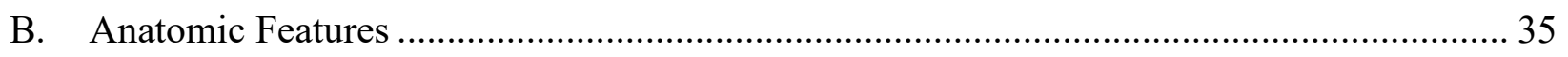

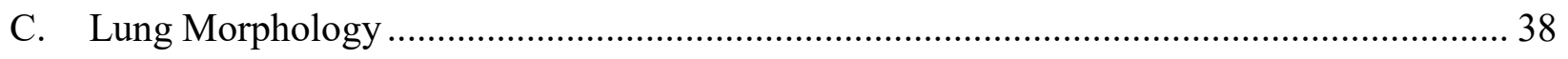

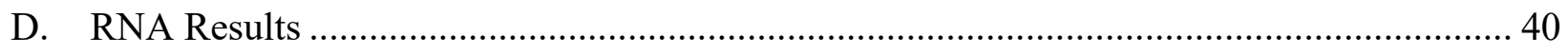

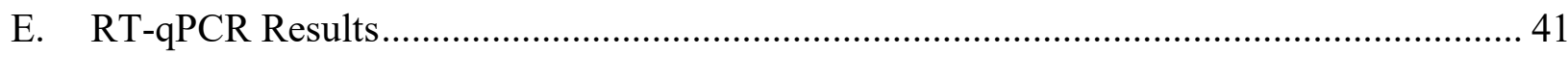

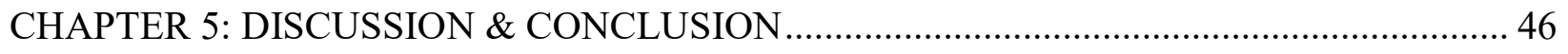

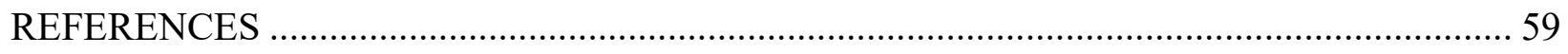

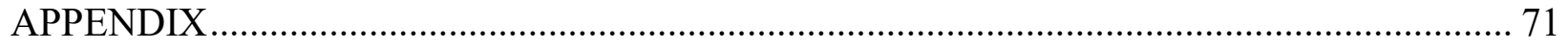

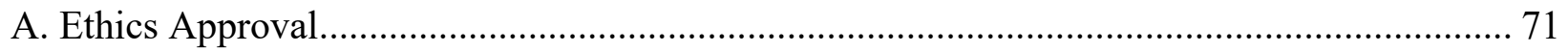

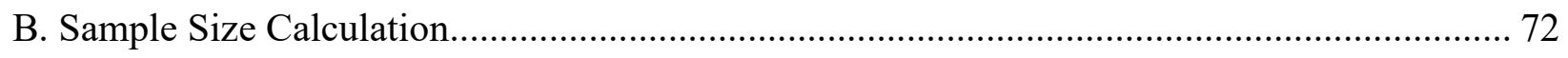

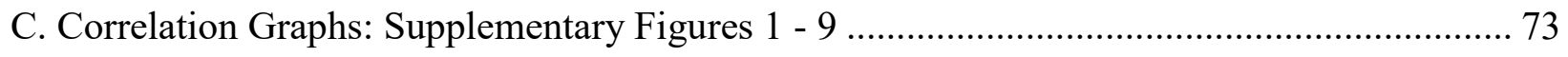

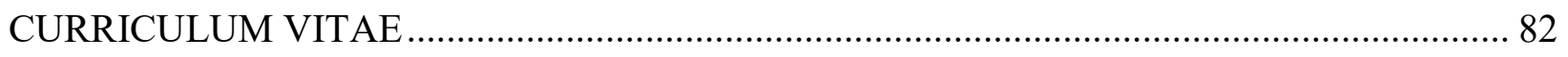




\section{LIST OF TABLES}

Table 1: Reference and GOI Primer Sequences, Efficiencies, $\mathrm{R}^{2}$, and Literature Resources Used for RT-qPCR.

Table 2: Endogenous Control and micro-RNA miScript Primer Assays, Efficiencies, $\mathrm{R}^{2}$, and Literature Resources Used for RT-qPCR 32

Table 3: Pregnant Rabbit Doe Weights and Surgical Times 34

Table 4: Size of Diaphragmatic Defects on Fetal Rabbit Autopsy 36

Table 5: Rabbit Fetal Body and Lung Weight Measurements. 37 


\section{LIST OF FIGURES}

Figure 1: Epithelial-Mesenchymal Transition (EMT) in Lung Development .......................... 11

Figure 2: The Role of Wnt Signaling in Lung Development................................................ 13

Figure 3: The Role of MicroRNAs in Gene Expression......................................................... 16

Figure 4: Proposed Effects of TO on Lung Development ................................................ 21

Figure 5: Housing for Pregnant New Zealand White Rabbits ................................................. 22

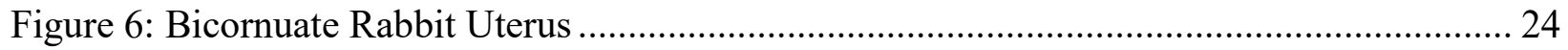

Figure 7: CDH Creation in the Rabbit Fetus ................................................................... 25

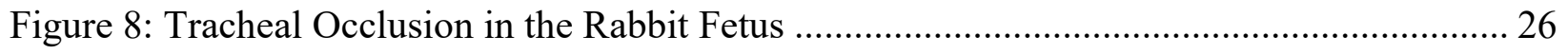

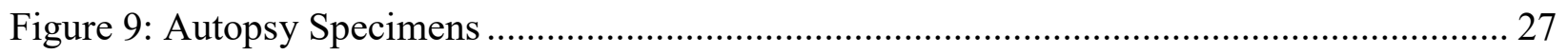

Figure 10: Autopsy Confirmation of Diaphragmatic Defect ............................................... 28

Figure 11: H\&E Stained Fetal Rabbit Lung Sections ...................................................... 29

Figure 12: Fetal Rabbit Surgery Flowchart ................................................................... 34

Figure 13: Lung Body Weight Ratio (LBWR) in Fetal Rabbits .......................................... 38

Figure 14: Mean Terminal Bronchiole Density (MTBD) in Fetal Rabbit Lungs ....................... 39

Figure 15: Fetal Rabbit RNA Sample Flowchart................................................................ 40

Figure 16: Relative Expression of Wnt2, BMP4, and Lg11 in Fetal Rabbit Lungs ................... 42

Figure 17: Relative Expression of PDE5A, MKI67, and WIF1 in Fetal Rabbit Lungs. ............. 43

Figure 18: Relative Expression of miR-33, miR-200b, and miR-375 in Fetal Rabbit Lungs. ..... 44

Figure 19: The Relationship of Wnt2, BMP4, Lg11, and PDE5A Expression vs MTBD in $\mathrm{CDH}+\mathrm{TO}$ Fetal Rabbit Lungs. 
Figure 20: Proposed EMT Pathways of Fetal Lung Development.....

Figure 21: Effect of TO on Proposed EMT Pathway Markers in the Rabbit Model of CDH ...... 56

Figure 22: The Effects of CDH and TO on Fetal Rabbit Lung Development .......................... 58 


\section{LIST OF APPENDICES}

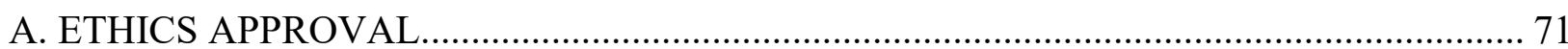

B. SAMPLE SIZE CALCULATION ............................................................................. 72

C. CORRELATION GRAPHS: SUPPLEMENTARY FIGURES 1 - 9.................................. 73

Supplementary Figure 1: Correlation Graphs of Wnt2 vs. LBWR and Wnt2 vs. MTBD ........... 73

Supplementary Figure 2: Correlation Graphs of BMP4 vs LBWR and BMP4 vs MTBD.......... 74

Supplementary Figure 3: Correlation Graphs of Lgl1 vs LBWR and Lg11 vs MTBD.............. 75

Supplementary Figure 4: Correlation Graphs of PDE5A vs LBWR and PDE5A vs MTBD ...... 76

Supplementary Figure 5: Correlation Graphs of MKI67 vs LBWR and MKI67 vs MTBD ........ 77

Supplementary Figure 6: Correlation Graphs of WIF1 vs LBWR and WIF1 vs MTBD ........... 78

Supplementary Figure 7: Correlation Graphs of miR-33 vs LBWR and miR-33 vs MTBD ....... 79

Supplementary Figure 8: Correlation Graphs of miR-200b vs LBWR and miR-200b vs MTBD 80

Supplementary Figure 9: Correlation Graphs of miR-375 vs LBWR and miR-375 vs MTBD ... 81 


\section{LIST OF ABBREVIATIONS}

BMP4 - Bone morphogenetic protein 4

$\mathrm{CDH}$ - Congenital diaphragmatic hernia

cDNA - Complementary DNA

DD - Diaphragmatic defect

DNA - Deoxyribonucleic acid

E - Embryonic day

EMC - Extracellular matrix

EMT - Epithelial-mesenchymal transition

EXIT - Ex-utero intrapartum treatment

FETO - Fetal endoluminal tracheal occlusion

FGF - Fibroblast growth factor

GATA6 - GATA binding protein 6

GOI - Gene of interest

$\mathrm{H} \& \mathrm{E}-$ Hematoxylin and eosin

HMGA2 - High mobility group AT-hook 2

iNO - Inhaled nitrous oxide

JNK - c-Jun N-terminal kinase

LEF - Lymphoid enhancer binding factor 1

Lgl1 - Late gestation lung protein 1

LRP - Low density lipoprotein receptor

miRNA - micro RNA

MKI67 - Marker of proliferation Ki-67 
MMTV - Mouse mammary tumor virus

mRNA - messenger RNA

$\mathrm{P}$ - Post-natal day

PCP - Prolylcarboxypeptidase

PDE5A - Phosphodiesterase 5A

PH - Pulmonary hypoplasia

RA - Retinoic acid

RNA - Ribonucleic acid

ROR - Retinoic acid receptor related orphan receptor

RT-qPCR - Real time quantitative polymerase chain reaction

RYK - Receptor-like tyrosine kinase

SMAD - Mothers against decapentaplegic

SMC - Smooth muscle cell

TCF - Transcription factor family

TGF- $\beta$ - Transforming growth factor- $\beta$

TO - Tracheal occlusion

WIF1 - Wnt inhibitor factor 1

Wnt - Wingless-type MMTV integration site

Wnt2 - Wnt family member 2

ZEB1 - Zinc Finger E-Box Binding Homeobox 1

ZEB 2 - Zinc Finger E-Box Binding Homeobox 2 


\section{CHAPTER 1: INTRODUCTION}

Congenital diaphragmatic hernia (CDH) is a birth defect that occurs in every 2000-4000 live births $[1,2]$. $\mathrm{CDH}$ occurs when a failure in the fusion of the diaphragm results in a diaphragmatic defect (DD) that allows intra-abdominal contents to herniate into the chest cavity, compressing the lung and inhibiting normal lung development [3]. Several theories exist to explain the pathophysiology of $\mathrm{CDH}$ including: abnormal phrenic nerve innervation, improper myotube formation, failure of pleuroperitoneal canal closure, and improper pleuroperitoneal fold development [3]. The dual-hit hypothesis suggests that $\mathrm{CDH}$ causes lung hypoplasia with two insults - the first affects both lungs prior to the completion of diaphragm development, and the second results from compression of the ipsilateral lung by intra-abdominal organs herniating into the chest [4]. $\mathrm{CDH}$ is detrimental to key components of lung development, including retinoic acid (RA), transforming growth factor- $\beta$ (TGF- $\beta$ ), and wingless-type MMTV integration site (Wnt) signaling pathways, which normally stimulate epithelial-mesenchymal transition (EMT) and lead to branching morphogenesis [3]. Clinically, $\mathrm{CDH}$ results in lung hypoplasia and pulmonary hypertension [3]. Lung hypoplasia results in decreased alveolar surface and vasculature causing hypoxia and hypercarbia, leading to pulmonary vasoconstriction, worsening pulmonary hypertension, right to left shunting, and a cycle of respiratory compromise [1,3]. Although $\mathrm{CDH}$ is also associated with various anomalies such as trisomy 13 and 18, congenital syndromes, and cardiac malformations, most fetuses that survive to term have isolated $\mathrm{CDH}$ [1]. The majority of $\mathrm{CDH}$ in humans, around $70 \%$, are posterolateral Bochdalek hernias. Approximately $27 \%$ of $\mathrm{CDH}$ cases are anterior Morgagni hernias, and 2-3\% are central hernias. 
Over the past 25 years, the overall survival of all $\mathrm{CDH}$ babies in Canada has risen from $50 \%$ to $80 \%$ [5]. There have been great advances in the medical management of patients with CDH that account for this $30 \%$ increase in survival. These medical advances include extracorporeal membrane oxygenation (ECMO), high frequency oscillating ventilation (HFOV), inhaled nitric oxide (iNO), and gentle ventilation with permissive hypercapnia [1]. These management options treat the sequelae of $\mathrm{CDH}$ rather than the condition itself [6]. This has led to improved survival of more severe cases of $\mathrm{CDH}$ and therefore results in more long-term complications in these patients including failure to thrive, gastroesophageal reflux, deafness, and neurological complications $[1,7]$. However, over the last decade, the mortality rate has remained stagnant at $20 \%[1,7]$.

The significant morbidity and mortality associated with $\mathrm{CDH}$ due to respiratory compromise led to the recognition of a need for fetal treatment that would allow lung growth and minimize lung hypoplasia [1]. In the 1980s, Harrison et al were the first to successfully repair CDH in utero and began a nonrandomized prospective trial comparing fetal $\mathrm{CDH}$ repair to medical management. The trial revealed that $\mathrm{CDH}$ repair was associated with premature rupture of membranes, premature delivery, and fetal death while showing no advantage in survival or length of stay compared to medical management $[1,8-11]$. The trial was therefore stopped early.

The concept of fetal tracheal occlusion (TO) came from the observation that fetuses with laryngeal atresia were born with hyperplastic lungs [1]. The mechanism of lung hyperplasia was thought to be due to mechanical distention from increased lung fluid pressure as a result of tracheal obstruction [1,12-14]. TO was first applied in the context of CDH in the early 1990s in the lamb CDH model, where significant lung growth and reversal of pulmonary hypoplasia was noted 
following TO $[1,15,16]$. TO in humans has evolved from an open Ex-utero Intrapartum Treatment (EXIT) technique to a minimally invasive procedure referred to as Fetal Endoluminal Tracheal Occlusion (FETO) [1,17]. Despite these advances, FETO is still associated with risks of premature rupture of membranes and premature delivery $[17,18]$. However, FETO does improve survival in fetuses with severe $\mathrm{CDH}$ by $25 \%$, and is therefore utilized in this high risk population of $\mathrm{CDH}$ fetuses in a handful of centres across the world $[17,18]$.

FETO also targets lung development on a molecular level. Human fetuses undergoing FETO were found to have increased levels of miR-200b in their tracheal fluid following release of the TO by balloon removal [19]. On the other hand, overexpression of miR-200b in hypoplastic CDH lungs resulted in decreased TGF- $\beta$ signaling which normally stimulates EMT and branching morphogenesis during fetal lung development [19]. Overall, research in human $\mathrm{CDH}$ fetuses is uncommon due to the rarity of the condition, difficulty with obtaining samples, and also ethical concerns. Animal models have therefore played a major role in $\mathrm{CDH}$ research and continue to be utilized to this day.

Although advances have been made in both post-natal medical management and fetal intervention for fetuses with $\mathrm{CDH}$, morbidity and mortality risks secondary to lung complications remain a significant concern for this population. Decades of research have been dedicated to the study of $\mathrm{CDH}$ and TO in order to broaden our understanding of this birth defect and the mechanism of a promising treatment. More recently, animal models have been utilized to explore potential prenatal therapies that may be used to stimulate lung growth in $\mathrm{CDH}$. The goal of such prenatal therapy is to augment and ultimately replace an invasive procedure such as FETO to treat lung 
hypoplasia in $\mathrm{CDH}$. The aim of this study was to replicate the rabbit model of $\mathrm{CDH}$ and to study the effects of TO on anatomic, morphologic, and molecular markers of fetal lung development. Identifying cell signaling markers that stimulate lung growth following TO could lead to potential non-invasive prenatal molecular therapies that promote lung growth and prevent the respiratory complications which are caused by $\mathrm{CDH}$. 


\section{CHAPTER 2: REVIEW OF LITERATURE}

\section{A. Fetal Lung Development}

In humans, lung development begins at 4 weeks gestation as the anterior foregut separates into the trachea, two lung buds, and the esophagus [20]. Lung development occurs in 5 stages: embryonic, pseudoglandular, canalicular, saccular, and alveolar [21]. The pseudoglandular stage occurs from 5-16 weeks of gestation and during this stage airway branching morphogenesis takes place [20]. The canalicular stage occurs from 16-26 weeks of gestation, during which time terminal bronchioles divide into respiratory bronchioles and alveolar ducts, and pulmonary vasculature forms [20]. Epithelial sacs are formed during the saccular stage which occurs from 26-38 weeks of gestation [20]. The final alveolar stage begins at 38 weeks of gestation and continues until approximately 7 years of age in children. During the alveolar stage, the epithelial sacs form alveoli through secondary septation [20].

The gestational period in rabbits is approximately 32 days [21-23]. The pseudoglandular stage of lung development occupies $75 \%$ of the gestational period and lasts until day 24 of gestation [21]. The canalicular phase occurs from 24-28 days gestation and the saccular stage from 27-30 days [21-23]. Similar to humans, the alveolar stage in rabbits begins in utero prior to delivery and continues in the post-natal period [22-24]. It is important to note that in fetal rabbits there is some overlap in gestational days for lung development as one stage transitions into the next.

\section{B. Fetal Diaphragm Development}

The diaphragm is the most essential skeletal muscle in mammals because it is required for respiration [25]. In humans, diaphragm development begins at 4 weeks of gestation, approximately 
at the same time as lung development [20]. The diaphragm is composed of the dorsomedial crural muscle, the ventrolateral costal muscle, and an amuscular central tendon [20]. The costal diaphragm is thin and composed of myofibers that extend from the ribs to the central tendon [25]. The crural diaphragm is thicker, attaches posteriorly to the vertebrae and surrounds the esophagus and aorta [25]. The central tendon is composed of connective tissue which holds the diaphragm muscles together and also attaches to the liver via the falciform and coronary ligaments [25]. During fetal development, the diaphragm originates from three embryologic sources - the septum transversum, pleuroperitoneal folds, and somites [25]. The septum transversum is a mesodermal sheet that forms a barrier between the chest and abdominal cavities and forms a scaffold for further diaphragm development [20,25]. The diaphragm muscle cells originate from somites which migrate as pleuroperitoneal folds [20]. The pleuroperitoneal folds, also known as the posthepatic mesenchymal plate, is a transient embryonic structure that lies on either side of the esophagus [25]. The diaphragm is innervated by the phrenic nerves which migrate from the neural tube originating from cervical nerves 3,4 and 5 [25].

Diaphragm development in rabbits occurs throughout the gestational period with a rapid progression during the last third of gestation and is fully complete one week post-partum [26]. At 20 days of gestation, early myogenesis of the diaphragm occurs with fusion of myoblasts to form myotubes [26]. Developing motor plates are observed at 22 days gestation, while connective tissue sheaths and differentiation of muscle fibres occurs at 25 days gestation [26]. Diaphragmatic muscle fibres form myotendinous junctions at 30 days gestation, and by one week post-partum the muscle fibres of the diaphragm are fully differentiated and development of the diaphragm is complete [26]. 


\section{Pathophysiology of CDH}

The dual-hit hypothesis explains the pathophysiology of lung hypoplasia in CDH based on research performed using the nitrofen-induced $\mathrm{CDH}$ rodent model, which showed that both ipsilateral and contralateral lungs are hypoplastic and lung development is impaired before the closure of the diaphragm [4]. In the dual-hit hypothesis, the first hit, or insult, affects both lungs and occurs prior to diaphragm formation as a result of environmental and genetic factors [4]. The second insult occurs following diaphragm development as a result of herniated intra-abdominal contents in the chest which compresses the ipsilateral lung and inhibits fetal breathing [4]. According to this hypothesis, lung growth into the pleuroperitoneal canal is disturbed and inhibits the growth of the posthepatic mesenchymal plate, which is the main origin of the diaphragm [4]. This theory therefore suggests that the diaphragmatic defect occurs because of abnormal development of the adjacent lung [3,4].

Several other theories also exist with regards to the pathophysiology of the diaphragmatic hernia itself. One theory is that the diaphragm does not fully develop properly due to abnormalities of phrenic nerve innervation $[3,27]$. Another theory suggests that a diaphragmatic defect occurs due to improper myotube formation which causes a weakness in the diaphragmatic muscle and results in rupture due to pressure from intra-abdominal organs [3]. Yet another theory proposes that $\mathrm{CDH}$ develops from the failure of pleuroperitoneal canal closure during the $10^{\text {th }}$ week of gestation in humans when intestines return to the abdominal cavity and enter the pleuroperitoneal canal thus blocking the closure of the canal and forming a diaphragmatic hernia $[3,28]$. Lastly, there is also a theory that suggests that CDH occurs as a result of abnormal pleuroperitoneal fold 
formation which then does not properly differentiate into the diaphragm as it would under normal conditions $[3,27]$.

\section{Animal Models of CDH}

Three types of $\mathrm{CDH}$ animal models exist - genetic, pharmacologic, and surgical. Genetic models of $\mathrm{CDH}$ are primarily in rodent models with knockout genes [6,7]. This model is perhaps the least popular because the majority of $\mathrm{CDH}$ cases in humans are not associated with genetic defects and so the genetic model of $\mathrm{CDH}$ is the least applicable to the human condition [6,7]. The pharmacologic model involves the use of herbicide 2,4-dichloro-phenyl-p-nitrophenylether (nitrofen) in rodents and has been primarily used to study the pathophysiology of CDH. The surgical model on the other hand, has been used in sheep and rabbits, and has proven to be more useful in the study of CDH treatments and interventions.

Nitrofen is a teratogenic herbicide that was first used to explore its diaphragmatic defect inducing effects in fetal rodents in the 1980s by Iritani [3,29]. Typically, $100 \mathrm{mg}$ of nitrofen is dissolved in $1 \mathrm{~mL}$ olive oil and administered on day 9 of gestation to induce CDH in rodents [4]. Nitrofen administration induces a right or left-sided diaphragmatic defect in 70-80\% of fetuses and causes lung hypoplasia in $100 \%$ of fetuses [3,6,30,31]. Advantages of the nitrofen-induced CDH rodent model include inexpensive cost and ease of use [3,6]. However, although nitrofen induces a diaphragmatic defect during early stages of lung development similar to humans, the use of a teratogen to induce this defect is concerning since there is no known teratogen associated $\mathrm{CDH}$ in

humans [3]. Nitrofen targets the retinoic acid (RA) signaling pathway and inhibits retinal 
dehydrogenase $[3,6]$. Infants with $\mathrm{CDH}$ were found to have $50 \%$ less plasma retinol and retinol binding protein. Therefore, the RA signaling pathway may be involved in the origin of CDH [3].

The surgical model of $\mathrm{CDH}$ has been utilized in exploring treatments and innovative therapies in $\mathrm{CDH}[3,6]$. This model has been utilized in sheep and rabbits [3,6]. The first surgical model of CDH was developed using fetal lambs by Delorimier in the 1960s [3,6,32]. The diaphragmatic defect was created surgically at 72-75 days of gestation, which corresponds with the canalicular phase of lung development, with term being 145-149 days of gestation. In the early 1990s, the surgical model of $\mathrm{CDH}$ was developed in fetal rabbits by Fauza et al [33]. There were many advantages identified in using rabbits instead of sheep - lower cost, shorter gestational period of 32 days, and similar lung physiology to humans. In the rabbit model, the diaphragmatic defect is created on gestational day 23 , which is also during the pseudoglandular phase of lung development [6]. The lung physiology is more similar to humans compared to other models because in rabbits alveolarization begins prior to birth and completes in the post-natal period, whereas in sheep, alveolarization is nearly complete at birth, and in rodents alveolarization begins in the post-natal period [24].

The surgical model of $\mathrm{CDH}$ has been used to study the effects of TO on lung development. Standard measures of lung growth and development include lung body weight ratio (LBWR) and mean terminal bronchiole density (MTBD). LBWR, the ratio of fetal lung weight over fetal body weight, is a gross anatomic measurement of lung growth and is commonly used to identify lung hypoplasia in $\mathrm{CDH}$ research $[22,24]$. MTBD is a morphologic measure of the number of mean terminal bronchioles per non-overlapping high powered field on microscopy [22]. MTBD is 
inversely proportional to the number of alveoli and is therefore used as a marker of lung hypoplasia in $\mathrm{CDH}$ [22]. Increased MTBD means that there are few alveoli and that the lung is underdeveloped and hypoplastic. On the other hand, decreased MTBD means increased number of alveoli in a normally developed lung. Animal studies have confirmed that TO increases LBWR and decreases MTBD in CDH fetuses, thus reversing lung hypoplasia. However, the molecular mechanism of TO and its effect on lung development pathways are not fully understood.

\section{E. EMT in Lung Development and the Wnt Signaling Pathway}

EMT is a fundamental developmental process where epithelial cells transform into mesenchymal-like cells [34]. This process occurs during embryologic development, gastrulation, and tissue repair [34]. During fetal lung development, several cell signaling pathways stimulate EMT including RA, TGF- $\beta$, and Wnt signaling (Figure 1). Wnt signaling is essential in lung development and stimulates EMT which leads to lung-branching morphogenesis [34]. Wnt signaling activates several intracellular pathways that regulate maintenance, self-renewal and differentiation of mammalian stem cells $[35,36]$. Wnt signaling is essential during early development to regulate body axis formation, organogenesis, and cell migration in vertebrates [36]. 


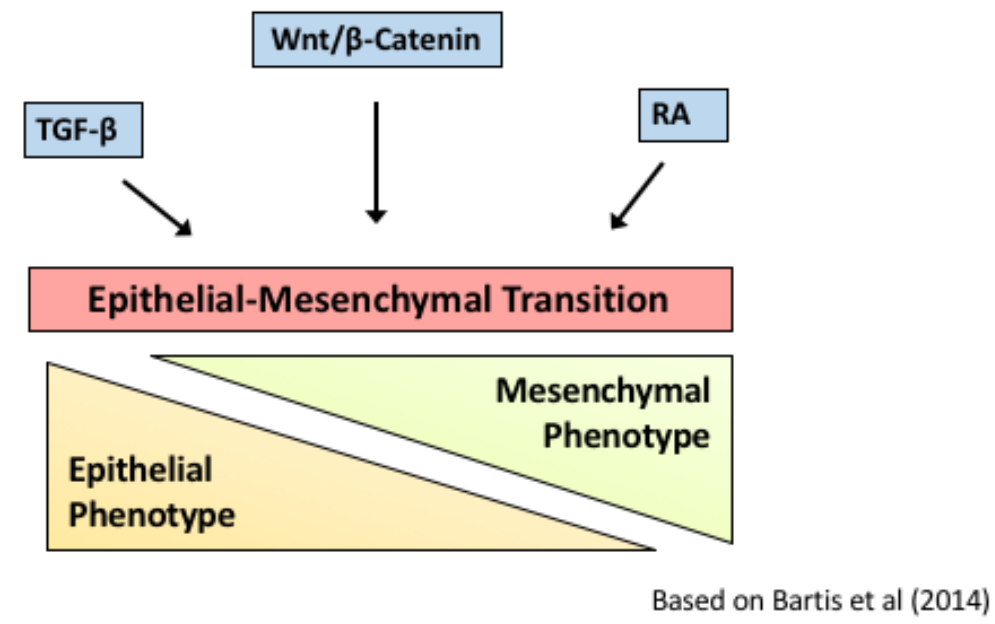

Figure 1: Epithelial-Mesenchymal Transition (EMT) in Lung Development. EMT is targeted by several cell signaling pathways including Wnt, TGF- $\beta$, and RA.

Wnt is a large family of cysteine-rich signaling molecules that are vertebrate homologues of Drosophila wingless [35]. The Wnt pathway was first discovered 30 years ago with the discovery of a proto-oncogene named Int-1, a homolog of Drosophila wingless that controls segment polarity in larvae [36]. Int-1 led to malignant transformation of mouse mammary tissue when inserted in the Mouse Mammary Tumor Virus (MMTV) [36]. The gene was therefore named Wnt1, winglesstype MMTV integration site family member 1 [36].

Nineteen Wnt ligands have been identified in vertebrates [35-37]. Their classification is based on amino acid sequence and not their functional properties [36]. Common structural features of Wnt proteins include a signal sequence for secretion, several highly charged amino acid residues, and multiple glycosylation sites [36]. Receptors of Wnt ligands include members of seven-pass transmembrane proteins Frizzleds (FZDs), low density lipoprotein receptor-related protein (LRP) 
co-receptors, and retinoic acid receptor related orphan receptor (ROR) and receptor-like tyrosine kinase (RYK) families [35,36].

Wnt pathways can be categorized as canonical and non-canonical, defined by their requirement or independence of intracellular $\beta$-catenin, respectively [35,36,38]. Wnt ligands elicit canonical or noncanonical response dependent on cell type, environment, and receptor type [36]. The Wnt signaling pathway is complex and dynamic [36]. When Wnt ligands bind to receptors and coreceptors on the cell surface, both $\beta$-catenin dependent and independent cascades are set in motion which can reinforce or oppose each other [36].

Canonical Wnt signaling controls cell proliferation, differentiation, migration, cell fate specification and stem cell renewal (Figure 2) [35,38]. The canonical Wnt pathway is mediated by stabilization of $\beta$-catenin $[35,38]$. In the absence of Wnt ligands, $\beta$-catenin is phosphorylated, ubiquinated, and degraded [35]. When Wnt ligands bind to receptors, the seven transmembrane FZD receptor and LRP co-receptor 5/6, they trigger intracellular responses that lead to inhibition of $\beta$-catenin phosphorylation $[35,36]$. The stabilized $\beta$-catenin accumulates and translocates to the nucleus where it interacts with the lymphoid enhancer binding factor 1 (LEF)/ transcription factor family (TCF) complex to regulate target gene expression [35]. Wnt1, Wnt2, Wnt3, Wnt10b are canonical Wnt ligands [36,39]. 


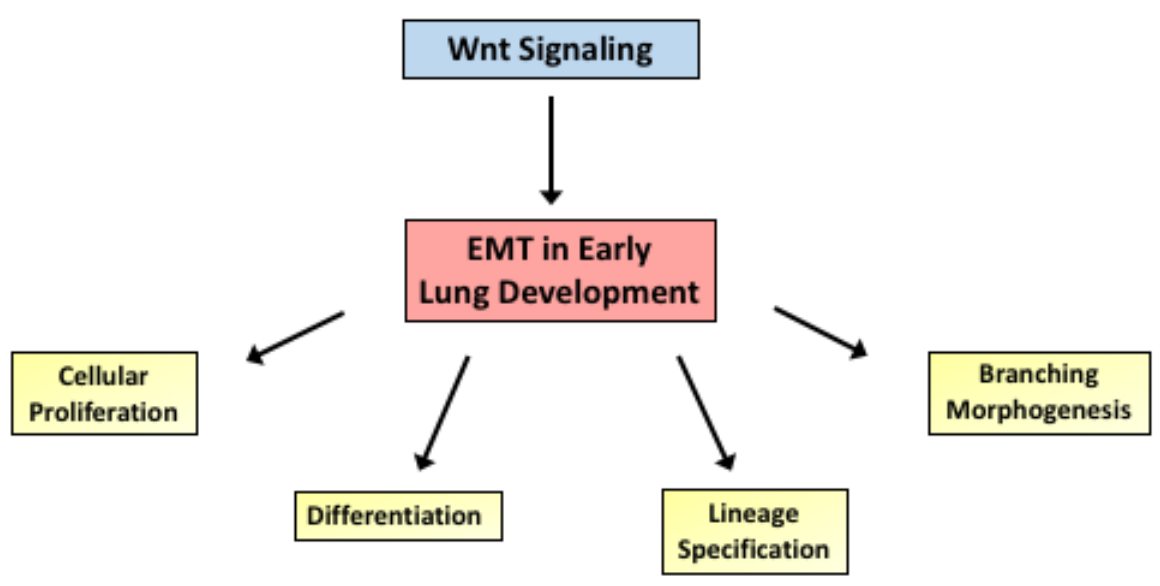

Figure 2: The Role of Wnt Signaling in Lung Development. Wnt signaling stimulates cellular proliferation, differentiation, lineage specification, and branching morphogenesis during fetal lung development.

Non-canonical Wnt signaling plays a role in cell migration, cell polarity and stem cell maintenance [35]. Non-canonical Wnt signaling regulates and represses canonical Wnt activity [35]. Non-canonical signaling cascades are subdivided into several $\mathrm{Wnt} / \mathrm{Ca}^{2+}$, Wnt/Prolylcarboxypeptidase (PCP) and Dishevelled (DVL)-c-Jun N-terminal kinase (JNK) pathways [35,36]. Wnt4, Wnt5a, Wnt5b, Wnt7a, Wnt 11, and Wnt16 are $\beta$-catenin-independent non-canonical Wnts [35,36].

Both canonical and non-canonical Wnt pathways are present in the lung. Wnt2, Wnt2b, Wnt3a, Wnt5a, Wnt5b, Wnt7b, Wnt9a, and Wnt11 are expressed in lung tissue [36,37]. Airway structure and function, including branching morphogenesis, are governed by epithelial mesenchymal interactions that involve the Wnt/ $\beta$-catenin pathway (Figure 2) [37,38]. Deletion of $\mathrm{Wnt} / \beta$-catenin results in abnormal epithelial, mesenchymal, and vascular development [38]. It also decreases secondary and tertiary branching, leading to elongated bronchiolar tubules with poorly branched and enlarged tips [38]. Wnt7b, for example, has been demonstrated to act on lung vascular smooth 
muscle cells (SMCs) through FZD1 and LRP5 [38]. Wnt7b is required for normal lung mesenchymal proliferation in a narrow window of development before embryonic day 15 in mice [37]. Wnt7b inactivation decreased airway branching, caused pulmonary hypoplasia, and decreased lung muscular smooth muscle [37].

Wnt2 signaling occurs through the canonical Wnt/ $\beta$-catenin pathway [39]. Wnt2 and Wnt2b specify lung progenitors within the anterior foregut during fetal development [39]. Wnt $2 / 2 b$ is expressed in the lung mesenchyme and is essential in fetal lung development and specification [39]. In the knockout mouse model, loss of Wnt2 leads to lung hypoplasia [39].

Wnt5a is the major Wnt ligand that activates the non-canonical Wnt pathway in the lung [35]. Wnt5a regulates branching morphogenesis during the pseudoglandular stage, promotes onset of the saccular stage, and cell differentiation during lung maturation [35]. Non-canonical Wnt signaling is important in pulmonary capillary patterning [35]. Deletion of Wnt5a results in truncation of the trachea, overexpansion of the distal airways, and abnormal capillary formation $[35,40,41]$. Non-canonical Wnt signaling is also critical for SMC function, extracellular matrix (ECM) expression, and lung fibroblast formation [35,38].

The Wnt signaling pathway has been studied in the context of pulmonary hypoplasia in CDH. Messenger RNA (mRNA) levels of Wnt7b and Wnt2 were significantly decreased during early lung development in the nitrofen-induced congenital diaphragmatic hernia rat model [37]. Bone morphogenetic protein 4 (BMP4), a downstream target of Wnt2 was downregulated in the ovine model of CDH [42]. Furthermore, in a large pulmonary transcriptome analysis of fetal rabbits, Wnt 
inhibitor factor 1 (WIF1) was upregulated in $\mathrm{CDH}$ and downregulated following TO, while marker of proliferation Ki-67 (MKI67) was upregulated in CDH+TO fetuses [43].

The RA signaling pathway also targets EMT during lung development [44]. Late gestation lung protein $1(\mathrm{Lgl1})$ is a downstream target of this pathway and remains prominent during alveolarization of the lung [44]. Nitrofen inhibits retinal dehydrogenase of the RA signaling pathway and downregulates Lg11 expression in CDH fetuses. Lgl1 was found to downregulated in the sheep model of $\mathrm{CDH}$ [42]. In the nitrofen-induced $\mathrm{CDH}$ rat model, Lgl1 was found to be upregulated in $\mathrm{CDH}$ fetal rat lungs following RA prenatal therapy [45].

EMT in lung development is likewise regulated by the TGF- $\beta$ signaling pathway. This pathway includes phosphodiesterases (PDEs) such as PDE4, that are altered in TGF- $\beta$ induced EMT [46]. PDE5 is prominent during lung development and plays an important role in angiogenesis, alveolarization, and maintaining normal fetal pulmonary hypertension [47]. Phosphodiesterase 5A (PDE5A) was previously reported to be increased in CDH fetal rabbit lungs, and decreased following TO [43].

\section{F. The role of microRNAs in Lung Development Pathways}

MicroRNAs (miRNAs) are small, non-coding RNAs that regulate gene expression through post-transcriptional silencing of mRNAs [19,48,49]. miRNAs work by accelerating the degradation of mRNAs or repressing translation, thereby negatively regulating the expression of target genes (Figure 3) [50]. miRNAs are therefore important in signal transduction and function as epigenetic regulators of cell signaling pathways [31,51]. miRNAs are essential for normal 
organogenesis during embryonic development $[19,48,50]$. To date, 1800 miRNAs have been identified in humans [48].

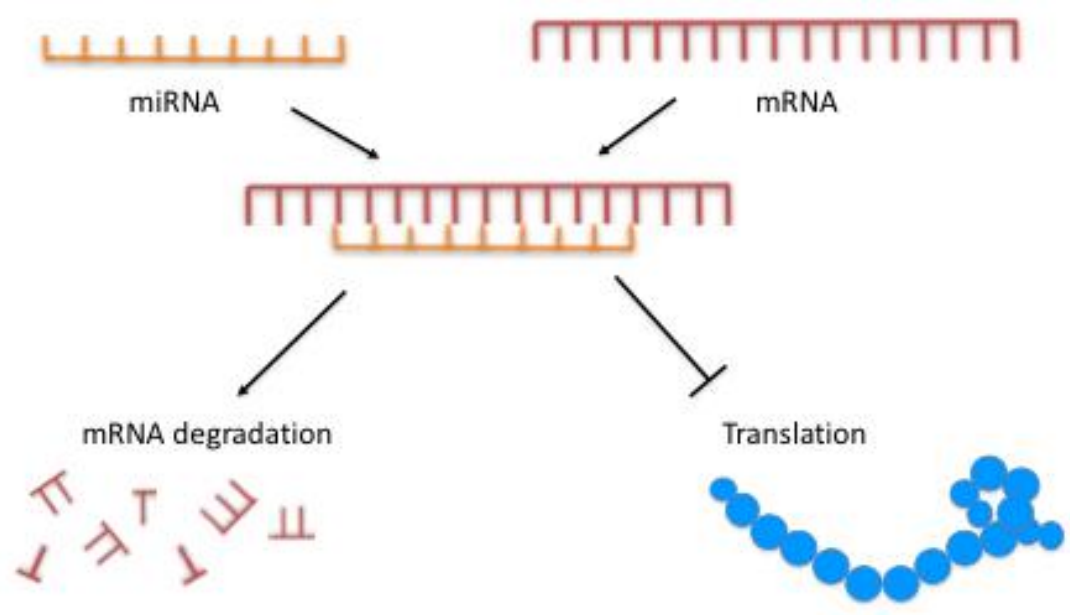

Figure 3: The Role of MicroRNAs in Gene Expression. MicroRNAs are non-coding RNAs that negatively regulate gene expression through the degradation of mRNA and the inhibition of translation to protein.

The study of miRNAs and their effect on cell signaling is a growing field, and several miRNAs have been linked to lung development pathways. miR-17 92 cluster is involved in epithelial bud morphogenesis and branching during early lung development by negatively regulating fibroblast growth factor (FGF) signaling [52]. miR-124 regulates lung epithelial maturation and has been linked to the $\mathrm{Wnt} / \beta$ catenin signaling pathway [53]. miR-142, which is highly expressed in mesenchyme during early lung development, has also been found to interact with the $\mathrm{Wnt} / \beta$ catenin signaling pathway [54-56]. The overexpression of miR-375 was found to inhibit alveolar epithelial differentiation by targeting the $\mathrm{Wnt} / \beta$ catenin signaling pathway $[57,58]$. 
miRNAs have also been studied in $\mathrm{CDH}$. There was increased expression of miR-375, an inhibitor of Wnt/ $\beta$-catenin, in hypoplastic CDH lungs [50,58]. miR-18a, which promotes cell proliferation and suppresses apoptosis, was found to be decreased in CDH [50,59]. Human fetus CDH lungs had miR-200b and miR-10a overexpression compared to control lungs of human fetuses from terminated pregnancies [19]. There was yet higher miR-200b expression in tracheal fluid of fetuses that survived FETO at time of balloon removal compared to time of balloon insertion [19]. miR-200b plays an important role in normal lung development by closely regulating TGF- $\beta$ signaling [19]. TGF- $\beta 2$ expression was found to be decreased in CDH lungs [19]. This is because miR-200b inhibits TGF- $\beta$ /SMAD signaling [19]. Therefore, TGF- $\beta$ activity enhances miR-200 family expression as part of a negative feedback loop [19]. miR-200 expression increased in $\mathrm{CDH}$ lungs and tracheal fluid samples of $\mathrm{CDH}$ patients responding to FETO, suggesting that increases in miR-200 might result from an inherent increased TGF- $\beta$ expression in hypoplastic lungs [19]. In a recent study, miR-200b knockout mice had abnormal lungs due to dysfunctional surfactant, increased fibroblast-like cells, thicker mesenchyme between alveolar walls, disturbed distal airway branching, and downregulation of epithelial cell differentiation [48]. miR-200b was highly expressed during different stages of lung development and found to regulate distal airway development by maintaining an epithelial cell phenotype [48].

Furthermore, the expression of several miRNAs were found to be altered in the nitrofeninduced $\mathrm{CDH}$ rodent model [50]. One study showed increased expression of 11 miRNAs and decreased expression of 14 miRNAs in the CDH group [50]. Most notably, there was a marked decrease in miR-33 in CDH rodent lungs [50]. miR-33 is a target of genes that regulate epithelialmesenchymal interactions, including PDGF and Wnt signaling pathways [50,60]. 


\section{G. Prenatal Therapy for CDH}

$\mathrm{CDH}$ is a birth defect that continues to be associated with significant morbidity and risk of death due to respiratory failure secondary to lung hypoplasia and pulmonary hypertension. Currently FETO is the only treatment that reverses lung hypoplasia associated with CDH. The idea of $\mathrm{TO}$ as a prenatal intervention for $\mathrm{CDH}$ came from an observation of lung hyperplasia in patients born with laryngeal atresia [1]. The theory of TO was that by blocking the airway, fluid would build up in the lung and cause it to grow [1,12-14]. Currently, FETO is being evaluated as a therapy for left-sided severe and moderate $\mathrm{CDH}$ as part of a global randomized clinical trial [18]. The procedure can be offered outside the trial in cases of severe right-sided CDH [18]. In the most recent literature, the FETO procedure takes a median amount of time of 10 minutes with a range of 3 to 93 minutes. The procedure is typically performed under local anesthesia and optional conscious sedation at 27-29 weeks gestation or at 30-32 weeks for moderate CDH cases [18]. Mothers are given tocolytics and antibiotics for 24 hours pre-procedure [18]. The mother is positioned in supine position and external manipulation of the fetus is performed if necessary in order to achieve an optimal fetal position with easy access to the fetal mouth [18]. The fetus is then injected with analgesics and neuromuscular blockers intramuscularly [18]. A skin incision is made in the mother's abdomen and a 10 Fr trocar is inserted into the amniotic cavity under ultrasound guidance and guided to be perpendicular to the fetal nose [18]. The fetoscope, a $1.3 \mathrm{~mm}$ fiber optic endoscope, is then inserted into the fetus' mouth and guided past the vocal cords and into the trachea to the level of the carina [18]. A detachable latex balloon is then inflated and released between the carina and vocal cords [18]. Following the procedure, patients are reassessed with ultrasound every 1-2 weeks [18]. The balloon is scheduled to be removed at 34 weeks gestation or 
earlier if birth is impending [18]. The balloon is punctured with a needle under ultrasound guidance and is expelled by the fetus spontaneously [18]. The reversal of TO before delivery is a key maneuver because persistent TO until birth has been found to decrease the number of type II pneumocytes resulting in decreased surfactant production and poorer outcomes [18].

Although prenatal TO for CDH was first established in the 1990s and is now performed using a minimally invasive technique, FETO remains classified as an experimental procedure and is performed in only a few centres in the world. Furthermore, this prenatal therapy is a surgical procedure and is associated with risks including premature rupture of membranes and premature delivery. For this reason, research efforts are focused on identifying less invasive prenatal therapy options for the treatment of $\mathrm{CDH}$ associated pulmonary hypoplasia. Recent literature is promising in showing that lung development signaling pathways may be potential targets for prenatal therapy in $\mathrm{CDH}$.

Both the RA and TGF- $\beta$ signaling pathways have been targets of prenatal therapies in $\mathrm{CDH}$ animal models. RA and vitamin A prenatal therapy reduced the incidence of CDH and severity of lung hypoplasia in fetuses of nitrofen treated pregnant rats [28]. Interestingly, plasma retinol levels have been found to be decreased in humans with $\mathrm{CDH}$ [3]. Therefore, although nitrofen is not associated with $\mathrm{CDH}$ in humans, the link between the nitrofen-induced $\mathrm{CDH}$ rodent model and human CDH may be the RA signaling pathway itself. Furthermore, prenatal miR-200b therapy in nitrofen treated pregnant rodents reversed moderate lung hypoplasia and decreased the incidence of CDH in fetuses [31]. Thus, miR-200b may be a promising new fetal therapy for lung hypoplasia in $\mathrm{CDH}$. 
In summary, EMT is a critical process during lung development that is regulated by signaling pathways including RA, TGF- $\beta$, and Wnt. Previous studies have primarily utilized rodent and sheep models of $\mathrm{CDH}$. The surgical rabbit model of $\mathrm{CDH}$ remains underutilized and is a promising model for $\mathrm{CDH}$ research because rabbit lung development most closely parallels human physiology.

\section{Purpose:}

The purpose of this research is to confirm that our rabbit model of $\mathrm{CDH}$ produces pulmonary hypoplasia which is reversed by TO, and to determine the effects of $\mathrm{CDH}$ and TO on lung development pathways that stimulate EMT, including RA, TGF- $\beta$ and Wnt signaling.

\section{Hypothesis:}

We hypothesized that: a) CDH fetuses will have hypoplastic lungs demonstrating low LBWR and high MTBD; b) CDH fetuses will have decreased expression of lung development genes c) TO will reverse the effects of $\mathrm{CDH}$ pulmonary hypoplasia thereby demonstrating increased LBWR and decreased MTBD similar to control fetuses; d) $\mathrm{CDH}+\mathrm{TO}$ fetuses will have similar levels of lung development markers to control fetuses (Figure 4). 


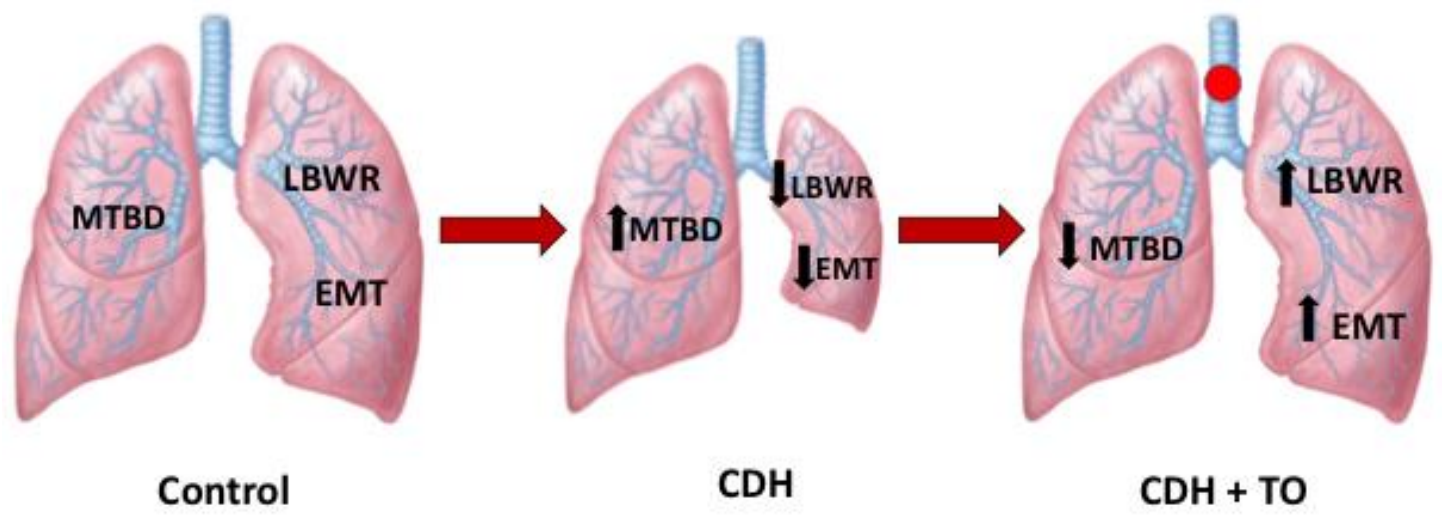

Figure 4: Proposed Effects of TO on Lung Development. CDH causes lung hypoplasia demonstrated by decreased LBWR, increased MTBD, and decreased EMT signaling pathway markers. TO reverses the effects of CDH by causing lung hyperplasia demonstrated by increased LBWR, decreased MTBD, and increased EMT markers, similar to control lungs. 


\section{CHAPTER 3: MATERIALS AND METHODS}

\section{A. Animal Handling and Surgeries}

All animal procedures were carried out in strict accordance with the guidelines of the Canadian Council of Animal Care (CCAC) as approved by the Western University Animal Care Committee (AUP 2016-041). All efforts were made to minimize suffering as per the approved protocol and with veterinary oversight. Time dated pregnant New Zealand White rabbits (Charles River, Sherbrooke) arrived at 13 days gestation. Each month, a group of 5 does arrived at our facility and were individually housed with free access to water, food, and environmental enrichment (Figure 5). Each doe underwent two surgeries, a CDH creation at 23 days gestation and a second surgery, the TO surgery 5 days later at 28 days gestation as previously described [23].

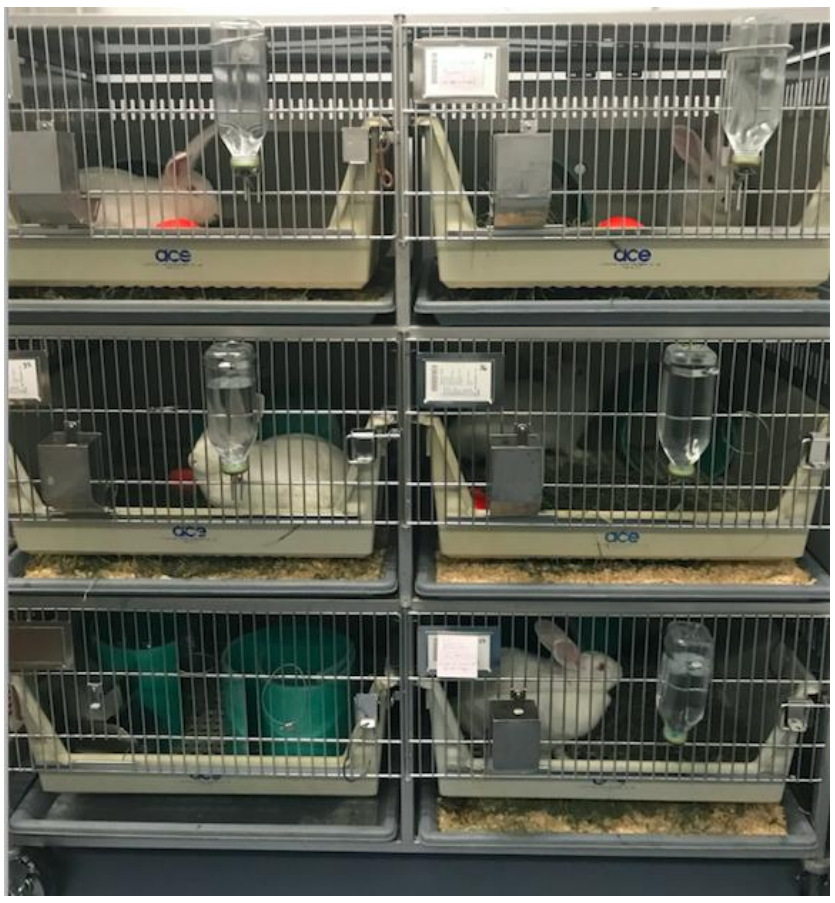

Figure 5: Housing for Pregnant New Zealand White Rabbits. Groups of five time-dated New Zealand White rabbits were received at 13 days gestation and housed individually with free access to food, water, and environmental enrichment. 
Pre-operatively, each doe received $0.12 \mathrm{mg} / \mathrm{kg}$ Buprenorphine SR SQ (conc. $3 \mathrm{mg} / \mathrm{mL}$, SigmaAldrich Corporation, St. Louis, MO, USA) for analgesia, Penicillin G 300000 IU IM (Pfizer Inc., New York, NY, USA) for the prevention of infection, and Depo-Provera 4.5 mg IM (Pfizer Inc.) to reduce the risk of spontaneous abortion. Anesthesia was induced with $5 \mathrm{mg} / \mathrm{kg}$ IM Ketamine (conc. 100 mg/mL), 0.15 mg/kg Dexmedetomidine IM (conc. 1 mg/mL, Clearsynth Labs Pvt. Ltd., Mumbai, India), $0.01 \mathrm{mg} / \mathrm{kg}$ Glycopyrrolate SQ (conc. $0.2 \mathrm{mg} / \mathrm{mL}$, Omega Laboratories Ltd., Montréal, QC, Canada), and maintained with 5\% Isoflurane (Baxter Healthcare Corporation, Deerfield, IL, USA) via facemask. Each doe received a $4 \mathrm{cc} / \mathrm{kg}$ bolus of $0.9 \% \mathrm{NaCl}$ SQ, followed by a maintenance rate of $5 \mathrm{~mL} / \mathrm{kg} / \mathrm{hr}$. Lacrilube was applied to the eyes and a water circulating pad was used to maintain normothermia intra-operatively. Soft restraints were used on all 4 limbs to secure the doe. Vital signs were monitored and maintained within normal limits including heart rate $180-250$, respiratory rate $30-60$, and temperature $38-40^{\circ} \mathrm{C}$.

$\mathrm{CDH}$ creation was performed at 23 days of gestation in a total of 75 fetuses. The does were pre-medicated as described above. The abdominal fur was trimmed, and the abdomen was prepared with $2 \%$ chlorhexidine (Laboratoire Atlas Inc., Montréal, QC, Canada) and draped. A lower midline laparotomy incision was made and the uterus was exposed. The number of fetuses in each uterine horn was counted. Two fetuses were chosen from the most ovarian end of each uterine horn, for a total of 4 fetuses per doe (Figure 6). Fetal position was determined by gentle palpation. A $1 \mathrm{~cm}$ hysterotomy was made on the anti-mesometrial side of the uterus with a \#15-blade scalpel (Aspen Surgical Products Inc., Caledonia, MI, USA) (Figure 7). A purse string suture was placed using a 6-0 Prolene ${ }^{\circledR}$ (Ethicon Inc., Somerville, NJ, USA). The left upper limb of the fetus was identified, exposed and retracted cephalad. A left-sided thoracotomy was made at the landmark 
between the lateral thoracic vessels using a 25-gauge needle (Becton, Dickinson and Company, Franklin Lakes, NJ, USA) and mosquito forceps (Figure 7). The lung was retracted, exposing the fetal diaphragm. The diaphragm was grasped with mosquito forceps and a piece was cut with fine scissors, creating the diaphragmatic defect (Figure 7). The chest wall was sutured with a 6-0 Prolene $^{\circledR}$ (Ethicon Inc., Somerville, NJ, USA). The fetus was repositioned into the uterus and the purse string was tied, thus closing the hysterotomy. The laparotomy incision was closed with a 30 Vicryl $^{\circledR}$ (Ethicon Inc., Somerville, NJ, USA) in a running fashion. The skin was closed in a running subcuticular fashion with a 4-0 Monocryl $^{\circledR}$ (Ethicon Inc., Somerville, NJ, USA). Postoperatively, the does were placed under a red warming light and transferred to their housing cage once mobile. Meloxicam $0.2 \mathrm{mg} / \mathrm{kg}$ SQ (conc. $5 \mathrm{mg} / \mathrm{mL}$, Boehringer Ingelheim Vetmedica Inc., St. Joseph, MO, USA) was administered every 24 hours for 2 days for post-operative analgesia.

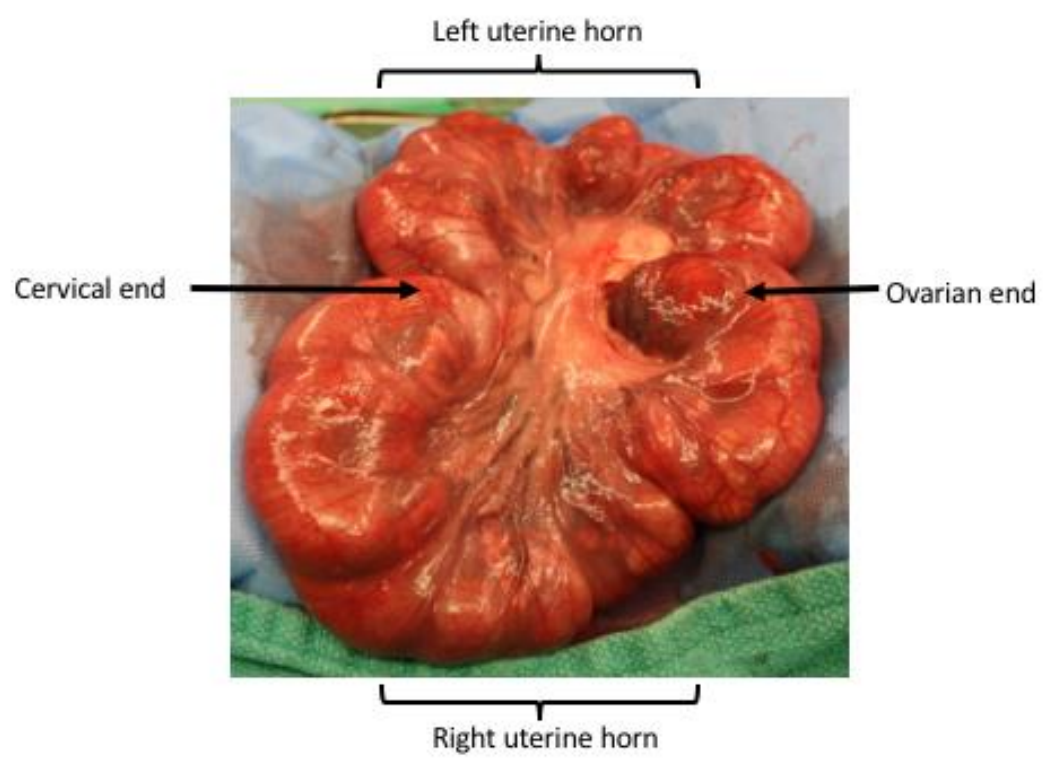

Figure 6: Bicornuate Rabbit Uterus. The pregnant New Zealand rabbit uterus is bicornuate with a right and left uterine horn containing multiple fetuses. Fetuses located at the ovarian end were used for surgical experimentation. 


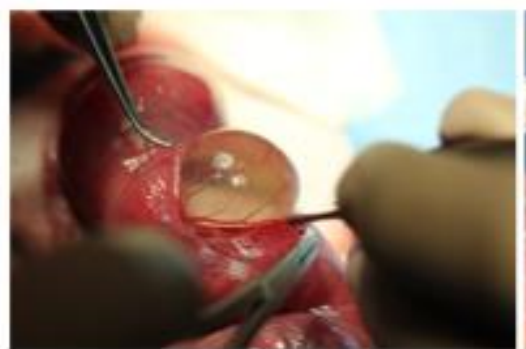

A.

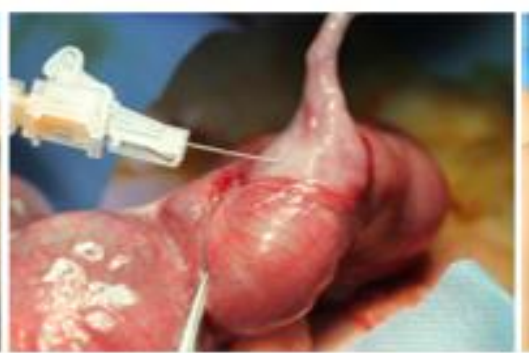

B.

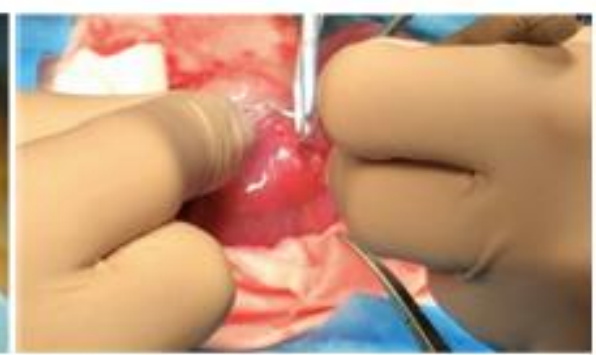

C.

Figure 7: CDH Creation in the Rabbit Fetus. A: Hysterotomy with bulging membranes. B: The fetus is minimally exposed with the left upper limb retracted cephalad and a 25-gauge needle is used to make a skin incision at the thoracotomy site. C: The diaphragmatic defect is created by grasping a piece of diaphragm and cutting it off with fine scissors.

TO was performed at 28 days gestation in a total of 17 fetuses. The does were pre-medicated as described above. Once anesthesia was induced, the abdomen was prepped and draped in a sterile fashion. The lower laparotomy incision was opened and fetuses were counted. Viability was noted. Half of the potentially viable $\mathrm{CDH}$ fetuses were chosen for TO. A hysterotomy was made and the fetal head was exposed. The snout was immediately covered with a saline soaked non-woven sponge to ensure no fetal breathing. A horizontal incision was made at the superior border of the thyroid gland. A fine snap was used to bluntly dissect down to the trachea. Once isolated, the trachea was double ligated with a 4-0 Vicryl ${ }^{\circledR}$ suture (Ethicon Inc., Somerville, NJ, USA) (Figure 8). Fetal skin was sutured with 6-0 Prolene ${ }^{\circledR}$ (Ethicon Inc., Somerville, NJ, USA). The hysterotomy was closed with 6-0 Prolene ${ }^{\circledR}$ (Ethicon Inc., Somerville, NJ, USA) in a running locking fashion. The doe's fascia was sutured with 3-0 Vicryl ${ }^{\circledR}$ (Ethicon Inc., Somerville, NJ, USA) and the skin was sutured with 4-0 Monocryl ${ }^{\circledR}$ (Ethicon Inc., Somerville, NJ, USA). Post-operative treatment was as described above. 


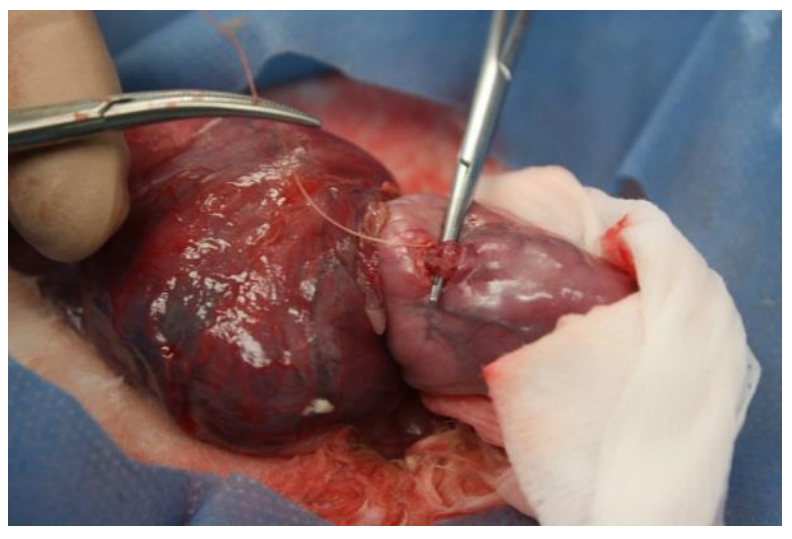

Figure 8: Tracheal Occlusion in the Rabbit Fetus. A hysterotomy has been made, the head exposed and neck extended. A small neck incision was used to isolate the trachea which was double ligated with sutures in order to perform the TO.

In the last set of 5 does, 10 sham $\mathrm{CDH}$ fetuses were generated. Surgical protocol was followed as previously described. Following CDH creation, two additional fetuses were chosen at the most ovarian end. A sham CDH was created by performing a left-sided thoracotomy without the creation of a diaphragmatic defect.

Fetal weights and lung tissue collection was performed at 31 days gestation. Each doe was euthanized individually in a room away from the remaining does. Each doe was sedated with 10$50 \mathrm{mg} / \mathrm{kg}$ Ketamine IM (conc. $100 \mathrm{mg} / \mathrm{mL}$ ) and 2.5-10 mg/kg Xylazine IM (conc. $100 \mathrm{mg} / \mathrm{mL}$, Bayer Healthcare LLC, Shawnee, KS, USA), and euthanized with $100 \mathrm{mg} / \mathrm{kg}$ Pentobarbital Sodium IV (conc. $50 \mathrm{mg} / \mathrm{mL}$, Oak Pharmaceuticals Inc., Lake Forest, IL, USA) administered through the ear vein. A midline laparotomy was made and the doe's heart was palpated to confirm the absence of cardiac activity. All fetuses were delivered (Figure 9). The snouts were immediately covered with a saline soaked non-woven sponge and each fetus was decapitated to ensure no fetal breathing. All fetuses were weighed. A sternotomy and midline laparotomy were performed and 
the diaphragm was assessed for the presence or absence of diaphragmatic defect (Figure 10). The neck was also incised in $\mathrm{CDH}+\mathrm{TO}$ fetuses and the trachea was assessed for presence of ligation. One control unoperated fetus was chosen from each doe containing other surgical specimens and was selected based on its weight being the average of the litter. Total lung weight and right lung weight were measured for each fetus and left lung weight was calculated by subtraction (Figure 9). Upper lung lobes were collected and stored in 4\% paraformaldehyde (Electron Microscopy Sciences, Hatfield, PA, USA) and lower lung lobes were flash frozen in liquid nitrogen and stored in $-80^{\circ} \mathrm{C}$.

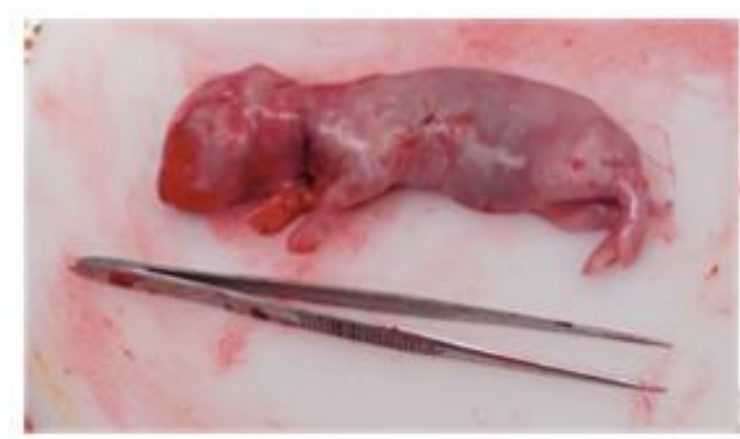

A.

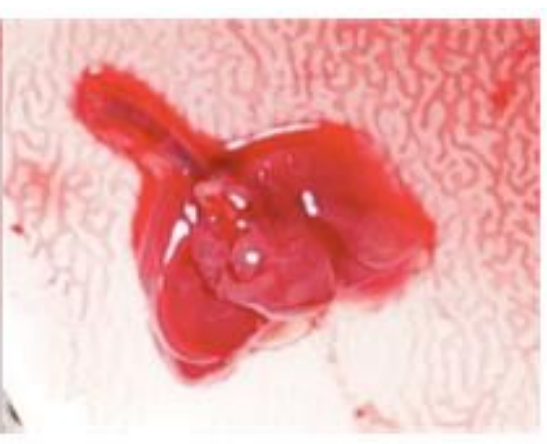

B.

Figure 9: Autopsy Specimens. A: $\mathrm{CDH}+\mathrm{TO}$ fetus as indicated by the sutures noted in the neck and left chest. The fetus has been positioned next to small forceps for size comparison. B: Magnified en bloc section of lungs, heart and trachea. The right and left lungs were further dissected and used in the study whereas the trachea and heart were discarded. 


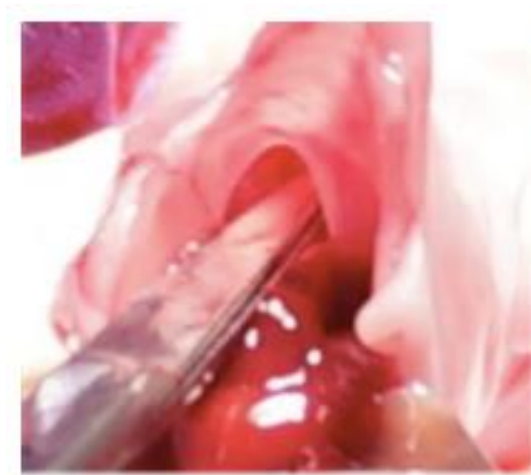

A.

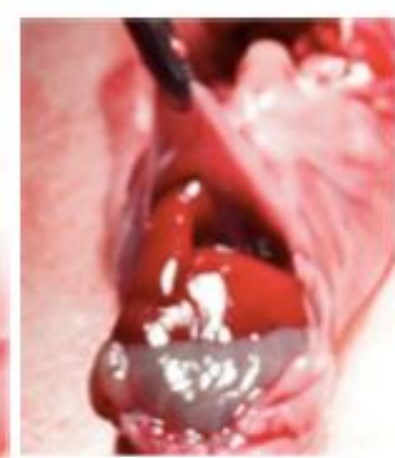

B.

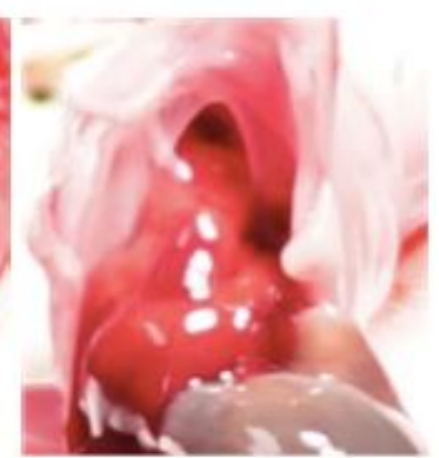

C.

Figure 10: Autopsy Confirmation of Diaphragmatic Defect. A: Tip of scissors placed within the diaphragmatic defect to emphasize presence and size of defect. B and C: Intra-abdominal organs herniating into the chest through the diaphragmatic defect.

\section{B. Lung Morphology}

Right and left upper lobes were immediately stored in $4 \%$ paraformaldehyde (Electron Microscopy Sciences, Hatfield, PA, USA), for 24 hours and then washed three times in PBS and stored in $70 \%$ Ethanol for 1-3 months. The tissue samples were processed, embedded in paraffin blocks, and 3-5 $\mu \mathrm{m}$ sections were cut. Two slides were made per block of tissue. The slides were treated with Hematoxylin and Eosin (H\&E) staining and stored at room temperature. A compound light microscope was used and slides were viewed at $100 \mathrm{x}$ magnification. The mean terminal bronchiole density (MTBD) is inversely proportional to number of alveoli, and is therefore used as a histologic marker of lung development [22]. The MTBD was calculated by counting the number of terminal bronchioles in non-overlapping high-power fields per slide [22]. Slides were de-identified and numbered so that the study group was not known at the time of MTBD calculation. An Aperio ScanScope slide scanner was used to take representative pictures of control, sham $\mathrm{CDH}, \mathrm{CDH}$, and $\mathrm{CDH}+\mathrm{TO}$ lung slides (Figure 11). 

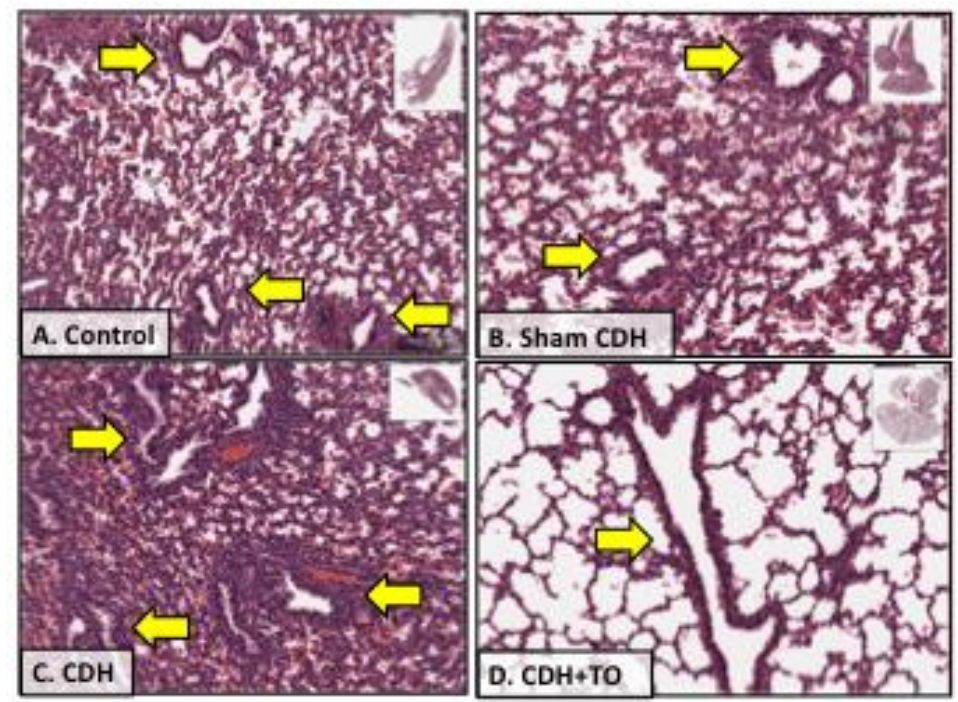

Figure 11: H\&E Stained Fetal Rabbit Lung Sections. H\&E stained lung sections showed more dense tissue with increased number of mean terminal bronchioles in hypoplastic CDH lungs compared to control and sham CDH. The histologic appearance of $\mathrm{CDH}+\mathrm{TO}$ sections was less dense with fewer mean terminal bronchioles. A representative picture is shown from each group: A. Control; B. Sham CDH; C. CDH; D. CDH+TO. The yellow arrows point to terminal bronchioles.

\section{RT-qPCR Studies}

\section{i. mRNA}

Right and left lower lobes were flash frozen in liquid nitrogen and stored at $-80^{\circ} \mathrm{C}$. The left lower lobe lung tissue was ground with a mortar and pestle in liquid nitrogen. Total cellular RNA was extracted using TRIzol ${ }^{\mathrm{TM}}$ Reagent (Thermo Fisher Scientific, Waltham, MA, USA) according to the manufacturer's protocol. RNA concentration and purity were determined using the NanoDrop Spectrophotometer (Thermo Fisher Scientific, Waltham, MA, USA). RNA integrity 
was evaluated with $1.5 \%$ agarose gel-electrophoresis and Agilent 2100 Bioanalyzer (Agilent, Santa Clara, CA, USA). RNA samples with an RNA integrity number (RIN) greater than 8 were included in the study. RNA was converted to single strand complementary DNA (cDNA) with a High-Capacity RNA-to-cDNA ${ }^{\mathrm{TM}}$ Kit (Thermo Fisher Scientific, Waltham, MA, USA) as per manufacturer's protocol using a BioRad C1000 thermal cycler (BioRad, Hercules, CA, USA). cDNA was diluted 1:40 with RNase-free water and stored at $-20^{\circ} \mathrm{C}$. Primer optimization was performed for reference genes (SDHA, ATCB, TOP1) and genes of interest (Wnt2, BMP4, Lgl1, PDE5A, MKI67, WIF1). Primers were tested by performing a temperature gradient protocol and calculating primer efficiencies using a 4-fold dilution series. Primers with efficiencies ranging between $90-110 \%$ were considered acceptable and used in the study (Table 1). Real time quantitative polymerase chain reaction (RT-qPCR) was performed in triplicate on a BioRad CFX384 (BioRad, Hercules, CA, USA), with the following cycling conditions: $95^{\circ} \mathrm{C}$ for 10 minutes, followed by 43 cycles of $95^{\circ} \mathrm{C}$ for 10 seconds, $60^{\circ} \mathrm{C}$ for 10 seconds and $72^{\circ} \mathrm{C}$ for 15 seconds. RT-qPCR reactions consisted of 1x final concentration of SensiFast SYBR No-ROX mix (FroggaBio, Toronto, Canada) primer at $200 \mathrm{nM}$ final concentration, and $3 \mu \mathrm{L}$ 1:40 cDNA template, in a total $8 \mu \mathrm{L}$ reaction volume. RT-qPCR results were analyzed using the BioRad CFX384 software (2- ${ }^{-\Delta \Delta \mathrm{Ct}}$ method).

\section{ii. MicroRNA}

RNA was converted to cDNA using the miScript II RT Kit (Qiagen, Hilden, Germany) and cDNA was diluted with $200 \mu \mathrm{L}$ RNase-free water according to the manufacturer's protocol. miRNA assays were reconstituted in $550 \mu \mathrm{L}$ TE Buffer (pH 8.0). Endogenous control (U6, miR103, miR-191) and target (miR-33, miR-200b, miR-375) assay (Qiagen, Hilden, Germany) 
efficiencies were determined using a 2-fold dilution series. miRNA assays with efficiencies ranging between 90-110\% were considered acceptable and used in the study (Table 2). RT-qPCR reactions were conducted using the miScript SYBR ${ }^{\circledR}$ Green PCR Kit (Qiagen, Hilden, Germany). The $10 \mu \mathrm{L}$ volume reactions consisted of $5 \mu \mathrm{L}$ 2x QuantiTect SYBR ${ }^{\circledR}$ Green PCR Master Mix, 1 $\mu \mathrm{L}$ 10x miScript Primer Assay, $1 \mu \mathrm{L} 10 \mathrm{x}$ miScript Universal Primer (Qiagen, Hilden Germany), $2 \mu \mathrm{L}$ RNase-free water, and $1 \mu \mathrm{L}$ Template cDNA. RT-qPCR was performed in triplicate on a BioRad CFX384 with the following cycling conditions: $95^{\circ} \mathrm{C}$ for 15 minutes, followed by 40 cycles of $94^{\circ} \mathrm{C}$ for 15 seconds, $55^{\circ} \mathrm{C}$ for 30 seconds, and $70^{\circ} \mathrm{C}$ for 30 seconds. RT-qPCR results were analyzed using the BioRad CFX384 software $\left(2^{-\Delta \Delta \mathrm{Ct}}\right.$ method).

\section{Statistical Analysis}

The Shapiro-Wilk test of normality was performed for all data sets. Non-parametric data was analyzed with the Kruskal-Wallis test. Parametric data was analyzed using the one-way ANOVA with Tukey's post hoc analysis. Statistical significance was considered to be $\mathrm{p}<0.05$. Body weight, lung weight, and surgical times were presented as mean \pm SEM. Lung body weight ratio (LBWR) and mean terminal bronchiole density (MTBD) were presented as box and whisker plots with the box showing the range of values from the $25^{\text {th }}$ to $75^{\text {th }}$ percentile, the line within the box representing the mean, and the whiskers showing the maximum and minimum values. RT-qPCR data was presented as relative quantification (RQ) and error bars (RQ max, RQ min) were derived from the standard deviation (SD) using BioRad CFX384 software (2 $2^{-\Delta \Delta \mathrm{Ct}}$ method). Correlation graphs were created to explore the relationship between mRNA/miRNA targets and degree of lung hypoplasia (LBWR and MTBD). Linear regression analysis was performed for the correlation graphs and the squared Pearson correlation coefficient $\left(\mathrm{R}^{2}\right)$ and $\mathrm{p}$-values were reported. 
Table 1: Reference and GOI Primer Sequences, Efficiencies, $\mathbf{R}^{2}$, and Literature Resources Used for RTqPCR

\begin{tabular}{|l|l|l|l|l|}
\hline $\begin{array}{l}\text { Reference } \\
\text { Gene }\end{array}$ & Target Sequence (5'-3') & $\mathbf{E}(\boldsymbol{\%})$ & $\mathbf{R}^{\mathbf{2}}$ & Reference Paper \\
\hline ATCB & $\begin{array}{l}\text { F: GATCTGGCACCACACCTTCT } \\
\text { R: TGATCTGGGTCATCTTCTCG }\end{array}$ & 107.0 & 0.95 & Vuckovic et al 2013 [23] \\
\hline SDHA & $\begin{array}{l}\text { F: ATCTATCAGCGTGCGTTCG } \\
\text { R: ATCAGCCACACAGCAGCAT }\end{array}$ & 96.6 & 0.99 & Vuckovic et al 2013 [23] \\
\hline TOP1 & $\begin{array}{l}\text { F: GCAGGCAATGAGAAGGAAGA } \\
\text { R: CACGTACTCCTGACCATCCA }\end{array}$ & 99.0 & 0.99 & Vuckovic et al 2013 [23] \\
\hline $\begin{array}{l}\text { Gene of } \\
\text { Interest }\end{array}$ & Target Sequence (5'-3') & $\mathbf{E ~ ( \% )}$ & $\mathbf{R}^{\mathbf{2}}$ & Reference Paper \\
\hline Wnt2 & $\begin{array}{l}\text { F: GGATGACCAAGTGCGAGTGT } \\
\text { R: GTCCAGTCAGCACTCTTGGG }\end{array}$ & 100.0 & 0.97 & $\begin{array}{l}\text { Emmerton-Coughlin et al 2014 } \\
\text { [42] }\end{array}$ \\
\hline BMP4 & $\begin{array}{l}\text { F: ACAATGTGACACGGTGGGAA } \\
\text { R: CCTGATGGGTCCGTGTATGG }\end{array}$ & 97.0 & 0.98 & $\begin{array}{l}\text { Emmerton-Coughlin et al 2014 } \\
{[42]}\end{array}$ \\
\hline Lg11 & $\begin{array}{l}\text { F: GCCAAGATCCTCATCGGCTA } \\
\text { R: AGGAAGAGGTGGTCCACACA }\end{array}$ & 102.0 & 0.97 & $\begin{array}{l}\text { Emmerton-Coughlin et al 2014 } \\
\text { [42] }\end{array}$ \\
\hline PDE5A & $\begin{array}{l}\text { F: CTTGGGCTACACCAACAACC } \\
\text { R: CCTCGGTTCAATGCAGAAGT }\end{array}$ & 105.5 & 0.99 & Engels et al 2016 [43] \\
\hline MKI67 & $\begin{array}{l}\text { F: AGGCAGGTGAACAAAAGACC } \\
\text { R: ATGAGCCCTCCCTATGACAA }\end{array}$ & 96.6 & 0.98 & Engels et al 2016 [43] \\
\hline WIF1 & $\begin{array}{l}\text { F: GTATGAACGGCGGACTTTGT } \\
\text { R: GTCCTGGTGGGCAAATACAT }\end{array}$ & 100.7 & 0.99 & Engels et al 2016 [43] \\
\hline
\end{tabular}

Table 2: Endogenous Control and micro-RNA miScript Primer Assays, Efficiencies, $\mathbf{R}^{\mathbf{2}}$, and Literature Resources Used for RT-qPCR

\begin{tabular}{|l|l|l|l|l|}
\hline $\begin{array}{l}\text { Endogenous } \\
\text { Control }\end{array}$ & Target Sequence (5'-3') & $\mathbf{E}(\mathbf{\%})$ & $\mathbf{R}^{\mathbf{2}}$ & Reference Paper \\
\hline RNU6-2 & $\begin{array}{l}\text { GTGCTCGCTTCGGCAGCACATATACTAAA } \\
\text { ATTGGAACGATACAGAGAAGATTAGCATG } \\
\text { GCCCCTGCGCAAGGATGACACGCAAATC } \\
\text { GTGAAGCGTTCCATATTTT }\end{array}$ & 98.4 & 0.95 & $\begin{array}{l}\text { Pereira-Terra et al } \\
2015 \text { [19] }\end{array}$ \\
\hline Rn-miR-103 & AGCAGCAUUGUACAGGGCUAUGA & 95.4 & 0.98 & Peltier et al 2008 [61] \\
\hline Mm-miR-191 & GCUGCACUUGGAUUUCGUUCCC & 99.8 & 0.85 & Peltier et al 2008 [61] \\
\hline Micro-RNA & Target Sequence (5'-3') & $\mathbf{E} \mathbf{( \% )}$ & $\mathbf{R}^{2}$ & Reference Paper \\
\hline Rn-miR-33 & GUGCAUUGUAGUUGCAUUGCA & 101.3 & 0.89 & $\begin{array}{l}\text { Zhu et al 2016 } \\
\text { [50] }\end{array}$ \\
\hline Rn-miR-200b & UAAUACUGCCUGGUAAUGAUGAC & 95.6 & 0.88 & $\begin{array}{l}\text { Pereira-Terra et al } \\
\text { 2015 [19] }\end{array}$ \\
\hline Rn-miR-375 & UUUGUUCGUUCGGCUCGCGUGA & 98.0 & 0.94 & Song et al 2015 [62] \\
\hline
\end{tabular}




\section{CHAPTER 4: RESULTS}

\section{A. Fetal Surgery}

Fetal surgeries were performed from the period of September to December 2017 and are summarised in Figure 12. Briefly, four groups of five pregnant does per group were operated on in total. There was a total of nineteen pregnant does as one doe was not pregnant at the time of operation and was immediately euthanized. Collectively the does produced a total of 222 fetuses. Overall, 137 of the 222 fetuses survived from the time of first surgery to the time of euthanasia, while 85 were dead at the time of organ retrieval. Fifty-eight diaphragmatic defects were created for the $\mathrm{CDH}$ group. Sixteen of the $\mathrm{CDH}$ fetuses survived. One $\mathrm{CDH}$ fetus was excluded on autopsy due to the absence of a diaphragmatic defect. As a result, a total of $15 \mathrm{CDH}$ fetuses were included in the study. A total of $17 \mathrm{CDH}+\mathrm{TO}$ operations were performed, of which 16 survived. One CDH+TO fetus was excluded on autopsy due to the absence of diaphragmatic defect, which resulted in a total of $15 \mathrm{CDH}+\mathrm{TO}$ specimens in the study. Ten left thoracotomies were performed to create a sham $\mathrm{CDH}$ group. Six of these sham $\mathrm{CDH}$ fetuses survived and were included in the study. In addition to our surgical specimens, one average sized unoperated fetus was chosen from every doe that also contained other surgical specimens, resulting in a total of 15 control fetuses. Therefore, 51 total fetuses were included in the study - 15 control, $15 \mathrm{CDH}, 15 \mathrm{CDH}+\mathrm{TO}$, and 6 sham $\mathrm{CDH}$. The mean total operative time for $\mathrm{CDH}$ creation was 1 hour and 8 minutes \pm 2 minutes per doe while the mean cut time, which excluded anesthesia time, was $46 \pm 2$ minutes. TO mean total operative time was $43 \pm 2$ minutes per doe and mean cut time was $18 \pm 2$ minutes (Table 3 ). 


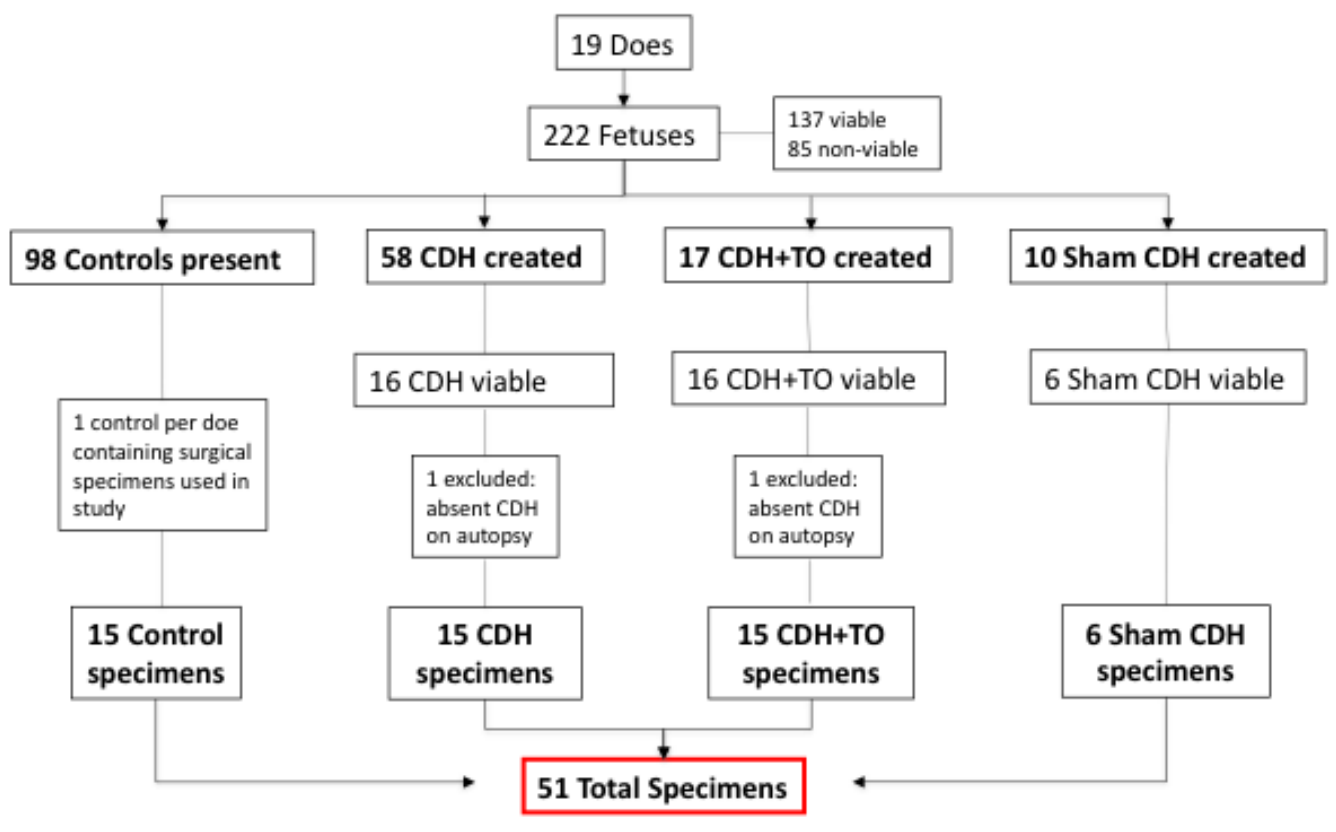

Figure 12: Fetal Rabbit Surgery Flowchart. Four biological groups were created - control, sham CDH, CDH, and $\mathrm{CDH}+\mathrm{TO} .58 \mathrm{CDH}$ fetuses were created, 16 survived, and 1 was excluded on autopsy due to absence of diaphragmatic defect (DD). $17 \mathrm{CDH}+\mathrm{TO}$ were created, 16 survived, and 1 was excluded on autopsy due to absence of DD. 10 sham CDH were created and 6 survived. 15 average sized fetuses were chosen from 98 viable unoperated control specimens. There were 51 total specimens included in the study - 15 control, 6 sham CDH, $15 \mathrm{CDH}$, and $15 \mathrm{CDH}+\mathrm{TO}$.

Table 3: Pregnant Rabbit Doe Weights and Surgical Times. Weight of pregnant does at each surgery timepoint and surgical times presented as mean \pm SEM. The mean total OR time includes the anesthesia and operative time. Mean cut time refers to the time during which surgery was performed, from initial incision to final skin closure.

\begin{tabular}{|l|c|c|c|}
\hline & $\begin{array}{c}\text { Mean Doe Weight } \\
(\mathrm{kg})\end{array}$ & $\begin{array}{c}\text { Mean Total OR Time } \\
(\mathrm{hr}: \mathrm{min})\end{array}$ & $\begin{array}{c}\text { Mean Cut Time } \\
(\mathrm{hr}: \mathrm{min})\end{array}$ \\
\hline CDH Creation & $4.01 \pm 0.6$ & $1: 08 \pm 0.02$ & $0: 46 \pm 0.02$ \\
\hline TO Creation & $3.89 \pm 0.6$ & $0: 43 \pm 0.02$ & $0: 18 \pm 0.02$ \\
\hline Delivery & $3.92 \pm 0.15$ & - & - \\
\hline
\end{tabular}




\section{B. Anatomic Features}

The size of diaphragmatic defect was noted on autopsy and subjectively measured as small $(+)$, moderate $(++)$ or large $(+++)$ (Table 4). Each sham CDH fetus had a left-sided thoracotomy and was confirmed to have an intact diaphragm with no defect. Within the CDH group, 8 fetuses had a large $\mathrm{CDH}$ with liver herniating into the left chest, and occasionally the spleen and stomach. The $\mathrm{CDH}$ group also contained 6 moderate diaphragmatic defects which were large but did not have intra-abdominal contents herniating into the chest at the time of autopsy. One fetus had a small diaphragmatic defect. The $\mathrm{CDH}+\mathrm{TO}$ group had 10 large and 5 moderate diaphragmatic hernias. The initial mean doe weight at time of $\mathrm{CDH}$ creation was $4.01 \pm 0.06 \mathrm{~kg}, 3.88 \pm 0.06 \mathrm{~kg}$ at TO, and $3.92 \pm 0.15 \mathrm{~kg}$ at time of euthanasia and organ retrieval (Table 3).

The mean fetal body weight was similar in control, sham $\mathrm{CDH}, \mathrm{CDH}$, and $\mathrm{CDH}+\mathrm{TO}$ fetuses (Table 5). Total lung weight was significantly decreased in $\mathrm{CDH}$ fetuses compared to control fetuses and significantly increased in $\mathrm{CDH}+\mathrm{TO}$ fetuses compared to $\mathrm{CDH}$ fetuses (Table 5). Similarly, right and left lung weights were lower in $\mathrm{CDH}$ compared to control and higher in CDH+TO compared to $\mathrm{CDH}$ fetuses (Table 5). Right and left lung weights were similar within each group except in the $\mathrm{CDH}+\mathrm{TO}$ fetuses, where right lungs were larger than left $(\mathrm{p}=0.04)$. The LBWR was significantly lower in the $\mathrm{CDH}$ group compared to control fetuses ( $\mathrm{p}=0.01$, Figure 13). The LBWR significantly increased in CDH fetuses following TO ( $\mathrm{p}=0.005$, Figure 13). 
Table 4: Size of Diaphragmatic Defects on Fetal Rabbit Autopsy. The size of diaphragmatic defect was subjectively measured. Large defects involved solid organs such as the liver herniating into the chest cavity. The number of fetuses are categorized by the size of diaphragmatic defect.

\begin{tabular}{|l|c|c|c|}
\hline & $\begin{array}{c}\text { Small } \\
(+)\end{array}$ & $\begin{array}{c}\text { Moderate } \\
(++)\end{array}$ & $\begin{array}{c}\text { Large } \\
(+++)\end{array}$ \\
\hline $\begin{array}{l}\text { Control } \\
(\mathrm{n}=15)\end{array}$ & - & - & - \\
\hline $\begin{array}{l}\text { Sham CDH } \\
(\mathrm{n}=6)\end{array}$ & 0 & 0 & 0 \\
\hline CDH & 1 & 6 & 8 \\
\hline $\mathrm{n}=15)$ & 0 & 5 & 10 \\
\hline $\begin{array}{l}\text { CDH+TO } \\
(\mathrm{n}=15)\end{array}$ & & & \\
\hline
\end{tabular}


Table 5: Rabbit Fetal Body and Lung Weight Measurements. CDH fetuses had smaller total lung weight, right lung weight, left lung weight, and LBWR compared to control ( $\mathrm{p}=0.008, \mathrm{p}=0.03, \mathrm{p}=0.002$ respectively). CDH+TO total lung weight, right lung weight, left lung weight, and LBWR were increased compared to CDH fetuses ( $\mathrm{p}=0.001$, $\mathrm{p}=0.0009, \mathrm{p}=0.02$ respectively). Fetal body weights were similar in all groups. Weights and LBWR presented as mean \pm SEM. Statistics calculated with one-way ANOVA and Tukey’s post-hoc analysis.

\begin{tabular}{|l|l|l|l|c|c|}
\hline & $\begin{array}{l}\text { Fetal Body } \\
\text { Weight }(\mathrm{g})\end{array}$ & $\begin{array}{l}\text { Total Lung } \\
\text { Weight }(\mathrm{g})\end{array}$ & $\begin{array}{l}\text { Right Lung } \\
\text { Weight }(\mathrm{g})\end{array}$ & Left Lung Weight (g) & $\begin{array}{c}\text { Lung Body Weight Ratio (LBWR) } \\
\text { (Lung weight /body weight (g)) }\end{array}$ \\
\hline $\begin{array}{l}\text { Control } \\
(\mathrm{n}=15)\end{array}$ & $37.49 \pm 2.16$ & $0.92 \pm 0.05$ & $0.48 \pm 0.03$ & $0.43 \pm 0.03$ & $0.025 \pm 0.0015$ \\
\hline Sham CDH & $41.88 \pm 5.38$ & $0.81 \pm 0.14$ & $0.47 \pm 0.08$ & $0.32 \pm 0.07$ & $0.020 \pm 0.0024$ \\
$(\mathrm{n}=6)$ & $34.19 \pm 2.17$ & $0.52 \pm 0.06^{*}$ & $0.30 \pm 0.03^{*}$ & $0.22 \pm 0.03^{*}$ & $0.016 \pm 0.0016^{*}$ \\
\hline $\mathrm{CDH}$ & & & & & \\
$(\mathrm{n}=15)$ & $36.47 \pm 1.87$ & $0.94 \pm 0.10^{*}$ & $0.56 \pm 0.06^{*}$ & $0.39 \pm 0.07^{*}$ & $0.026 \pm 0.0030^{*}$ \\
\hline $\begin{array}{l}\mathrm{CDH}+\mathrm{TO} \\
(\mathrm{n}=15)\end{array}$ & & & & & \\
\hline
\end{tabular}




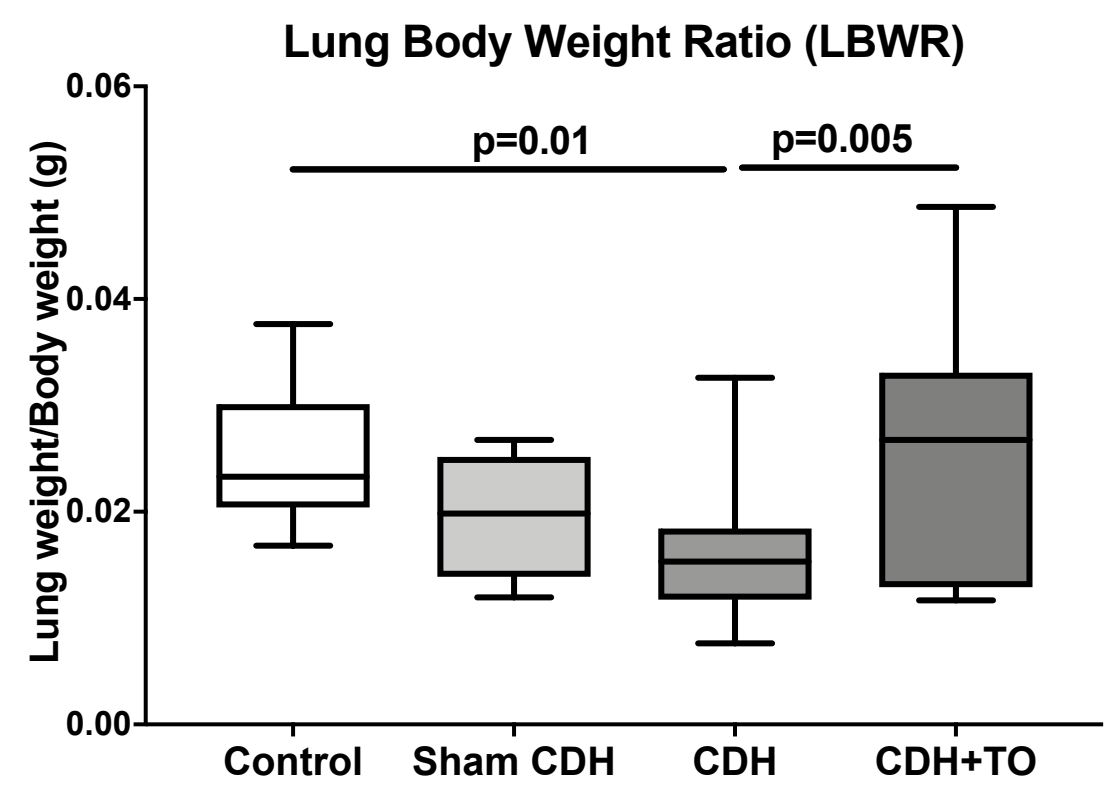

Figure 13: Lung Body Weight Ratio (LBWR) in Fetal Rabbits. LBWR was significantly decreased in CDH fetuses compared to control $(\mathrm{p}=0.01)$ and $\mathrm{CDH}+\mathrm{TO}(\mathrm{p}=0.005)$ fetuses. LBWR was similar in CDH+TO and control fetuses. Control $n=15$, Sham CDH n=6, CDH n=15, and CDH+TO n=15. Box and whisker plot shows the range of values from the $25^{\text {th }}$ to $75^{\text {th }}$ percentile, the line within the box depicts the mean, and the whiskers show the maximum and minimum values. Statistical analysis performed using one-way ANOVA and Tukey’s post hoc analysis.

\section{Lung Morphology}

The right upper lobe (RUL) and left upper lobe (LUL) was processed from each biological specimen: control $n=15$, sham $\mathrm{CDH} n=6, \mathrm{CDH} n=15, \mathrm{CDH}+\mathrm{TO} n=15$ (Figure 14). Each lung lobe was processed, and two representative slides were made per block of tissue: control - RUL $n=30$, LUL $n=30 ;$ sham CDH - RUL n $=12$, LUL n=12; CDH - RUL n=30, LUL n=30; CDH+TO RUL n =30, LUL n=30 (Figure 14). Therefore, 204 fetal rabbit lung slides were analyzed in total. There was no difference in MTBD between right and left upper lobes within each group - control 6.05 vs 6.03 ( $\mathrm{p}=0.43$ ), sham $\mathrm{CDH} 5.42$ vs 4.96 ( $\mathrm{p}=0.47)$, CDH 10.34 vs. 9.79 ( $\mathrm{p}=0.49)$, and CDH+TO 5.33 vs. 6.98 ( $\mathrm{p}=0.09$ ) (Figure 14). The MTBD was significantly higher in CDH fetuses 
compared to control and sham CDH fetuses $(\mathrm{p}<0.0001$ and $\mathrm{p}=0.0001$ respectively, Figure 14). MTBD was significantly decreased in CDH fetuses following TO ( $<<0.0001$, Figure 14). MTBD in $\mathrm{CDH}+\mathrm{TO}$ fetuses was similar to control and sham $\mathrm{CDH}$ fetuses. The histologic appearance of lung specimens showed more dense-appearing tissue with increased number of terminal bronchioles in $\mathrm{CDH}$ compared to control and sham $\mathrm{CDH}$, and less dense tissue with fewer mean terminal bronchioles in $\mathrm{CDH}+\mathrm{TO}$ specimens (Figure 11).

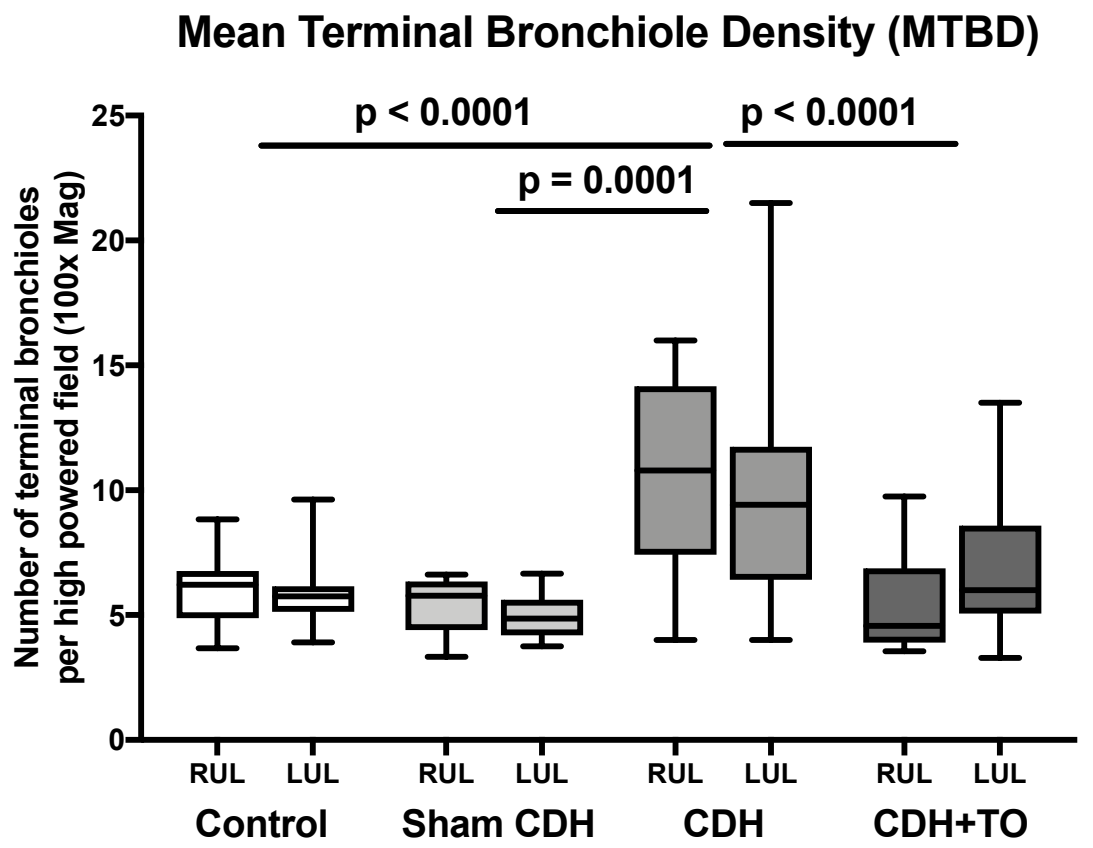

Figure 14: Mean Terminal Bronchiole Density (MTBD) in Fetal Rabbit Lungs. MTBD was significantly increased in $\mathrm{CDH}$ fetuses compared to control, sham $\mathrm{CDH}$, and $\mathrm{CDH}+\mathrm{TO}$ fetuses $(\mathrm{p}<0.0001, \mathrm{p}=0.0001$, and $\mathrm{p}<0.0001$, respectively). $\mathrm{CDH}+\mathrm{TO}$ had decreased MTBD that was similar to control and sham $\mathrm{CDH}$. MTBD was similar in RUL and LUL within each group. Biological groups: control $n=15$, sham $\mathrm{CDH} n=6, \mathrm{CDH} n=15$, and CDH+TO n=15. Slides: control - RUL n= 30, LUL $n=30$; sham CDH - RUL n = 12, LUL n=12; CDH - RUL n=30, LUL n=30; $\mathrm{CDH}+\mathrm{TO}-\mathrm{RUL} \mathrm{n}=30, \mathrm{LUL} \mathrm{n}=30$. Box and whisker plot shows the range of values from the $25^{\text {th }}$ to $75^{\text {th }}$ percentile, the line within the box depicts the mean, and the whiskers show the maximum and minimum values. Statistical analysis performed using one-way ANOVA and Tukey's post hoc analysis. 


\section{RNA Results}

RNA was extracted from 51 left lower lobe (LLL) lung tissue samples (Figure 15). Following RNA integrity testing, 6 samples were excluded due to poor quality RNA containing an RNA integrity number $(\mathrm{RIN})<8$ (Figure 15$)$. These samples were ultimately excluded because there was no remaining lung tissue left for these samples and further RNA extraction could not be performed. Therefore, a total of 46 RNA samples were included in the study - 14 control, 6 sham CDH, $12 \mathrm{CDH}$, and $14 \mathrm{CDH}+\mathrm{TO}$ RNA samples (Figure 15).

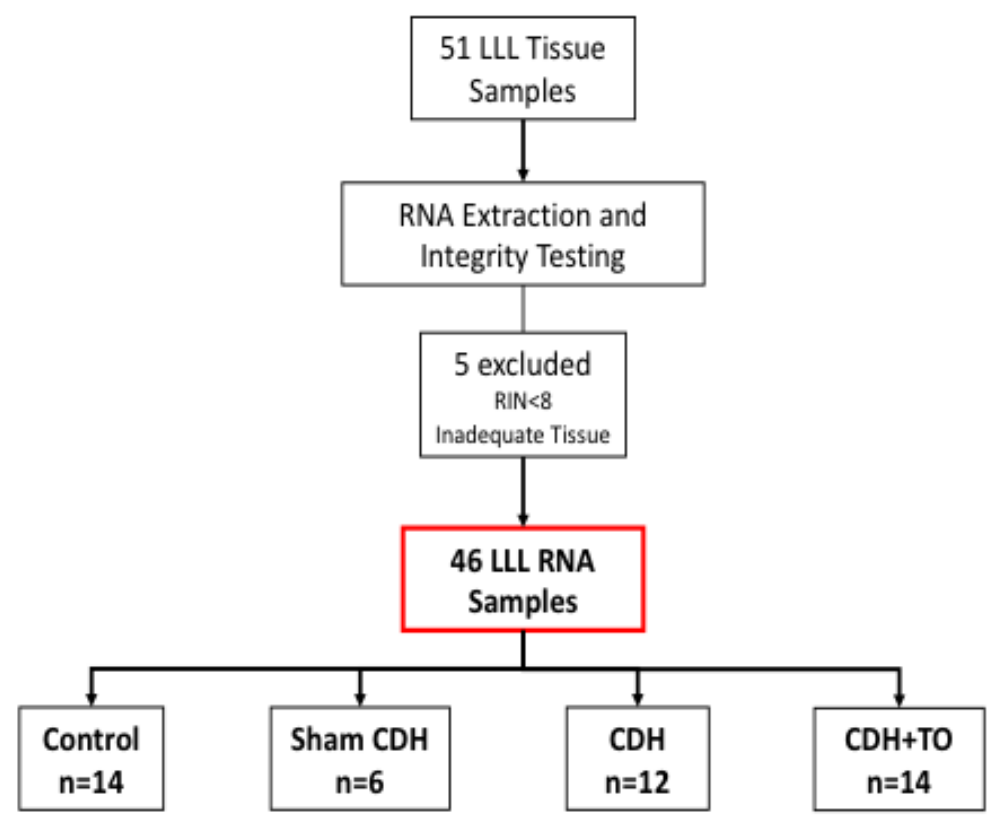

Figure 15: Fetal Rabbit RNA Sample Flowchart. RNA was extracted from 51 left lower lobe (LLL) lung tissue samples. The samples were tested for RNA integrity and 5 were excluded due to poor quality RNA and inadequate tissue. There were 46 total RNA samples included in the study: 14 control, 6 sham CDH, $12 \mathrm{CDH}$, and 14 $\mathrm{CDH}+\mathrm{TO}$. 


\section{E. RT-qPCR Results}

The relative expression of Wnt2 was similar in all groups: control=1.00 $(1.29,0.78)$, sham $\mathrm{CDH}=1.24(1.61,0.96), \mathrm{CDH}=1.31(1.73,1.00), \mathrm{CDH}+\mathrm{TO}=1.14(1.65,0.79)(\mathrm{p}=0.1$, Figure 16). BMP4 expression was also unchanged: control=1.00 (1.29, 0.77), sham $\mathrm{CDH}=1.11(1.29,0.96)$, $\mathrm{CDH}=1.05(1.3,0.85), \mathrm{CDH}+\mathrm{TO}=1.05(1.37,0.8)(\mathrm{p}=0.8$, Figure 16). Lgl1 was significantly lower in $\mathrm{CDH}+\mathrm{TO}$ fetuses compared to $\mathrm{CDH}$ and sham $\mathrm{CDH}$ fetuses ( $\mathrm{p}=0.03$ and $\mathrm{p}=0.006$, respectively): control=1.00 (1.31, 0.76), sham $\mathrm{CDH}=1.17(1.65,0.83), \mathrm{CDH}=1.16(1.55,0.87), \mathrm{CDH}+\mathrm{TO}=0.82$ $(1.02,0.65)$ (Figure 16).

PDE5A expression was similar in all groups: control=1.00 $(1.42,0.70)$, sham $\mathrm{CDH}=1.15(1.48$, 0.90), $\mathrm{CDH}=1.12(1.41,0.89), \mathrm{CDH}+\mathrm{TO}=0.89(1.20,0.66)(\mathrm{p}=0.09$, Figure 17). WIF1 expression was also unchanged: control=1.00 (1.58, 0.63), sham $\mathrm{CDH}=0.61(1.38,0.27), \mathrm{CDH}=0.8(1.39$, $0.46), \mathrm{CDH}+\mathrm{TO}=1.02(1.98,0.52)(\mathrm{p}=0.3$, Figure 17$)$. MKI67 expression was significantly increased in $\mathrm{CDH}+\mathrm{TO}$ compared to control fetuses: control=1.00 $(1.68,0.60)$, sham $\mathrm{CDH}=1.02$ $(1.83,0.57), \mathrm{CDH}=1.14(1.67,0.78), \mathrm{CDH}+\mathrm{TO}=1.9(3.46,1.04)(\mathrm{p}=0.01$, Figure 17).

miR-33 expression was significantly higher in $\mathrm{CDH}+\mathrm{TO}$ fetuses compared to sham $\mathrm{CDH}$ fetuses: control=1.00 (2.29, 0.44); sham $\mathrm{CDH}=0.46$ (1.21, 0.17); $\mathrm{CDH}=0.66$ (1.19, 0.37); $\mathrm{CDH}+\mathrm{TO}=1.24(2.19,0.71)(\mathrm{p}=0.03$, Figure 18$)$. The relative expression of miR-200b was similar in all groups: control=1.00 (1.24, 0.80); sham $\mathrm{CDH}=0.88(1.01,0.76) ; \mathrm{CDH}=1.07(1.35,0.84)$; $\mathrm{CDH}+\mathrm{TO}=1.02(1.30,0.80)(\mathrm{p}=0.39$, Figure 18$)$. There were also no changes in the expression of miR-375: control=1.00 (1.36, 0.74); sham $\mathrm{CDH}=0.99$ (1.41, 0.70); $\mathrm{CDH}=1.25$ (1.90, 0.83); $\mathrm{CDH}+\mathrm{TO}=1.16(1.59,0.84)(\mathrm{p}=0.32$, Figure 18$)$. 
Wnt 2
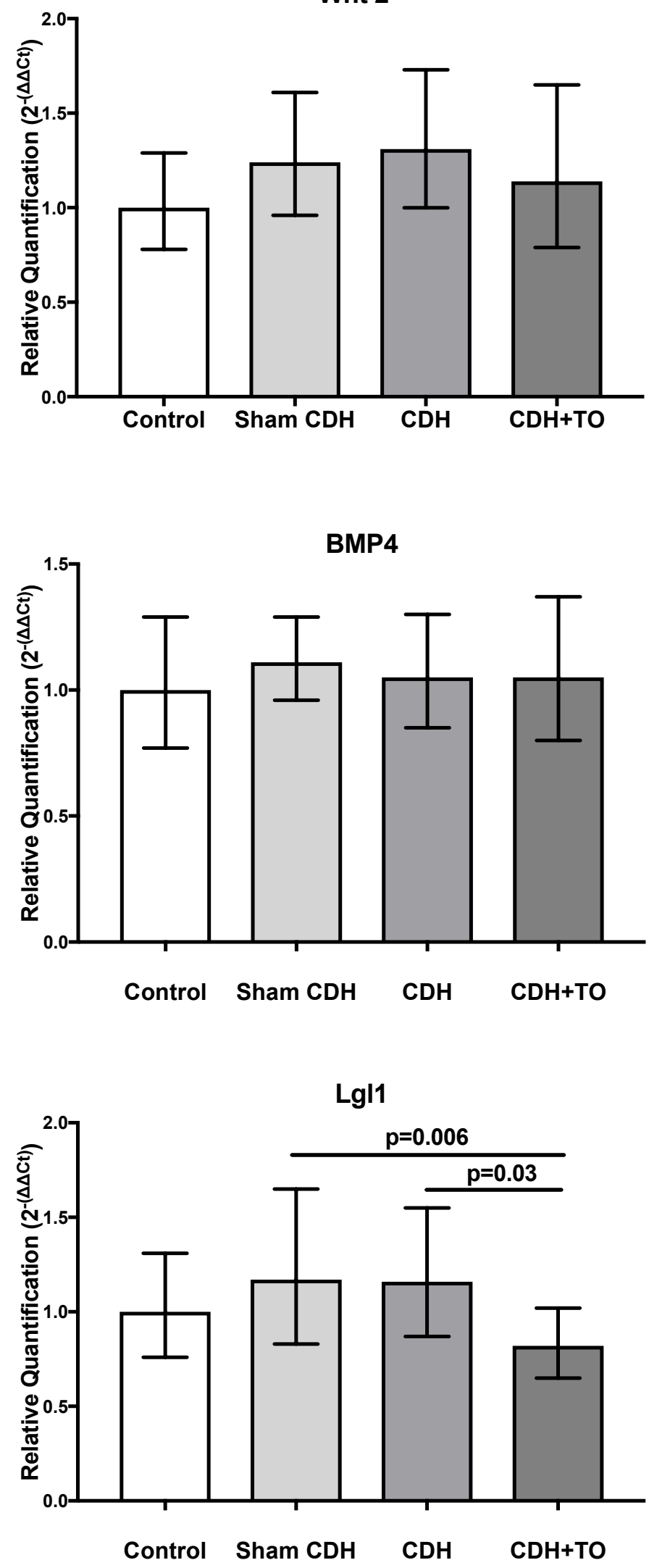

Figure 16: Relative Expression of Wnt2, BMP4, and Lgl1 in Fetal Rabbit Lungs. Expression of Wnt2 and BMP4 was similar in control, sham $\mathrm{CDH}, \mathrm{CDH}$ and $\mathrm{CDH}+\mathrm{TO}$ fetuses $(\mathrm{p}=0.1$ and $\mathrm{p}=0.8$, respectively). Lgl1 was decreased in $\mathrm{CDH}+\mathrm{TO}$ compared to $\mathrm{CDH}$ and sham CDH fetuses $(p=0.03$ and $p=0.006$, respectively). Control $n=14$, Sham $\mathrm{CDH} n=6$, $\mathrm{CDH} n=12$, and $\mathrm{CDH}+\mathrm{TO} \mathrm{n}=14$. Statistical analysis performed using one-way ANOVA and Tukey's post hoc analysis. 

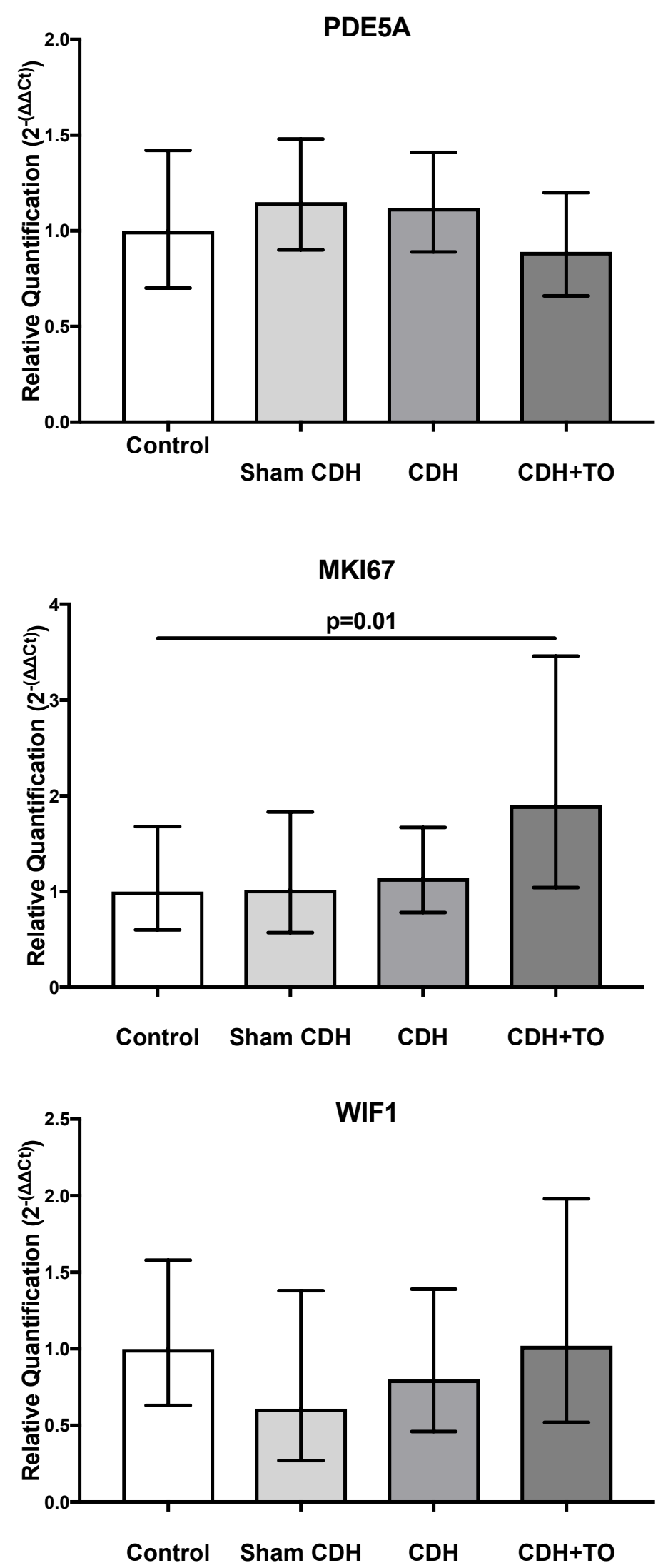

Figure 17: Relative Expression of PDE5A, MKI67, and WIF1 in Fetal Rabbit Lungs.

MKI67 expression was increased in $\mathrm{CDH}+\mathrm{TO}$ compared to control fetuses $(\mathrm{p}=0.01)$. PDE5A and WIF1 expression was similar in all groups $(\mathrm{p}=0.09$ and $\mathrm{p}=0.3$, respectively). Control $\mathrm{n}=14$, Sham $\mathrm{CDH} n=6, \mathrm{CDH} n=12$, and $\mathrm{CDH}+\mathrm{TO}$ $\mathrm{n}=14$. Statistical analysis performed using oneway ANOVA and Tukey's post hoc analysis for PDE5A and MKI67. Kruskal-Wallis test used for WIF1 expression. 
miR-33

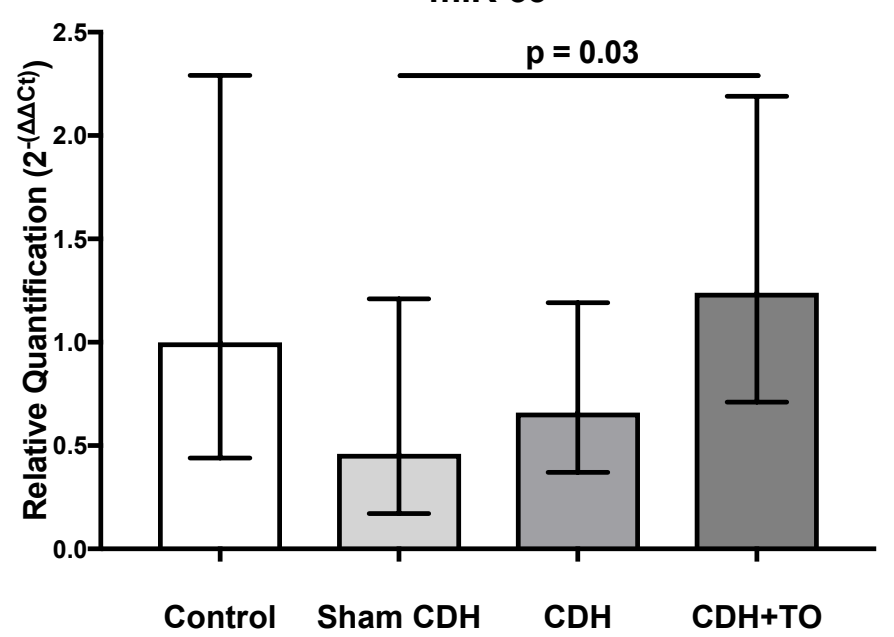

miR-200b

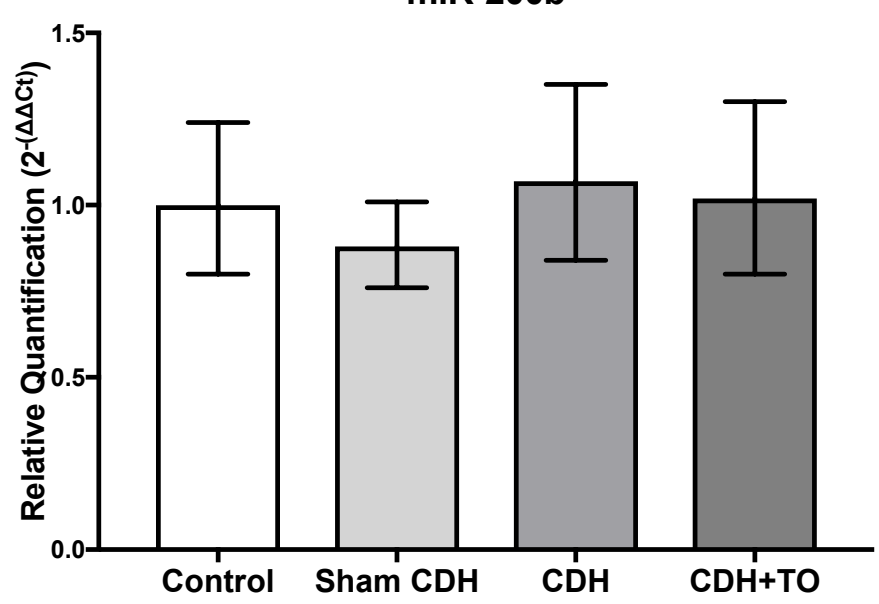

miR-375

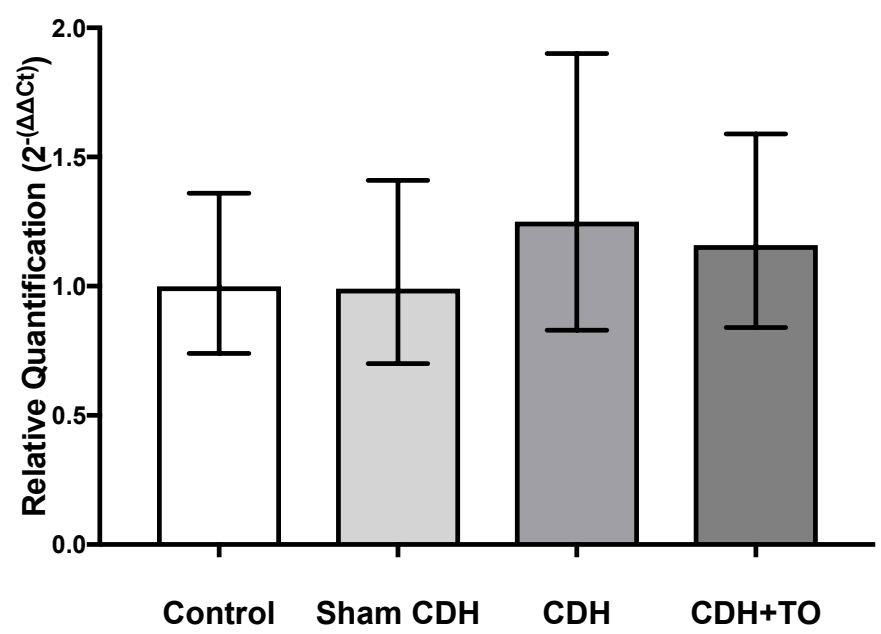

Figure 18: Relative Expression of miR-33, miR-200b, and miR-375 in Fetal Rabbit

Lungs. miR-33 expression was increased in $\mathrm{CDH}+\mathrm{TO}$ compared to sham $\mathrm{CDH}$ fetuses $(p=0.03) . m i R-200 b$ and $m i R-375$ expression was similar in all groups $(\mathrm{p}=0.39$ and $\mathrm{p}=0.32$, respectively). Control $n=14$, Sham $\mathrm{CDH} n=6$, $\mathrm{CDH} n=12$, and $\mathrm{CDH}+\mathrm{TO} \mathrm{n}=14$. Statistical analysis performed using one-way ANOVA and Tukey's post hoc analysis. 
Correlation graphs showed that there were weak correlations with no significant relationship between most target mRNAs and miRNAs versus LBWR and MTBD (Supplementary Material). Interestingly, there was a pattern observed in the $\mathrm{CDH}+\mathrm{TO}$ group that showed a positive relationship between Wnt2 vs MTBD $\left(\mathrm{R}^{2}=0.13, \mathrm{p}=0.20\right)$, BMP4 vs $\mathrm{MTBD}\left(\mathrm{R}^{2}=0.25, \mathrm{p}=0.07\right)$, Lgl1 vs MTBD $\left(\mathrm{R}^{2}=0.22, \mathrm{p}=0.09\right)$, and a significant positive relationship between PDE5A vs $\operatorname{MTBD}\left(\mathrm{R}^{2}=0.31, \mathrm{p}=0.04\right)$ (Figure 19).

CDH+TO

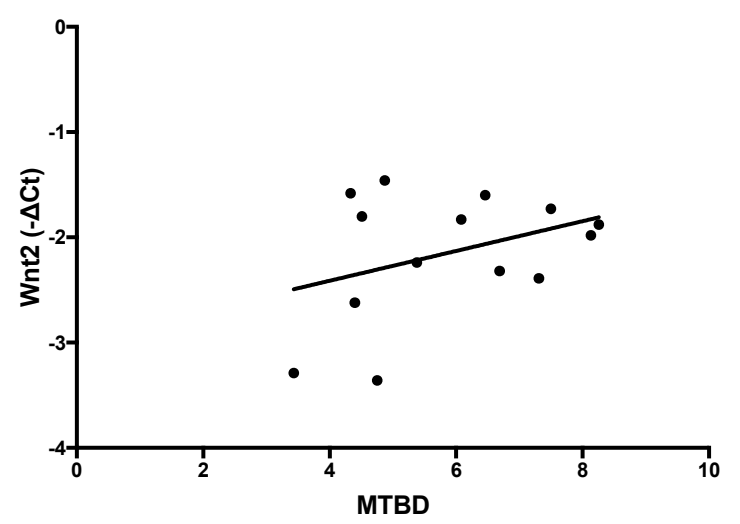

CDH+TO

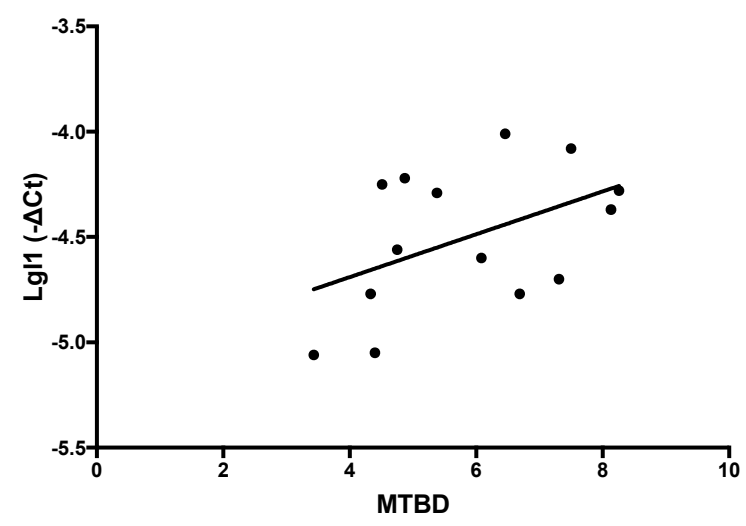

CDH+TO

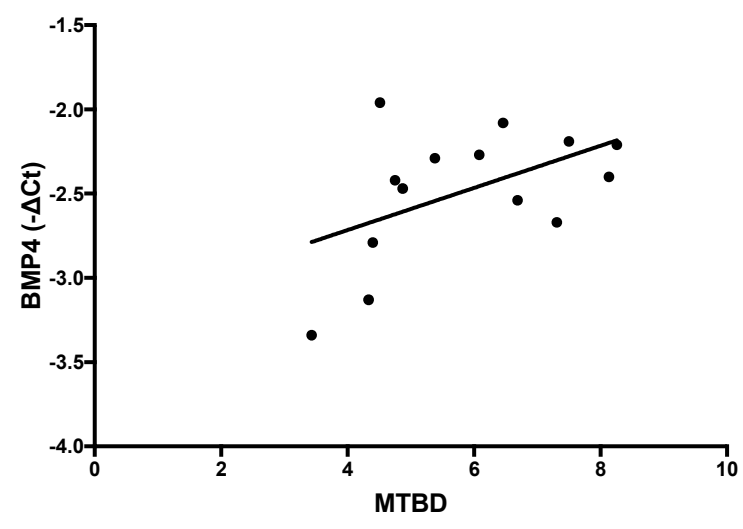

CDH+TO

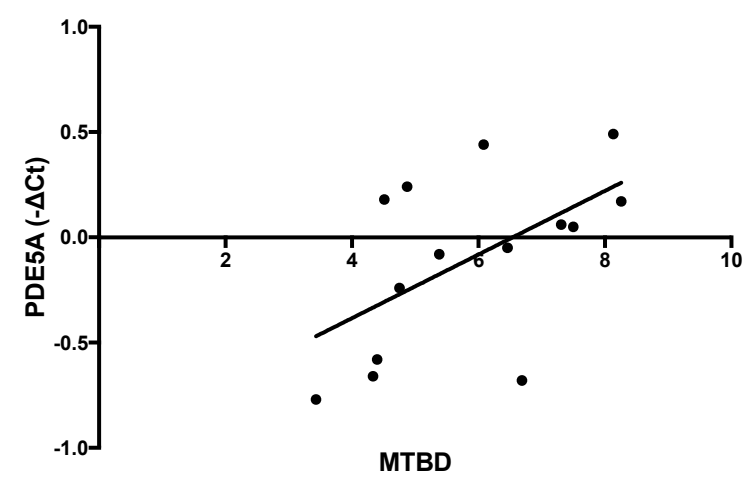

Figure 19: The Relationship of Wnt2, BMP4, Lgl1, and PDE5A Expression vs MTBD in CDH+TO Fetal Rabbit

Lungs. There is a positive relationship between Wnt2 vs MTBD $\left(\mathrm{R}^{2}=0.13, \mathrm{p}=0.20\right)$, BMP4 vs MTBD $\left(\mathrm{R}^{2}=0.25\right.$, $\mathrm{p}=0.07)$, Lgl1 vs MTBD $\left(\mathrm{R}^{2}=0.22, \mathrm{p}=0.09\right)$, and PDE5A vs MTBD $\left(\mathrm{R}^{2}=0.31, \mathrm{p}=0.04\right)$. Control $\mathrm{n}=14$, Sham CDH $\mathrm{n}=6, \mathrm{CDH} \mathrm{n}=12$, and $\mathrm{CDH}+\mathrm{TO} \mathrm{n}=14$. 


\section{CHAPTER 5: DISCUSSION \& CONCLUSION}

Fetal lung development is controlled by several intricate cellular pathways including RA, TGF$\beta$, and Wnt signaling. These pathways all contribute to epithelial-mesenchymal transition (EMT), a critical component of early lung development. Wnt signaling is highlighted in the current study because this essential signaling pathway has not been thoroughly explored in the context of lung development in $\mathrm{CDH}$. However, in addition to Wnt signaling, components of other critical EMT pathways were also explored. The Wnt signaling pathway involves miR-33, miR-375, Wnt2, BMP4, and WIF1. miR-200b targets TGF- $\beta$ signaling, which may be linked to PDE5 expression. Lgl1 is a downstream member of the RA pathway and stimulates alveolarization. MKI67 is a marker of cell growth and can be used as an indicator of lung development. The purpose of this study was to establish a rabbit model of $\mathrm{CDH}$ and determine the effects of TO on EMT pathways of lung development. In the current study, TO increased miR-33 and MKI67 expression, while Lg11 mRNA expression was decreased in CDH+TO fetuses. miR-200b, miR-375, Wnt2, BMP4, PDE5A, and WIF1 levels were unchanged (Figure 20). 


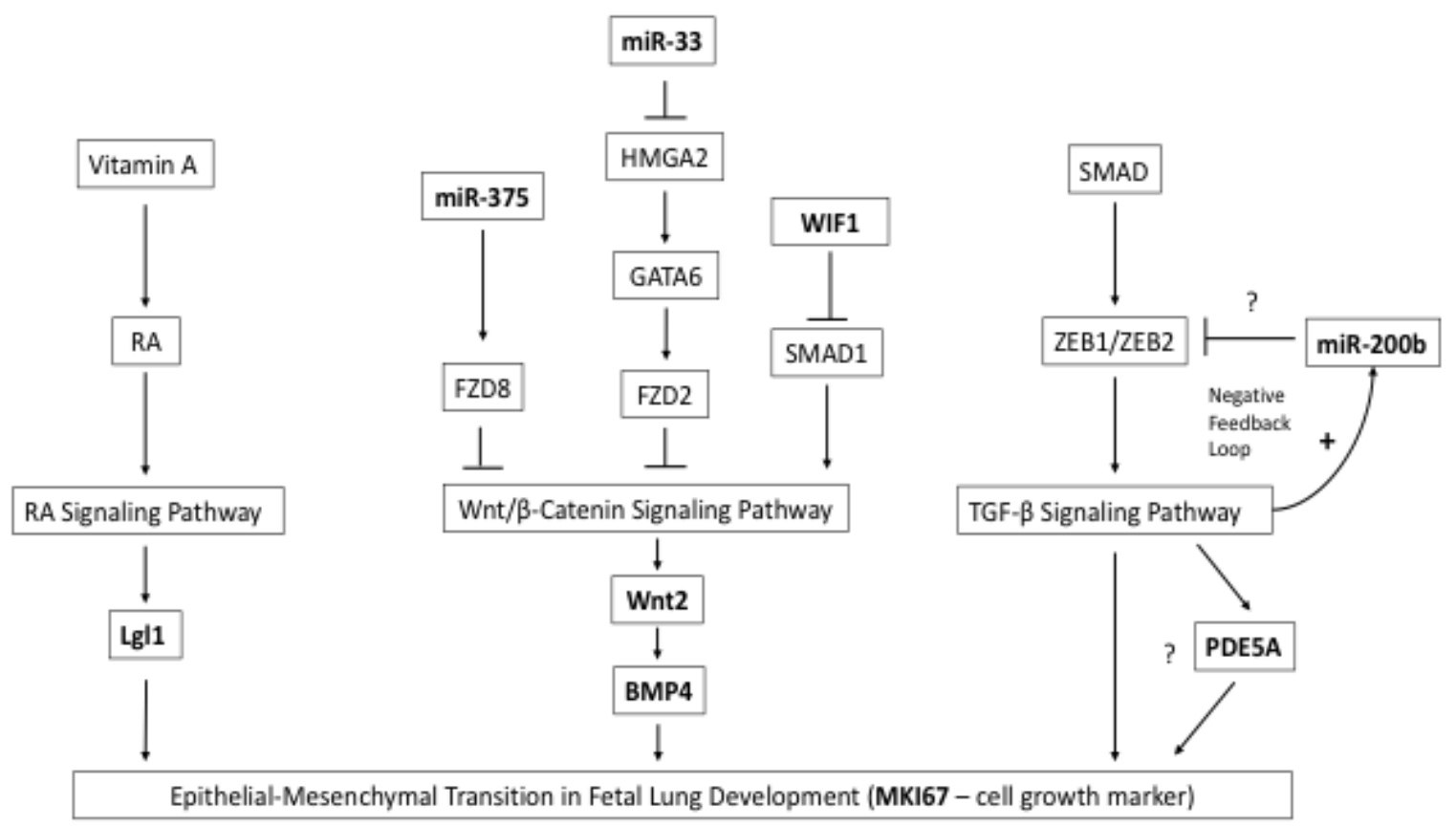

Figure 20: Proposed EMT Pathways of Fetal Lung Development. This pathway includes Wnt, TGF- $\beta$, and RA signaling. miRNAs and mRNAs investigated in the current study are bolded: Wnt signaling pathway - miR-33, miR375, Wnt2, BMP4, WIF1; RA signaling pathway - Lgl1; TGF- $\beta$ signaling pathway - miR-200b, PDE5A; and cell proliferation marker, MKI67.

The surgical rabbit model is useful for $\mathrm{CDH}$ research because the diaphragmatic defect is created during the pseudoglandular stage, similarly to humans, and thus most closely reflects the effects of CDH in human lung development [24]. In addition, the rabbit has a short gestation and produces large litters. Unlike nitrofen induced CDH rodent models, surgical models are ideal in the study of TO and other interventions for $\mathrm{CDH}$ since there is no concern about the effect of nitrofen on the developing lung or other organs [6]. The surgical sheep model has also been used in $\mathrm{CDH}$ research, however, $\mathrm{CDH}$ is created later in gestation during the canalicular stage which does not reflect the human condition $[42,63]$. Sheep also have a much longer gestational period of 145-149 days, produce fewer fetuses and is a much more costly model [6]. Despite the benefits of 
the rabbit model of $\mathrm{CDH}$, it has been under-utilized and remains outnumbered by nitrofen-induced rodent models of $\mathrm{CDH}$ due to increased cost and technical difficulty. Of the published rabbit $\mathrm{CDH}$ papers, only a few have studied the effects of TO, and to the best of our knowledge, none have studied the impact of $\mathrm{CDH}$ and potential rescue effects of $\mathrm{TO}$ on the Wnt signaling pathway $[43,64,65]$ (Figure 20).

This rabbit model of $\mathrm{CDH}$ and TO was successfully replicated and physiologically consistent with previously published data. The learning curve and difficulty of performing fetal rabbit surgery accounted for non-survivors in this study. The survival rate of $\mathrm{CDH}$ fetuses was $27 \%$ in this study compared to $41 \%$ in previously reported data [66]. It is important to note that in previous studies fetuses were exposed to only one surgery, $\mathrm{CDH}$ creation, whereas in this study all fetuses also underwent a second operation. Therefore, the $10 \%$ increase in mortality in this study is likely due to increased stress to fetuses due to a second operation. In addition, sham CDH fetuses likely died due to operative stress and prolonged operative time because this surgery was added to each doe that was also already undergoing $\mathrm{CDH}$ creation and TO.

Furthermore, the size of diaphragmatic defects on autopsy were subjectively measured with only one defect noted to be small with no intra-abdominal contents herniating into the thoracic cavity, whereas the remaining defects were either moderate or large with the liver and other intraabdominal organs herniating into the chest. These defects are analogous to the more severe cases of $\mathrm{CDH}$ in humans that would quality for FETO. Interestingly, the size of diaphragmatic defect has not been reported in other $\mathrm{CDH}$ animal studies. 
In this study, $\mathrm{CDH}$ induced lung hypoplasia was confirmed with quantification of LBWR and MTBD (Figure 13 and 14). Decreased LBWR and increased MTBD are markers of lung hypoplasia and are commonly used to define lung hypoplasia in CDH literature [22-24,66]. Lung hypoplasia that was induced through $\mathrm{CDH}$ was subsequently reversed by $\mathrm{TO}$ as postulated $[23,43]$. Interestingly in this study, both right and left lungs were hypoplastic in $\mathrm{CDH}$ and hyperplastic following TO according to both weight and MTBD. On a mechanical level, TO is thought to work by fluid building up in the lung, thus causing stretch-induced lung growth and maturation $[23,67,68]$. Although it is well established that TO reverses pulmonary hypoplasia in human CDH babies and animal $\mathrm{CDH}$ models, the molecular mechanism and effect on lung development signaling pathways is not fully understood [1]. This continues to be an area requiring further exploration with the potential for determining molecular prenatal therapies for CDH associated lung hypoplasia that stimulate lung development. miR-200b and RA have recently been explored as prenatal therapies in $\mathrm{CDH}$ animal models, which poses an exciting area for future translational research $[31,45]$.

Wnt signaling is critical in lung development and plays an important role in EMT during early stages, which ultimately regulates proximal-distal patterning, including branching morphogenesis, during later stages of lung development [37,69-71]. MKI67 is a cell proliferation marker that has been studied in the context of the canonical Wnt/ $\beta$-catenin signaling pathway in embryonic lung growth [72]. Similar to other reports, in the current rabbit CDH study, MKI67 was significantly upregulated by TO compared to control fetuses (Figure 17) [43]. 
Wnt2 is part of the canonical Wnt/ $\beta$ catenin signaling pathway and BMP4 is a downstream target of this pathway $[69,73]$. In a previously reported study of Wnt2 and BMP4 in the nitrofeninduced $\mathrm{CDH}$ rodent model, fetuses were sacrificed at multiple time points during the gestational period, and gene expression was therefore analyzed during different stages of lung development [37]. The overall trend of Wnt expression was that Wnt2 was highly expressed during early lung development in normal control fetuses, decreased over time, and was low at term on E21 [37]. Wnt2 and BMP4 expression was decreased in CDH lungs compared to control on E15 during early stages of lung development [37]. In CDH fetuses, Wnt2 and BMP4 expression increased over the gestational period and was similar to control fetuses at term on E21 [37]. In the ovine surgical model of $\mathrm{CDH}$, there was no significant difference in Wnt2 expression in $\mathrm{CDH}$ fetal sheep compared to control sheep at term gestation [42]. In the current study, Wnt2 and BMP4 expression was similar in control, sham $\mathrm{CDH}, \mathrm{CDH}$, and $\mathrm{CDH}+\mathrm{TO}$ fetal rabbit lungs (Figure 16). All of these lung specimens were taken at term and gene expression was analyzed during late stages of lung development. These results may be explained by the dynamic expression of Wnt signaling pathway genes during different stages of lung development, and are consistent with the current literature. In future studies, to further confirm Wnt expression, gene analysis should be performed during each stage of lung development in order to capture the changes in expression that occur during fetal lung development.

WIF1 is a Wnt inhibitor factor that inhibits Wnt proteins by targeting SMAD1 in epithelial cells during lung development $[43,74]$. WIF1 expression was similar in control, sham CDH, CDH, and $\mathrm{CDH}+\mathrm{TO}$ fetuses (Figure 17). Although these WIF1 expression results are not consistent with the literature, previously reported WIF1 data in rabbit and rodent CDH models also presents 
conflicting results $[43,75]$. WIF1 was upregulated in $\mathrm{CDH}$ fetal rabbits and downregulated following TO [43]. However, SMAD1 and WIF1 were downregulated in the nitrofen-induced rodent model of $\mathrm{CDH}$ during the saccular stage of lung development on E18 and E21 [43,75]. The variation in these findings could be due to differences in species-specific gene expression, the mode and timing of $\mathrm{CDH}$ induction, and the stage of lung development at which time the lung tissue was analyzed. For example, WIF1 expression in a sample of lung tissue collected during early lung development stages may be different than a sample collected at term during late stages of lung development. It is also important to note that earlier reports of gene expression in the rabbit model of CDH have been conducted with small animal numbers of 3-4 per group and in the current report animal groups consisted of 12-14 fetuses per group. These larger numbers were based on power calculations using pilot study data that compared MTBD results between CDH and control fetuses (Supplementary Material).

EMT is regulated by the Wnt signaling pathway and this process is also complemented by the RA signaling pathway of lung development. Lgl1 is a downstream target of the RA signaling pathway and plays an important role during late stages of lung development as a regulator of branching morphogenesis and alveolarization [42,44,45,76-78]. Discrepancies in Lgl1 expression between the rabbit and other models were also identified. In the current study, Lgl1 expression in $\mathrm{CDH}$ rabbit fetuses was similar to control fetuses, but downregulated in $\mathrm{CDH}+\mathrm{TO}$ fetuses compared to sham CDH fetuses (Figure 16). Lgl1 in the rat and sheep CDH models has been previously observed to be downregulated [42][45]. Possible explanations for these discordant findings are that different models (i.e. chemical vs surgical) involve different pathways or mechanisms, so prenatal interventions such as TO will have different effects [43]. Different species 
have variable lengths of gestation and therefore different time frames for the stages of lung development [43]. At term gestation, fetal rabbits are in the process of alveolarization which begins in the prenatal period and continues in the post-natal period, similar to humans. In comparison, alveolarization is complete in fetal sheep at term gestation, and does not begin until the post-natal period in rodents [24]. Since Lgl1 is primarily involved in alveolarization, downregulation of Lg11 following TO could be due to negative feedback from the completion of alveolarization as a result of the compensatory effects of TO.

In the current study, PDE5A expression was observed to be consistent across the animal groups (Figure 17). However, there was a significant positive correlation between PDE5A expression and degree of lung hypoplasia (Figure 19). This suggests that PDE5A expression is decreased in less hypoplastic lungs with decreasing MTBD in $\mathrm{CDH}+\mathrm{TO}$ fetal rabbits. This is consistent with previous reports of increased PDE5A expression in $\mathrm{CDH}$ fetal rabbits and decreased expression in CDH+TO fetuses [43]. PDE5A is a member of the phosphodiesterase (PDE) family and functions as an enzyme that metabolizes cGMP in the lung [79]. Interestingly, some PDEs are altered in TGF- $\beta$ induced EMT, although this has mostly been shown in PDE4 [46]. Fetal pulmonary hypertension is mediated by PDEs, such as PDE5, which counteract cAMP and cGMP vasodilatory pathways in the lung [47]. PDE5 is prevalent in the lung and in normal lungs its expression increases to the end of gestation and then rapidly decreases after birth [47]. During normal fetal lung development, the formation of pulmonary vasculature parallels the development of the bronchial tree [47]. In utero, pulmonary hypertension is normal for fetuses [47]. Pulmonary pressures are equivalent to systemic pressures as the placenta, and not the lung, performs the majority of gas exchange for the fetus [47]. During the gestational period, rapid vascular growth 
occurs in preparation for the shift to lung gas exchange after birth [47]. In CDH, abnormal vascular development results in pulmonary vascular hypoplasia, decreased pulmonary blood flow, and abnormal pulmonary vasoconstriction which exacerbates pulmonary hypertension and causes it to persist after birth [47]. Clinically, PDE5 inhibitors such as Sildenafil are used to treat pulmonary hypertension due to their smooth muscle relaxation properties [80]. The treatment of rats with Sildenafil induced alveolar and vascular growth, suggesting that PDE5 may play a role in both alveologenesis and angiogenesis [81].

Recently it has become apparent that a complex interplay occurs between miRNAs and mRNAs. miRNAs are non-coding RNAs that function as post-transcriptional regulators of gene expression [56]. miR-33 is an upstream regulator of the Wnt signaling pathway and was found to be downregulated in $\mathrm{CDH}$ rat fetuses [50]. In the current study, miR-33 was upregulated in our $\mathrm{CDH}+\mathrm{TO}$ fetuses compared to sham $\mathrm{CDH}$ fetal rabbit lungs (Figure 18). There was a decrease in miR-33 expression in CDH fetuses, however, this was not statistically significant (Figure 18). miR-33 targets high mobility group AT-hook 2 (HMGA2) in the canonical Wnt/ $\beta$-catenin signaling pathway [50,82]. HMGA2 is essential in cell proliferation and epithelial differentiation during embryogenesis [72]. HMGA2 knockout enhances Wnt signaling by decreasing Wnt antagonizing proteins, GATA binding protein 6 (GATA6) and FZD2 [72]. During early stages of lung development in the nitrofen-induced $\mathrm{CDH}$ rodent model, GATA6 was downregulated along with Wnt2 and its downstream target BMP4 [37]. The role of miR-33 in fetal lung development has not been thoroughly investigated. Interestingly, miR-33 appears to stimulate fetal lung development, rather than inhibit cell growth as previously reported for lung cancer cells. miR-33 expression plays a inhibitory role in cellular development of lung cancers, and decreases lung 
carcinogenesis and metastasis [83]. miR-33a upregulation inhibits EMT, growth, and metastasis of non-small cell lung cancer cells $[84,85]$. miR-33b suppresses tumor cell growth and EMT by inhibiting Wnt/ $\beta$-catenin signaling in lung adenocarcinoma cells [83]. miR-33b was also found to inhibit proliferation of lung squamous cell carcinoma [86]. miR-33 could be used as a potential therapeutic target in lung adenocarcinoma, and due to its tumor-suppressive properties, it has been proposed that miR-33 be used as a prognostic marker or a therapeutic target for lung cancers [8386]. In general, previous research has been heavily focused on miR-33 in the context of lung cancer, so the role of miR-33 in fetal lung development is a potentially exciting area for further study.

In the current study, miR-375 expression was similar in all animal groups and was unaltered by $\mathrm{CDH}$ and TO (Figure 18). miR-375 has not yet been studied in the context of CDH. During lung development, miR-375 inhibits the Wnt/ $\beta$-catenin signaling pathway by targeting FZD8 [57,58]. Overexpression of miR-375 inhibited alveolar epithelial trans-differentiation in fetal rat lungs at term gestation [58]. miR-375 expression increased throughout development as was significantly elevated at term during the saccular stage compared to the earlier canalicular stage [58]. This is consistent with previously reported data that shows a decreasing trend in Wnt2 expression throughout lung development stages in fetal rats [37]. Although miR-375 appeared to be elevated in $\mathrm{CDH}$ rabbit fetuses in the current study, this was not significantly different compared to the other animal groups (Figure 18). The literature suggests that miR-375 expression varies with developmental stage. Therefore, differences in the current study's results and previously reported data may be due to the inability to capture changes in gene expression during the different stages of lung development in the current study since all specimens were collected at term gestation. This 
multi-stage tissue collection approach is important in determining the role of miR-375 and crucial in order to adequately compare expression to previously reported data in other animal models.

EMT in fetal lung development is also regulated by the TGF- $\beta$ signaling pathway $[31,87]$. miR-200b regulates TGF- $\beta$ signaling in a negative feedback loop by targeting transcription factors zinc finger e-box binding homeobox 1 (ZEB1) and ZEB2 [19,31]. miR-200b has been specifically identified in the peripheral lung of mice, where it regulates epithelial and fibroblast cell differentiation in distal lung airway development [48]. miR-200b was upregulated in human fetuses with CDH, and even further upregulated in the tracheal fluid of FETO responders [19]. miR-200b was also upregulated in the rabbit model of $\mathrm{CDH}$, however, variable changes in miR200b expression were identified following TO [64]. In the rodent model of CDH, miR-200b expression was dependent on both the region of lung tissue and stage of lung development. miR200b expression was decreased in the mesenchyme and epithelium of rat CDH lungs in early lung development, during pseudoglandular and canalicular stages, compared to control lungs [31]. However, miR-200b expression was similar to control fetuses at term during the saccular stage of lung development [31]. In addition, miR-200b became localized in the proximal epithelium of large airways compared to distal terminal saccules [31]. Furthermore, miR-200b prenatal therapy in nitrofen rats reduced the incidence of $\mathrm{CDH}$ fetuses [31]. In our current study, there was no difference in miR-200b expression in control, sham $\mathrm{CDH}, \mathrm{CDH}$, and $\mathrm{CDH}+\mathrm{TO}$ fetal rabbit lungs (Figure 18). These findings were similar to the previously reported rodent data that showed similar levels of miR-200b at term gestation. The disadvantage of our rabbit study was that we were not able to capture the distribution pattern of miR-200b in the lung or analyze miR-200b expression levels during different stages of lung development. 


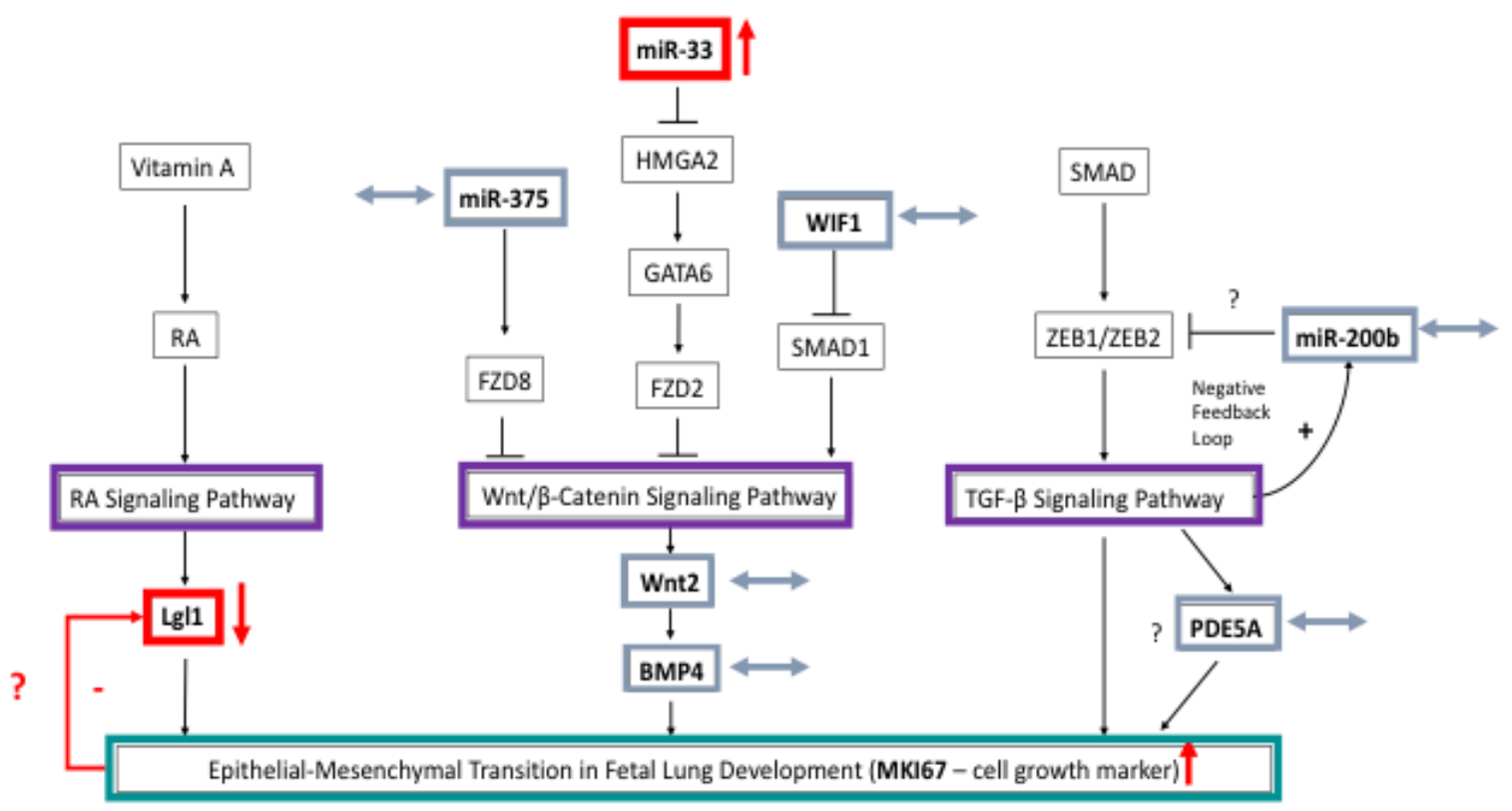

Figure 21: Effect of TO on Proposed EMT Pathway Markers in the Rabbit Model of CDH. TO increased expression of miR-33 and MKI67, and decreased expression of Lgl1 in fetal CDH+TO rabbits. The expression of other Wnt and TGF- $\beta$ signaling markers miR-375, WIF1, Wnt2, BMP4, miR-200b, and PDE5A, were unchanged.

There are several possible explanations for the differences in gene expression results reported in our study compared to previously reported literature. Firstly, some previously reported studies include low specimen numbers of 3-4 $\mathrm{CDH}$ or $\mathrm{CDH}+\mathrm{TO}$ fetuses. Small sample sizes could potentially skew results, while larger samples are likely more realistic in reflecting biological variance. The Engels paper was also at risk of possible selection bias: $6 \mathrm{CDH}+\mathrm{TO}$ RNA samples were analyzed, but 3 were excluded. Results for two of the samples clustered with the CDH group and were therefore considered non-responsive to the TO treatment, and one sample was excluded because it was considered an outlier. Secondly, chemical and surgical models are very different with respect to $\mathrm{CDH}$ creation. Nitrofen induces a diaphragmatic defect early in gestation in addition to its teratogenic effect on the RA pathway. Conversely, a surgical defect in rabbits is 
created at a similar gestational age and lung development stage to humans. Thus, CDH induction and prenatal interventions such as TO will have different effects on gene expression [43]. Thirdly, different species have variable lengths of fetal gestation and stages of lung development [43]. Comparing changes in gene expression at term gestation in multiple species may not coincide with the same stage of lung development. This could be explored in the future by analyzing gene expression from lungs at different stages of development in the fetal rabbit and not just at term gestation. Lastly, gene expression may also vary from species to species, so comparing the same gene in different species may result in discordant data [43]. There were also several limitations in our study. The gene expression results were based on mRNA in whole lung tissue. Unfortunately, the distribution and localization of gene expression within the lung was not analyzed. Differences have been described in proximal - distal airways, which our study was not able to examine. This could be explored in the future with techniques such as immunohistochemistry and in situ hybridization, although it remains difficult to find rabbit primers and antibodies [43,64]. Furthermore, mRNA levels may not correspond to functional protein levels in tissue $[88,89]$. Therefore, to fully understand the genotype to phenotype expression relationship, protein analysis should be performed in addition to RT-qPCR assessment of RNA transcripts $[88,89]$. 


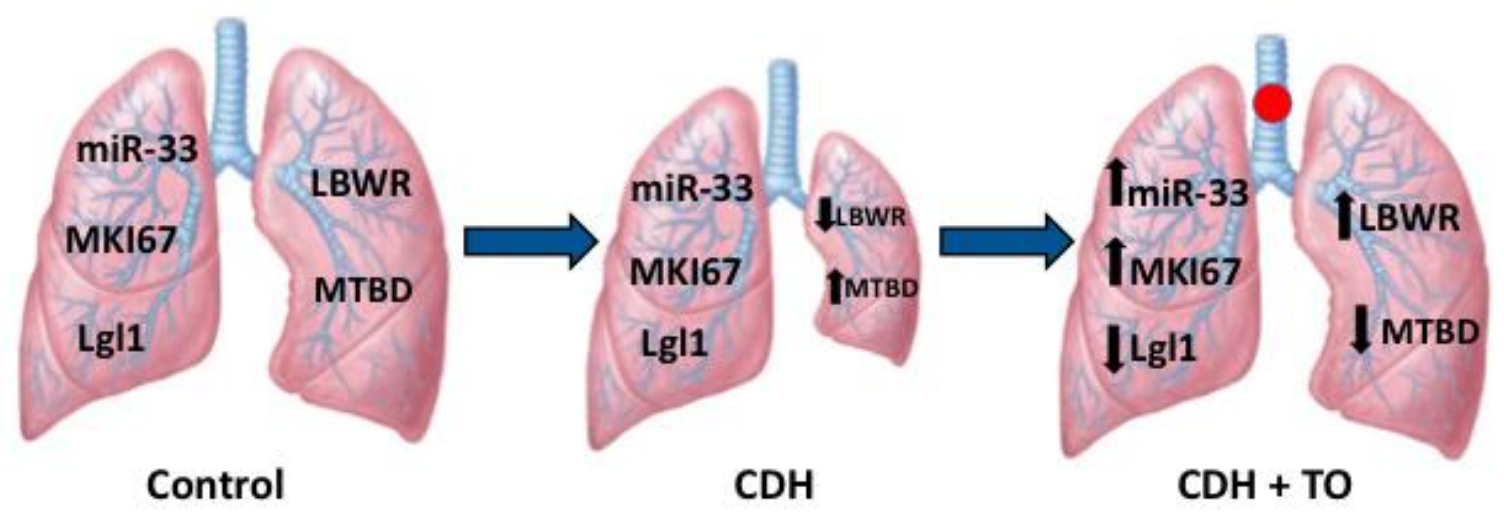

Figure 22: The Effects of CDH and TO on Fetal Rabbit Lung Development. CDH caused lung hypoplasia demonstrated by low LBWR and high MTBD with no significant difference in lung development markers. TO reversed lung hypoplasia in CDH fetuses resulting in high LBWR and low MTBD. TO increased expression of miR33 and MKI67 and decreased Lgl1 expression.

In conclusion, the rabbit model of $\mathrm{CDH}$ caused pulmonary hypoplasia which was reversed by TO (Figure 22). TO stimulated early Wnt/ $\beta$-catenin signaling by upregulating miR-33. This mechanism stimulated lung development as reflected by the upregulation of cell proliferation marker MKI67. TO likely downregulated Lgl1 expression through a negative feedback loop following alveolarization at term gestation in $\mathrm{CDH}$ fetal rabbits (Figure 21). This research has deepened our understanding of the effects of $\mathrm{CDH}$ and $\mathrm{TO}$ on lung development pathways involved in EMT, and specifically multiple components of the Wnt signaling pathway. We have established the groundwork for future research that may include exploring gene expression during different stages of lung development, analyzing the distribution of mRNA within the lung tissue, determining protein distribution to gain more information on gene expression at the functional level, and developing prenatal therapy using molecular lung development targets such as miR-33. 


\section{REFERENCES}

[1] Laberge JM, Flageole H. Fetal tracheal occlusion for the treatment of congenital diaphragmatic hernia. World J Surg 2007;31:1577-86. doi:10.1007/s00268-007-9074-7.

[2] Doyle NM, Lally KP. The CDH Study Group and advances in the clinical care of the patient with congenital diaphragmatic hernia. Semin Perinatol 2004;28:174-84.

[3] Gosche JR, Islam S, Boulanger SC. Congenital diaphragmatic hernia: Searching for answers. Am J Surg 2005;190:324-32. doi:10.1016/j.amjsurg.2005.05.035.

[4] Keijzer R, Liu J, Deimling J, Tibboel D, Post M. Dual-hit hypothesis explains pulmonary hypoplasia in the nitrofen model of congenital diaphragmatic hernia. Am J Pathol 2000;156:1299-306. doi:10.1016/S0002-9440(10)65000-6.

[5] Puligandla PS, Msc M, Skarsgard ED. The Canadian Pediatric Surgery Network Congenital Diaphragmatic Hernia Evidence Review Project: Developing national guidelines for care. Paediatr Child Heal 2016;21:183-6.

[6] Van Loenhout RB, Tibboel D, Post M, Keijzer R. Congenital diaphragmatic hernia: Comparison of animal models and relevance to the human situation. Neonatology 2009;96:137-49. doi:10.1159/000209850.

[7] Chiu PPL, Sauer C, Mihailovic A, Adatia I, Bohn D, Coates AL, et al. The price of success in the management of congenital diaphragmatic hernia: is improved survival accompanied by an increase in long-term morbidity? J Pediatr Surg 2006;41:888-92. doi:10.1016/j.jpedsurg.2006.01.026.

[8] Harrison MR, Adzick NS, Longaker MT, Goldberg JD, Rosen MA, Filly RA, et al. Successful Repair in Utero of a Fetal Diaphragmatic Hernia after Removal of Herniated Viscera from the Left Thorax. N Engl J Med 1990;322:1582-4. 
doi:10.1056/NEJM199005313222207.

[9] Harrison MR, Langer JC, Adzick NS, Golbus MS, Filly RA, Anderson RL, et al.

Correction of congenital diaphragmatic hernia in utero, V. Initial clinical experience. J

Pediatr Surg 1990;25:47-55; discussion 56-7. doi:10.1016/S0022-3468(05)80163-0.

[10] Harrison MR, Adzick NS, Flake AW, Jennings RW, Estes JM, MacGillivray TE, et al. Correction of congenital diaphragmatic hernia in utero: VI. hard-earned lessons. J Pediatr Surg 1993;28:1411-8. doi:10.1016/S0022-3468(05)80338-0.

[11] Harrison MR, Adzick NS, Bullard KM, Farrell JA, Howell LJ, Rosen MA, et al. Correction of congenital diaphragmatic hernia in utero VII: a prospective trial. J Pediatr Surg 1997;32:1637-42. doi:S0022-3468(97)90472-3 [pii].

[12] Alcorn D, Adamson TM, Lambert TF, Maloney JE, Ritchie BC, Robinson PM. Morphological effects of chronic tracheal ligation and drainage in the fetal lamb lung. J Anat 1977;123:649-60.

[13] Moessinger AC, Harding R, Adamson TM, Singh M, Kiu GT. Role of lung fluid volume in growth and maturation of the fetal sheep lung. J Clin Invest 1990;86:1270-7. doi:10.1172/JCI114834.

[14] Hashim E, Laberge JM, Chen MF, Quillen EW. Reversible tracheal obstruction in the fetal sheep: Effects on tracheal fluid pressure and lung growth. J Pediatr Surg 1995;30:1172-7. doi:10.1016/0022-3468(95)90015-2.

[15] DiFiore JW, Fauza DO, Slavin R, Peters CA, Fackler JC, Wilson JM. Experimental fetal tracheal ligation reverses the structural and physiological effects of pulmonary hypoplasia in congenital diaphragmatic hernia. J Pediatr Surg 1994;29:248-57. doi:10.1016/00223468(94)90328-X. 
[16] Flageole H, Evrard VA, Vandenberghe K, Lerut TE, Deprest JAM. Tracheoscopic endotracheal occlusion in the ovine model: Technique and pulmonary effects. J Pediatr Surg 1997;32:1328-31. doi:10.1016/S0022-3468(97)90314-6.

[17] Jani JC, Nicolaides KH, Gratacós E, Valencia CM, Doné E, Martinez JM, et al. Severe diaphragmatic hernia treated by fetal endoscopic tracheal occlusion. Ultrasound Obstet Gynecol 2009;34:304-10. doi:10.1002/uog.6450.

[18] Van der Veeken L, Russo FM, De Catte L, Gratacos E, Benachi A, Ville Y, et al. Fetoscopic endoluminal tracheal occlusion and reestablishment of fetal airways for congenital diaphragmatic hernia. Gynecol Surg 2018;15. doi:10.1186/s10397-018-1041-9.

[19] Pereira-Terra P, Deprest J a, Kholdebarin R, Khoshgoo N, DeKoninck P, Boerema-De Munck A a, et al. Unique Tracheal Fluid MicroRNA Signature Predicts Response to FETO in Patients With Congenital Diaphragmatic Hernia. Ann Surg 2015;262:1-11. doi:10.1097/SLA.0000000000001054.

[20] Ameis D, Khoshgoo N, Keijzer R. Abnormal lung development in congenital diaphragmatic hernia. Semin Pediatr Surg 2017;26:123-8. doi:10.1053/j.sempedsurg.2017.04.011.

[21] Wu J, Yamamoto H, Gratacos E, Ge X, Verbeken E, Sueishi K, et al. Lung development following diaphragmatic hernia in the fetal rabbit. Hum Reprod 2000;15:2483-8. doi:10.1093/humrep/15.12.2483.

[22] Roubliova XI, Biard JM, Ophalvens L, Gallot D, Jacques C, Verbeken EK, et al. Morphology of the developing fetal lung - the rabbit experimental model. Mod Res Educ Top Microsc 2007:417-25.

[23] Vuckovic A, Herber-Jonat S, Flemmer AW, Roubliova XI, Jani JC. Alveolarization Genes 
Modulated by Fetal Tracheal Occlusion in the Rabbit Model for Congenital

Diaphragmatic Hernia: A Randomized Study. PLoS One 2013;8.

doi:10.1371/journal.pone.0069210.

[24] Wu J, Yamamoto H, Gratacos E, Ge X, Verbeken E, Sueishi K, et al. Lung development following diaphragmatic hernia in the fetal rabbit. Hum Reprod 2000;15:2483-8. doi:10.1093/humrep/15.12.2483.

[25] Merrell AJ, Kardon G. Development of the diaphragm - A skeletal muscle essential for mammalian respiration. FEBS J 2013;280:4026-35. doi:10.1111/febs.12274.

[26] Yamashiro S, Harris WH, Stopps TP. Ultrastructural study of developing rabbit diaphragm. J Anat 1984;139 ( Pt 1:67-79.

[27] Allan DW, Greer JJ. Pathogenesis of nitrofen-induced congenital diaphragmatic hernia in fetal rats. J Appl Physiol 1997;83:338-47.

[28] Thébaud B, Tibboel D, Rambaud C, Mercier JC, Bourbon JR, Dinh-Xuan a T, et al. Vitamin A decreases the incidence and severity of nitrofen-induced congenital diaphragmatic hernia in rats. Am J Physiol 1999;277:L423-9.

[29] Iritani I. Experimental study on embryogenesis of congenital diaphragmatic hernia. Anat Embryol (Berl) 1984;169:133-9.

[30] Kluth D, Kangah R, Reich P, Tenbrinck R, Tibboel D, Lambrecht W. Nitrofen-induced diaphragmatic hernias in rats: An animal model. J Pediatr Surg 1990;25:850-4. doi:10.1016/0022-3468(90)90190-K.

[31] Khoshgoo N, Kholdebarin R, Pereira-Terra P, Mahood TH, Falk L, Day CA, et al. Prenatal microRNA miR-200b Therapy Improves Nitrofen-induced Pulmonary Hypoplasia Associated With Congenital Diaphragmatic Hernia. Ann Surg 2017:1. 
doi:10.1097/SLA.0000000000002595.

[32] Delorimier AA, Tierney DF PH. Hypoplastic lungs in fetal lambs with surgically produced congenital diaphragmatic hernia. Surgery 1967;62:12-7.

[33] Fauza DO, Tannuri U, Ayoub AAR, Capolozzi VL, Saldiva PHN, Maksoud JG. Surgically produced congenital diaphragmatic hernia in fetal rabbits. J Pediatr Surg 1994;29:882-6. doi:10.1016/0022-3468(94)90008-6.

[34] Bartis D, Mise N, Mahida RY, Eickelberg O, Thickett DR. Epithelial-mesenchymal transition in lung development and disease: Does it exist and is it important? Thorax 2014;69:760-5. doi:10.1136/thoraxjnl-2013-204608.

[35] Li C, Bellusci S, Borok Z, Minoo P. Non-canonical WNT signalling in the lung. J Biochem 2015;158:355-65. doi:10.1093/jb/mvv081.

[36] Van Camp JK, Beckers S, Zegers D, Van Hul W. Wnt Signaling and the Control of Human Stem Cell Fate. Stem Cell Rev Reports 2014;10:207-29. doi:10.1007/s12015-0139486-8.

[37] Takayasu H, Nakazawa N, Montedonico S, Puri P. Down-regulation of Wnt signal pathway in nitrofen-induced hypoplastic lung. J Pediatr Surg 2007;42:426-30. doi:10.1016/j.jpedsurg.2006.10.018.

[38] De Langhe SP, Reynolds SD. Wnt signaling in lung organogenesis. Organogenesis 2008;4:100-8. doi:10.4161/org.4.2.5856.

[39] Goss AM, Tian Y, Tsukiyama T, Cohen ED, Zhou D, Lu MM, et al. Wnt2/2b and $\beta$ Catenin Signaling Are Necessary and Sufficient to Specify Lung Progenitors in the Foregut. Dev Cell 2009;17:290-8. doi:10.1016/j.devcel.2009.06.005.

[40] Yamaguchi T, Bradley A, McMahon A, Jones S. A Wnt5a pathway underlies outgrowth 
of multiple structures in the vertebrate embryo. Development 1999;126:1211-23.

[41] Li C, Xiao J, Hormi K, Borok Z, Minoo P. Wnt5a participates in distal lung morphogenesis. Dev Biol 2002;248:68-81. doi:10.1006/dbio.2002.0729.

[42] Emmerton-Coughlin HMA, Martin KK, Chiu JSS, Zhao L, Scott LA, Regnault TRH, et al. BMP4 and LGL1 are Down Regulated in an Ovine Model of Congenital Diaphragmatic Hernia. Front Surg 2014;1:1-5. doi:10.3389/fsurg.2014.00044.

[43] Engels AC, Brady PD, Kammoun M, Finalet Ferreiro J, DeKoninck P, Endo M, et al. Pulmonary transcriptome analysis in the surgically induced rabbit model of diaphragmatic hernia treated with fetal tracheal occlusion. Dis Model Mech 2016;9:221-8. doi:10.1242/dmm.021626.

[44] Nadeau K, Montermini L, Mandeville I, Xu M, Weiss ST, Sweezey NB, et al. Modulation of $\operatorname{lgl1}$ by steroid, retinoic acid, and vitamin D models complex transcriptional regulation during alveolarization. Pediatr Res 2010;67:375-81.

doi:10.1203/PDR.0b013e3181d23656.

[45] Ruttenstock EM, Doi T, Dingemann J, Puri P. Prenatal retinoic acid treatment upregulates late gestation lung protein 1 in the nitrofen-induced hypoplastic lung in late gestation. Pediatr Surg Int 2011;27:125-9. doi:10.1007/s00383-010-2783-2.

[46] Kolosionek E, Savai R, Ghofrani HA, Weissmann N, Guenther A, Grimminger F, et al. Expression and Activity of Phosphodiesterase Isoforms during Epithelial Mesenchymal Transition: The Role of Phosphodiesterase 4. Mol Biol Cell 2009;20:4751-65. doi:10.1091/mbc.E09-01-0019.

[47] Farrow KN, Steinhorn RH. Phosphodiesterases: Emerging therapeutic targets for neonatal pulmonary hypertension. Handb Exp Pharmacol 2011;204:251-77. doi:10.1007/978-3- 
642-17969-3_11.

[48] Khoshgoo N, Visser R, Falk L, Day CA, Ameis D, Iwasiow BM, et al. MicroRNA-200b regulates distal airway development by maintaining epithelial integrity. Sci Rep 2017;7:6382. doi:10.1038/s41598-017-05412-y.

[49] Ambros V. The functions of animal microRNAs. Nature 2004;431:350-5. doi:10.1038/nature02871.

[50] Zhu S, He Q, Zhang R, Wang Y, Zhong W, Xia H, et al. Decreased expression of miR-33 in fetal lungs of nitrofen-induced congenital diaphragmatic hernia rat model 2016;51:1096-100.

[51] Inui M, Martello G, Piccolo S. MicroRNA control of signal transduction. Nat Rev Mol Cell Biol 2010;11:252-63. doi:10.1038/nrm2868.

[52] Carraro G, El-Hashash A, Guidolin D, Tiozzo C, Turcatel G, Young BM, et al. miR-17 family of microRNAs controls FGF10-mediated embryonic lung epithelial branching morphogenesis through MAPK14 and STAT3 regulation of E-Cadherin distribution. Dev Biol 2009;333:238-50. doi:10.1016/j.ydbio.2009.06.020.

[53] Wang Y, Huang C, Chintagari NR, Xi D, Weng T, Liu L. miR-124 regulates fetal pulmonary epithelial cell maturation. Am J Physiol Lung Cell Mol Physiol 2015;309:L400-13. doi:10.1152/ajplung.00356.2014.

[54] Shrestha A, Mukhametshina RT, Taghizadeh S, Vásquez-Pacheco E, Cabrera-Fuentes H, Rizvanov A, et al. MicroRNA-142 is a multifaceted regulator in organogenesis, homeostasis, and disease. Dev Dyn 2017;246:285-90. doi:10.1002/dvdy.24477.

[55] Carraro G, Shrestha A, Rostkovius J, Contreras A, Chao C-M, El Agha E, et al. miR-142$3 p$ balances proliferation and differentiation of mesenchymal cells during lung 
development. Development 2014;141:1272-81. doi:10.1242/dev.105908.

[56] Cushing L, Jiang Z, Kuang P, Lu J. The Roles of miRNAs and Protein Components of the miRNA Pathway in Lung Development and Diseases. Am J Respir Cell Mol Biol 2014. doi:10.1165/rcmb.2014-0232RT.

[57] Song JL, Nigam P, Tektas SS, Selva E. MicroRNA regulation of Wnt signaling pathways in development and disease. Cell Signal 2015;27:1380-91.

doi:10.1016/j.cellsig.2015.03.018.

[58] Wang Y, Huang C, Reddy Chintagari N, Bhaskaran M, Weng T, Guo Y, et al. miR-375 regulates rat alveolar epithelial cell trans-differentiation by inhibiting Wnt/beta-catenin pathway. Nucleic Acids Res 2013;41:3833-44. doi:10.1093/nar/gks1460.

[59] Lu Y, Thomson JM, Wong HYF, Hammond SM, Hogan BLM. Transgenic overexpression of the microRNA miR-17-92 cluster promotes proliferation and inhibits differentiation of lung epithelial progenitor cells. Dev Biol 2007;310:442-53. doi:10.1016/j.ydbio.2007.08.007.

[60] Johar D, Siragam V, Mahood TH, Keijzer R. New insights into lung development and diseases: the role of microRNAs. Biochem Cell Biol 2015;93:139-48. doi:10.1139/bcb2014-0103.

[61] Peltier HJ, Latham GJ. Normalization of microRNA expression levels in quantitative RTPCR assays: Identification of suitable reference RNA targets in normal and cancerous human solid tissues. RNA 2008;14:844-52. doi:10.1261/rna.939908.

[62] Song JL, Nigam P, Tektas SS, Selva E. MicroRNA regulation of Wnt signaling pathways in development and disease. Cell Signal 2015;27:1380-91. doi:10.1016/j.cellsig.2015.03.018. 
[63] Alcorn DG, Adamson TM, Maloney JE, Robinson PM. A morphologic and morphometric analysis of fetal lung development in the sheep. Anat Rec 1981;201:655-67. doi:10.1002/ar.1092010410.

[64] Eastwood MP, Deprest J, Russo FM, Wang H, Mulhall D, Iwasiow B, et al. MicroRNA $200 \mathrm{~b}$ is upregulated in the lungs of fetal rabbits with surgically induced diaphragmatic hernia. Prenat Diagn 2018.

[65] Prat Ortells J, Albert A, Tarrado X, Krauel L, Cruz R, Moreno-Álvarez Ó, et al. Airway and vascular maturation stimulated by tracheal occlusion do not correlate in the rabbit model of diaphragmatic hernia. Pediatr Res 2014;75:487-92. doi:10.1038/pr.2013.244.

[66] Flemmer AW, Jani JC, Bergmann F, Muensterer OJ, Gallot D, Hajek K, et al. Lung tissue mechanics predict lung hypoplasia in a rabbit model for congenital diaphragmatic hernia. Pediatr Pulmonol 2007;42:505-12. doi:10.1002/ppul.20618.

[67] Kitano Y, Von Allmen D, Kanai M, Quinn TM, Davies P, Flake AW. Fetal lung growth after short-term tracheal occlusion is linearly related to intratracheal pressure. J Appl Physiol 2001;90:493-500.

[68] Benachi A, Chailley-Heu B, Delezoide AL, Dommergues M, Brunelle F, Dumez Y, et al. Lung growth and maturation after tracheal occlusion in diaphragmatic hernia. Am J Respir Crit Care Med 1998;157:921-7. doi:10.1164/ajrccm.157.3.9611023.

[69] Shu W, Guttentag S, Wang Z, Andl T, Ballard P, Lu MM, et al. Wnt/ $\beta$-catenin signaling acts upstream of N-myc, BMP4, and FGF signaling to regulate proximal-distal patterning in the lung. Dev Biol 2005;283:226-39. doi:10.1016/j.ydbio.2005.04.014.

[70] Pongracz JE, Stockley RA. Wnt signalling in lung development and diseases. Respir Res 2006;7. doi:10.1186/1465-9921-7-15. 
[71] Warburton D, Bellusci S, De Langhe S, Del Moral P-M, Fleury V, Mailleux A, et al. Molecular Mechanisms of Early Lung Specification and Branching Morphogenesis. Pediatr Res 2005;57:26R-37R. doi:10.1203/01.PDR.0000159570.01327.ED.

[72] Singh I, Mehta A, Contreras A, Boettger T, Carraro G, Wheeler M, et al. Hmga2 is required for canonical WNT signaling during lung development. BMC Biol 2014;12. doi:10.1186/1741-7007-12-21.

[73] Zhang M, Shi J, Huang Y, Lai L. Expression of canonical WNT/ $\beta$-CATENIN signaling components in the developing human lung. BMC Dev Biol 2012;12:21.

[74] Xu B, Chen C, Chen H, Zheng S-G, Bringas P, Xu M, et al. Smad1 and its target gene Wif1 coordinate BMP and Wnt signaling activities to regulate fetal lung development. Development 2011;138:925-35. doi:10.1242/dev.062687.

[75] Fujiwara N, Doi T, Gosemann JH, Kutasy B, Friedmacher F, Puri P. Smad1 and WIF1 genes are downregulated during saccular stage of lung development in the nitrofen rat model. Pediatr. Surg. Int., vol. 28, 2012, p. 189-93. doi:10.1007/s00383-011-2987-0.

[76] Oyewumi L, Kaplan F, Gagnon S, Sweezey NB. Antisense oligodeoxynucleotides decrease LGL1 mRNA and protein levels and inhibit branching morphogenesis in fetal rat lung. Am J Respir Cell Mol Biol 2003;28:232-40. doi:10.1165/rcmb.4877.

[77] Oyewumi L, Kaplan F, Sweezey NB. Lgl1, a mesenchymal modulator of early lung branching morphogenesis, is a secreted glycoprotein imported by late gestation lung epithelial cells. Biochem J 2003;376:61-9. doi:10.1042/BJ20030591.

[78] Zhang H, Sweezey NB, Kaplan F. LGL1 modulates proliferation, apoptosis and migration of human fetal lung fibroblasts. Am J Physiol Lung Cell Mol Physiol 2014:ajplung.00119.2014. doi:10.1152/ajplung.00119.2014. 
[79] Klinger JR, Abman SH, Gladwin MT. Nitric oxide deficiency and endothelial dysfunction in pulmonary arterial hypertension. Am J Respir Crit Care Med 2013;188:639-46. doi:10.1164/rccm.201304-0686PP.

[80] Noori S, Friedlich P, Wong P, Garingo A, Seri I. Cardiovascular effects of sildenafil in neonates and infants with congenital diaphragmatic hernia and pulmonary hypertension. Neonatology 2007;91:92-100. doi:10.1159/000097125.

[81] Ladha F, Bonnet S, Eaton F, Hashimoto K, Korbutt G, Thébaud B. Sildenafil improves alveolar growth and pulmonary hypertension in hyperoxia-induced lung injury. Am $\mathbf{J}$ Respir Crit Care Med 2005;172:750-6. doi:10.1164/rccm.200503-510OC.

[82] Rice SJ, Lai S-C, Wood LW, Helsley KR, Runkle EA, Winslow MM, et al. MicroRNA33a mediates the regulation of high mobility group AT-hook 2 gene (HMGA2) by thyroid transcription factor 1 (TTF-1/NKX2-1). J Biol Chem 2013:jbc-M113.

[83] Qu J, Li M, An J, Zhao B, Zhong W, Gu Q, et al. MicroRNA-33b inhibits lung adenocarcinoma cell growth, invasion, and epithelial-mesenchymal transition by suppressing Wnt/ß-catenin/ZEB1 signaling. Int J Oncol 2015;47:2141-52. doi:10.3892/ijo.2015.3187.

[84] Yang L, Yang J, Li J, Shen X, Le Y, Zhou C, et al. MircoRNA-33a inhibits epithelial-tomesenchymal transition and metastasis and could be a prognostic marker in non-small cell lung cancer. Sci Rep 2015;5. doi:10.1038/srep13677.

[85] Zhu C, Zhao Y, Zhang Z, Ni Y, Li X, Yong H. MicroRNA-33a inhibits lung cancer cell proliferation and invasion by regulating the expression of $\beta$-catenin. Mol Med Rep 2015;11:3647-51. doi:10.3892/mmr.2014.3134.

[86] Qu JJ, Li M, An J, Zhong W, Gu Q, Cao L, et al. miR-33b inhibits tumor EMT and 
migration in lung squamous cell carcinoma by targeting TWIST1. Int J Clin Exp Patho 2016;9:789-801.

[87] Gregory PA, Bert AG, Paterson EL, Barry SC, Tsykin A, Farshid G, et al. The miR-200 family and miR-205 regulate epithelial to mesenchymal transition by targeting ZEB1 and SIP1. Nat Cell Biol 2008;10:593-601. doi:10.1038/ncb1722.

[88] Edfors F, Danielsson F, Hallström BM, Käll L, Lundberg E, Pontén F, et al. Gene-specific correlation of RNA and protein levels in human cells and tissues. Mol Syst Biol 2016;12:883. doi:10.15252/msb.20167144.

[89] Liu Y, Beyer A, Aebersold R. On the Dependency of Cellular Protein Levels on mRNA Abundance. Cell 2016;165:535-50. doi:10.1016/j.cell.2016.03.014. 


\section{APPENDIX}

\section{A. Ethics Approval}

AUP Number: 2016-041

PI Name: Regnault, Timothy

AUP Title: The Effects of Congerital Diaphragmatic Hemia and Tracheal Occlusion on the Wnt Signaling Pathway in a Rabbit Model.

Approval Date: 09/28/2016

Official Notice of Animal Use Subcommittee (AUS) Approval: Your new Animal Use Protocol (AUP) entitles "The Effects of Congenital Diaphragmatic Hemia and Tracheal Occlusion on the Wnt Signaling Pathway in a Rabbit Model" has beenAPPROVED by the Animal Use Subcommittee of the University Council on Animal Care. This approval, although valid for four years, and is subject to anmual Protocol Renewal. 2016-041:-1

1. This AUP number must be indicated when ordering animals for this project.

2. Animals for other projects may notbe ordered under this AUP number.

3. Purchases of animals other than through this systemmust be cleared through the ACVS office. Health certificates will be required.

The holder of this Animal Use Protocol is responsible to ensure that all associatedsa fety components (biosa fety, ra diation sa fety, general laboratory sa fety) comply with institutional safety standards andhave received all necessary approvals. Please consult directly with your institutional sa fety officers.

On behalf of the Animal Use Subcommittee, University Council on Animal Care 


\section{B. Sample Size Calculation}

Resource: www.stat.ubc.ca

Based on pilot study data:

mu1: Control MTBD = 5.33

mu2: $\mathrm{CDH}$ MTBD $=7.87$

Sigma $=2$

2-sided test

Alpha $=0.05$

Desired power $=0.80$

Result: Sample size $=10$

Screen Shot of Website Sample Size Calculator:

Inference for Means: Comparing Two Independent Samples

(To use this page, your browser must recognize JavaScript.)

Choose which calculation you desire, enter the relevant population values for mu1 (mean of population 1), mu2 (mean of population 2), and sigma (common standard deviation) and, if calculating power, a sample size (assumed the same for each sample). You may also modify $\alpha$ (type I error rate) and the power, if relevant. After making your entries, hit the calculate button at the bottom.

- Calculate Sample Size (for specified Power)

- Calculate Power (for specified Sample Size)

Enter a value for mu1: 5.33

Enter a value for mu2: 7.87

Enter a value for sigma: 2

- 1 Sided Test

- 22 Sided Test

Enter a value for $\alpha$ (default is .05):

Enter a value for desired power (default is .80 ): .80

The sample size (for each sample separately) is: 10

Calculate

Reference: The calculations are the customary ones based on normal distributions. See for example Hypothesis Testing: Two-Sample Inference - Estimation of Sample Size and Power for Comparing Two Means in Bernard Rosner's Fundamentals of Biostatistics.

Rollin Brant

Email me at: rollin@stat.ubc.ca 


\section{Correlation Graphs: Supplementary Figures 1 - 9}
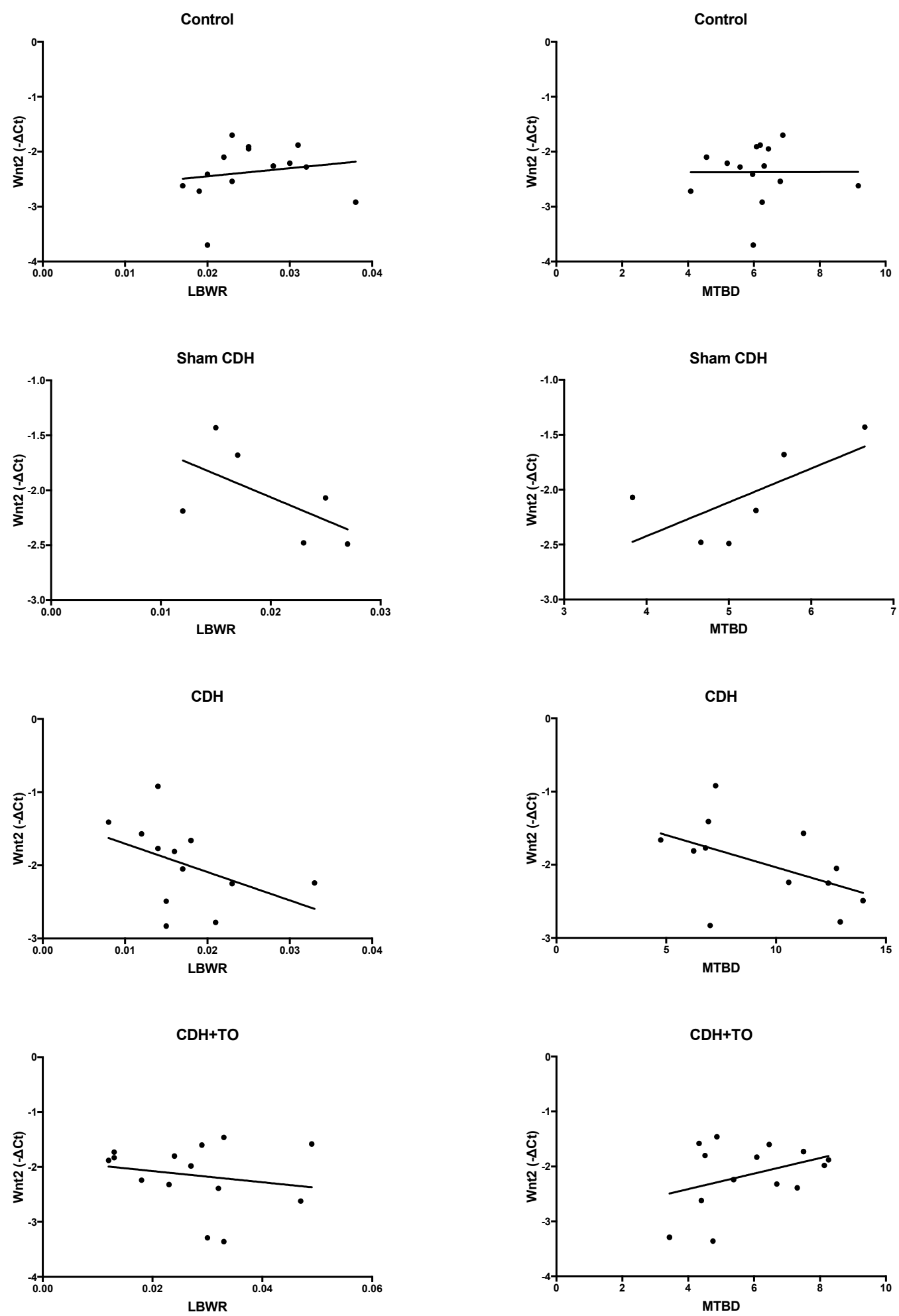

Supplementary Figure 1: Correlation Graphs of Wnt2 vs. LBWR and Wnt2 vs. MTBD. Wnt 2 expression data presented as $-\Delta \mathrm{Ct}$. Wnt2 vs LBWR - control $\mathrm{R}^{2}=0.03, \mathrm{p}=0.57$; sham $\mathrm{CDH} \mathrm{R}^{2}=0.34, \mathrm{p}=0.22 ; \mathrm{CDH} \mathrm{R}^{2}=0.19, \mathrm{p}=0.16$; $\mathrm{CDH}+\mathrm{TO} \mathrm{R}^{2}=0.04, \mathrm{p}=0.5$. Wnt 2 vs MTBD - control $\mathrm{R}^{2}=0.000005, \mathrm{p}=0.99 ;$ sham $\mathrm{CDH} \mathrm{R}^{2}=0.47, \mathrm{p}=0.13 ; \mathrm{CDH}$ $\mathrm{R}^{2}=0.25, \mathrm{p}=0.10 ; \mathrm{CDH}+\mathrm{TO} \mathrm{R}^{2}=0.13, \mathrm{p}=0.20$. 

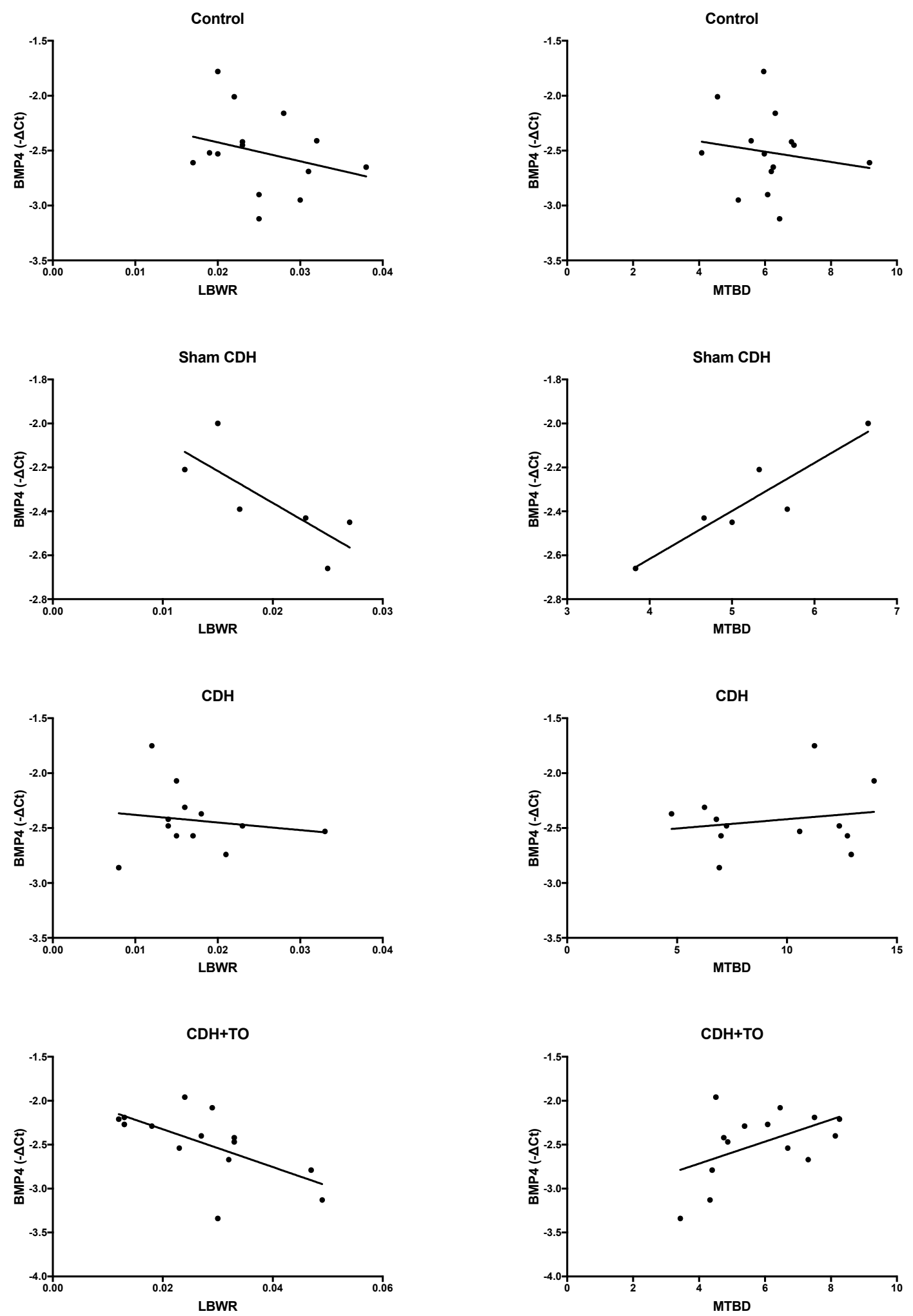

Supplementary Figure 2: Correlation Graphs of BMP4 vs LBWR and BMP4 vs MTBD. BMP4 expression data presented as $-\Delta$ Ct. BMP4 vs LBWR - control $\mathrm{R}^{2}=0.08, \mathrm{p}=0.33$; sham $\mathrm{CDH} \mathrm{R}^{2}=0.59, \mathrm{p}=0.07$; $\mathrm{CDH} \mathrm{R}^{2}=0.02$, $\mathrm{p}=0.64 ; \mathrm{CDH}+\mathrm{TO} \mathrm{R}^{2}=0.40, \mathrm{p}=0.02$. BMP4 vs MTBD - control $\mathrm{R}^{2}=0.02, \mathrm{p}=0.60$; sham $\mathrm{CDH} \mathrm{R}^{2}=0.85, \mathrm{p}=0.01$; $\mathrm{CDH} \mathrm{R}^{2}=0.03, \mathrm{p}=0.57$; $\mathrm{CDH}+\mathrm{TO} \mathrm{R}^{2}=0.25, \mathrm{p}=0.07$. 

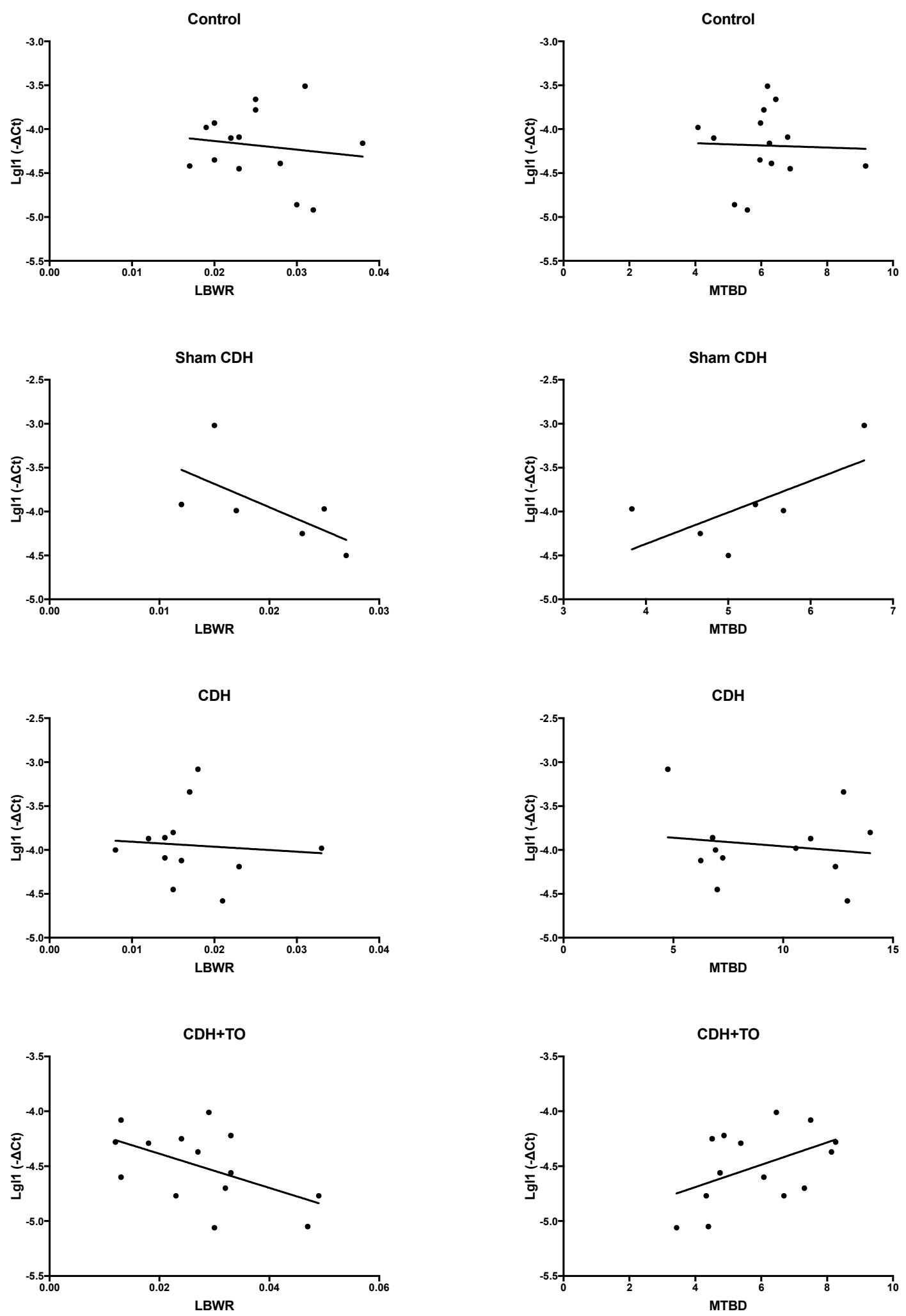

Supplementary Figure 3: Correlation Graphs of Lgl1 vs LBWR and Lgl1 vs MTBD. Lgl1 expression data presented as $-\Delta \mathrm{Ct}$. Lgl1 vs LBWR - control $\mathrm{R}^{2}=0.02$, $\mathrm{p}=0.63$; sham $\mathrm{CDH} \mathrm{R}^{2}=0.41, \mathrm{p}=0.17 ; \mathrm{CDH} \mathrm{R}^{2}=0.01, \mathrm{p}=0.79$; $\mathrm{CDH}+\mathrm{TO} \mathrm{R}^{2}=0.28, \mathrm{p}=0.05$. Lgl1 vs MTBD - control $\mathrm{R}^{2}=0.0013, \mathrm{p}=0.90 ;$ sham $\mathrm{CDH} \mathrm{R}^{2}=0.47, \mathrm{p}=0.14 ; \mathrm{CDH}$ $\mathrm{R}^{2}=0.02, \mathrm{p}=0.64 ; \mathrm{CDH}+\mathrm{TO} \mathrm{R}^{2}=0.22, \mathrm{p}=0.09$. 

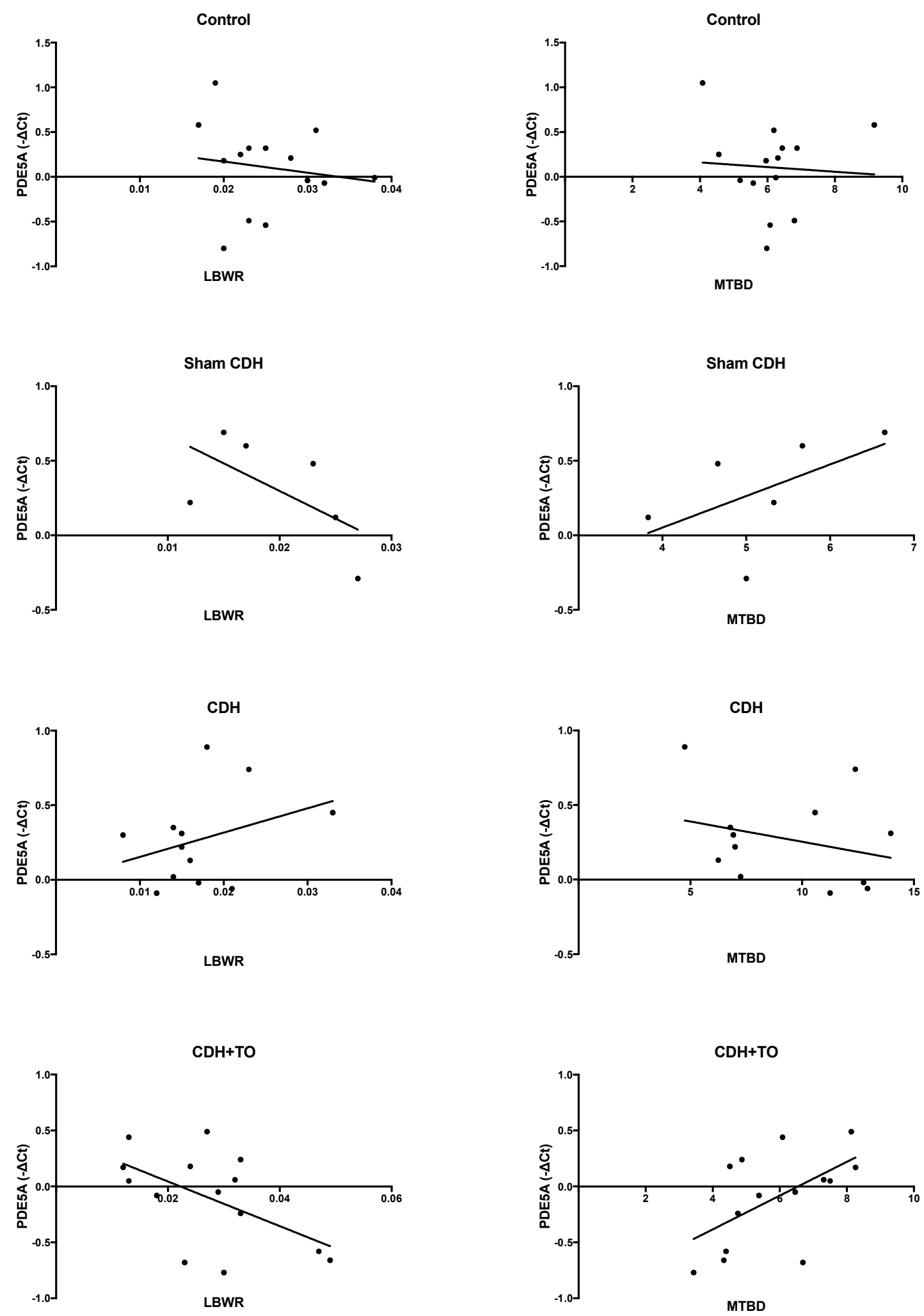

Supplementary Figure 4: Correlation Graphs of PDE5A vs LBWR and PDE5A vs MTBD. PDE5A expression data presented as $-\triangle \mathrm{Ct}$. PDE5A vs LBWR - control $\mathrm{R}^{2}=0.02, \mathrm{p}=0.61$; sham $\mathrm{CDH} \mathrm{R}^{2}=0.38, \mathrm{p}=0.20 ; \mathrm{CDH} \mathrm{R}^{2}=0.11$, $\mathrm{p}=0.29 ; \mathrm{CDH}+\mathrm{TO} \mathrm{R}^{2}=0.30, \mathrm{p}=0.04$. PDE5A vs MTBD - control $\mathrm{R}^{2}=0.004, \mathrm{p}=0.83 ;$ sham $\mathrm{CDH}^{2}=0.31, \mathrm{p}=0.25$; $\mathrm{CDH} \mathrm{R} \mathrm{R}^{2}=0.08, \mathrm{p}=0.38 ; \mathrm{CDH}+\mathrm{TO} \mathrm{R}^{2}=0.31, \mathrm{p}=0.04$. 

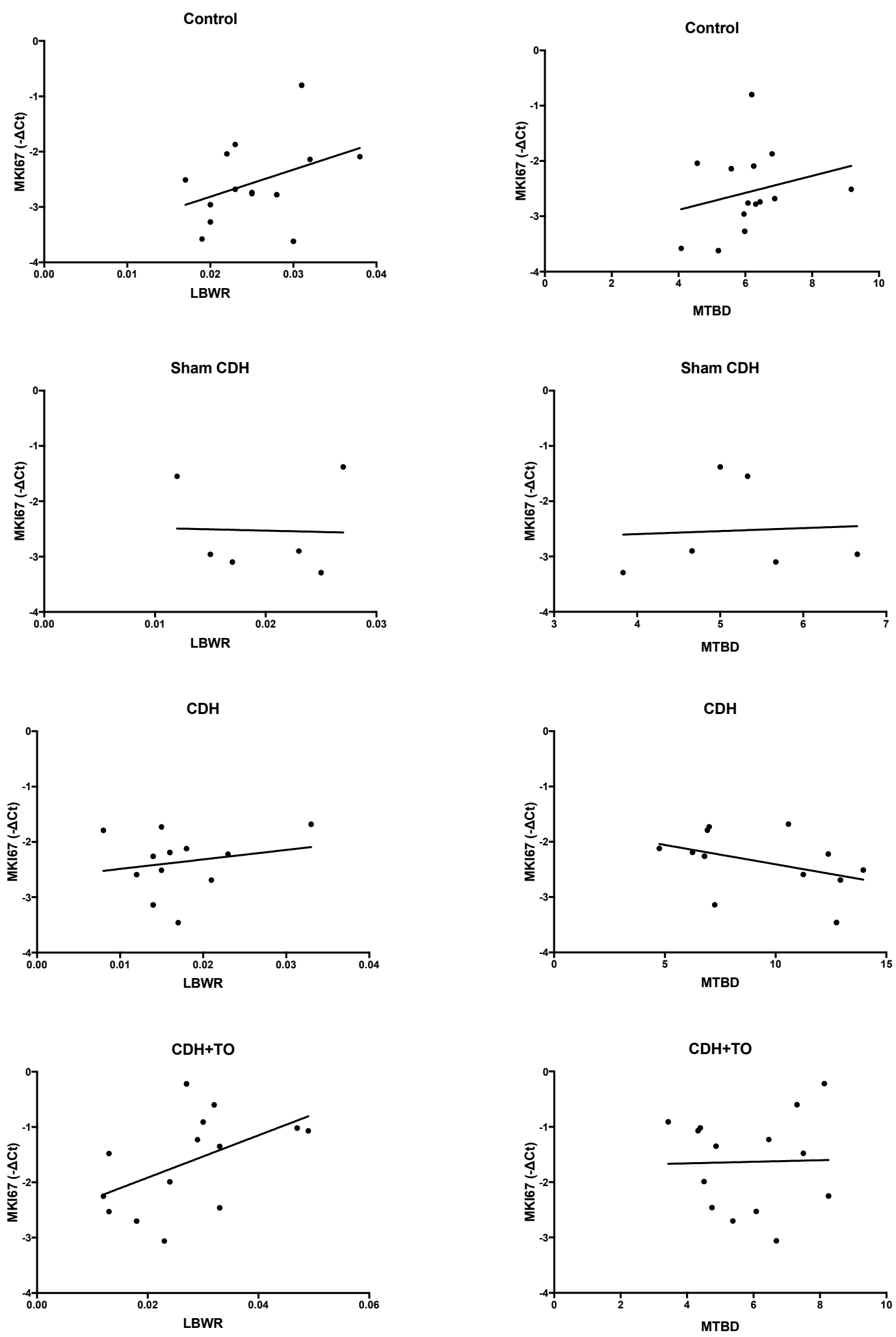

Supplementary Figure 5: Correlation Graphs of MKI67 vs LBWR and MKI67 vs MTBD. MKI67 expression data presented as $-\Delta$ Ct. MKI67 vs LBWR - control $\mathrm{R}^{2}=0.15, \mathrm{p}=0.17$; sham $\mathrm{CDH} \mathrm{R}^{2}=0.001, \mathrm{p}=0.95$; $\mathrm{CDH} \mathrm{R}^{2}=0.04$, $\mathrm{p}=0.54 ; \mathrm{CDH}+\mathrm{TO} \mathrm{R}^{2}=0.26, \mathrm{p}=0.06$. MKI67 vs MTBD - control $\mathrm{R}^{2}=0.06, \mathrm{p}=0.40$; sham $\mathrm{CDH} \mathrm{R}^{2}=0.004, \mathrm{p}=0.91$; $\mathrm{CDH} \mathrm{R}^{2}=0.17, \mathrm{p}=0.19 ; \mathrm{CDH}+\mathrm{TO} \mathrm{R}^{2}=0.0007, \mathrm{p}=0.93$. 

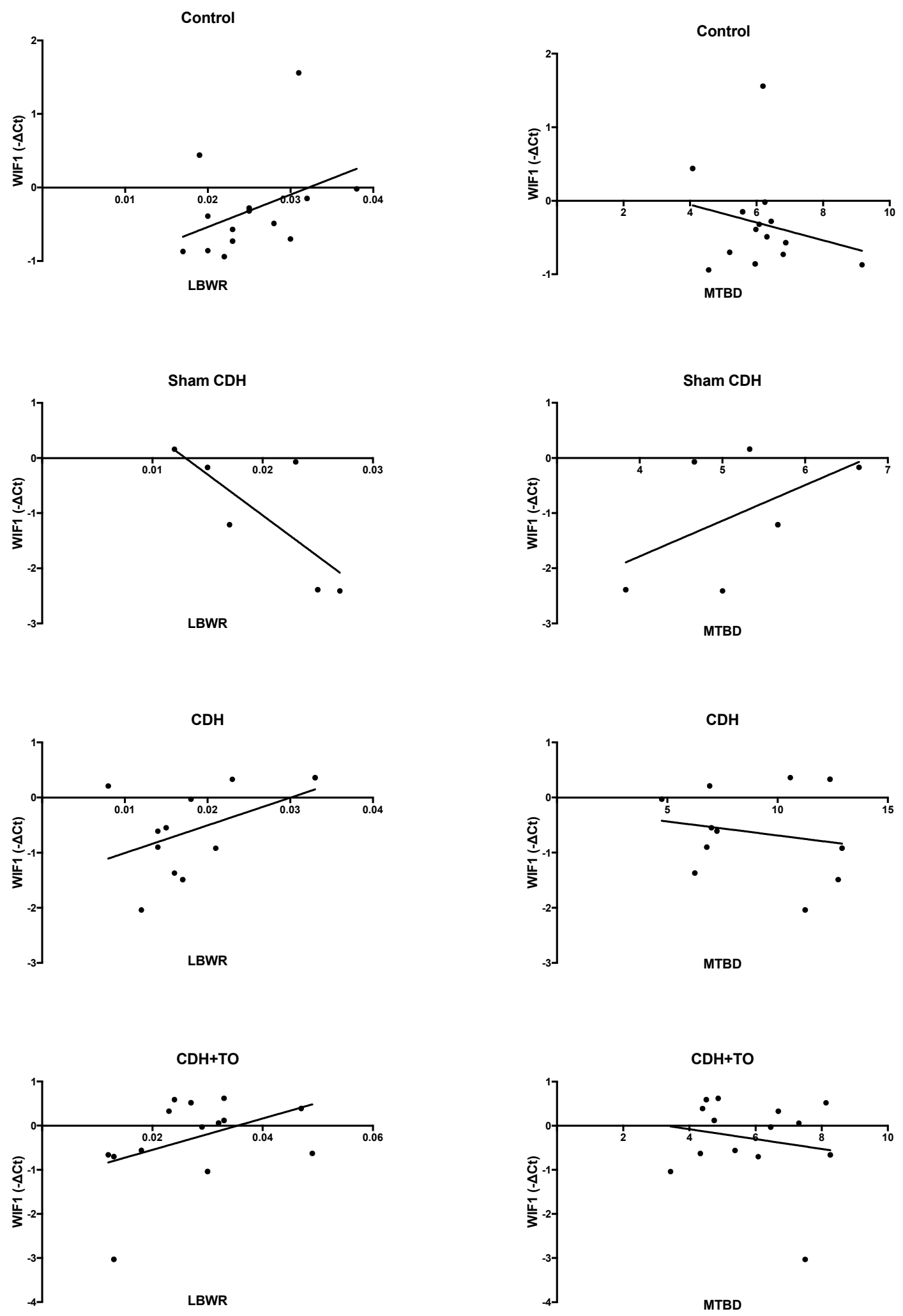

Supplementary Figure 6: Correlation Graphs of WIF1 vs LBWR and WIF1 vs MTBD. WIF1 expression data presented as $-\Delta$ Ct. WIF1 vs LBWR - control $\mathrm{R}^{2}=0.16, \mathrm{p}=0.16$; sham $\mathrm{CDH} \mathrm{R}^{2}=0.58, \mathrm{p}=0.08 ; \mathrm{CDH} \mathrm{R}^{2}=0.17, \mathrm{p}=0.21$; $\mathrm{CDH}+\mathrm{TO} \mathrm{R}^{2}=0.18, \mathrm{p}=0.13$. WIF1 vs MTBD - control $\mathrm{R}^{2}=0.05, \mathrm{p}=0.45$; sham $\mathrm{CDH} \mathrm{R}^{2}=0.28, \mathrm{p}=0.28 ; \mathrm{CDH}$ $\mathrm{R}^{2}=0.04, \mathrm{p}=0.57 ; \mathrm{CDH}+\mathrm{TO} \mathrm{R}^{2}=0.03, \mathrm{p}=0.54$. 

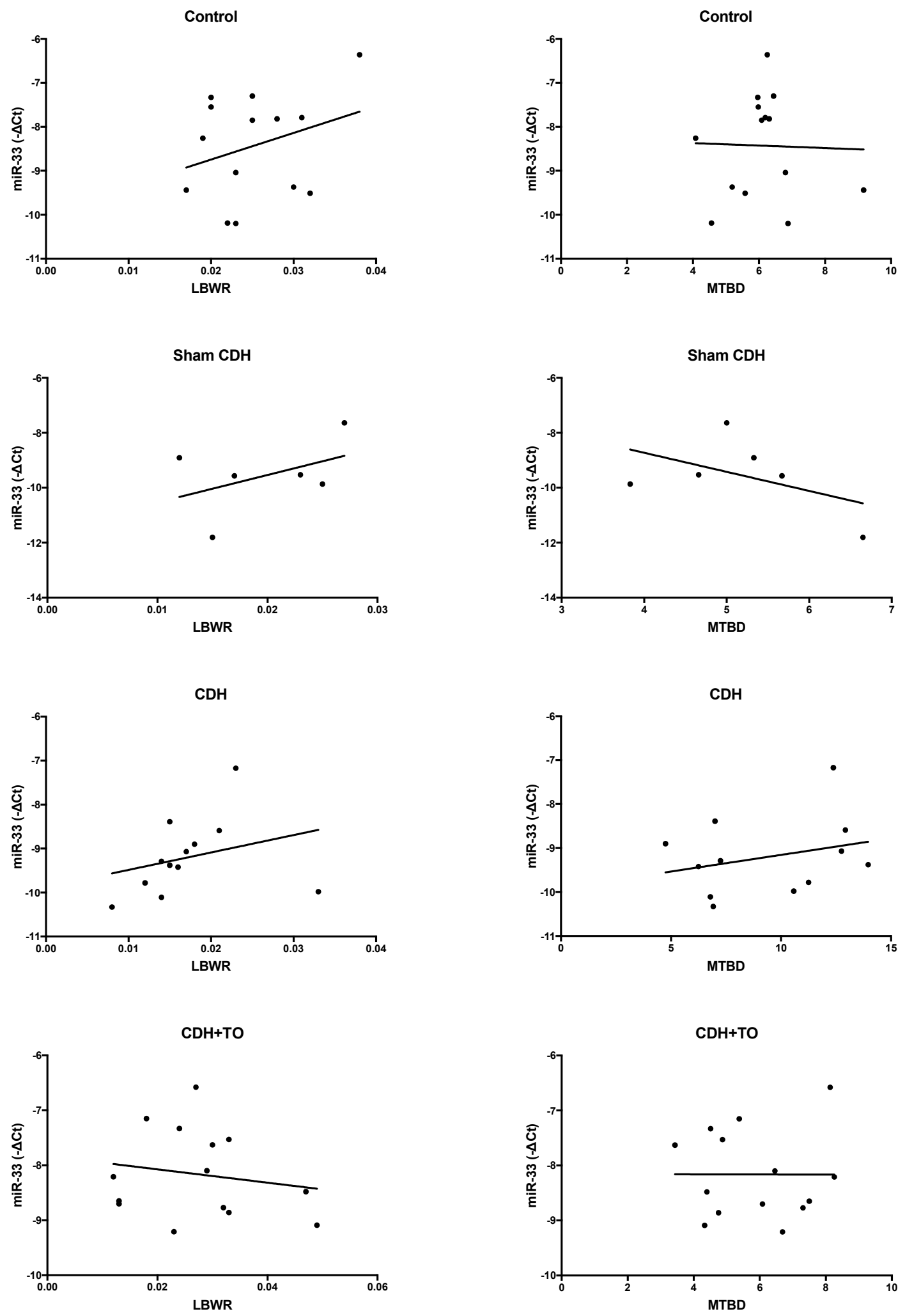

Supplementary Figure 7: Correlation Graphs of miR-33 vs LBWR and miR-33 vs MTBD. miR-33 expression data presented as $-\Delta$ Ct. miR-33 vs LBWR - control $\mathrm{R}^{2}=0.090, \mathrm{p}=0.3$; sham $\mathrm{CDH} \mathrm{R}^{2}=0.19, \mathrm{p}=0.38 ; \mathrm{CDH} \mathrm{R}^{2}=0.08$, $\mathrm{p}=0.37$; $\mathrm{CDH}+\mathrm{TO} \mathrm{R}^{2}=0.03, \mathrm{p}=0.55$. miR-33 vs MTBD - control $\mathrm{R}^{2}=0.0008, \mathrm{p}=0.92$; sham $\mathrm{CDH}^{2}=0.24, \mathrm{p}=0.33$; $\mathrm{CDH} \mathrm{R}^{2}=0.08, \mathrm{p}=0.38 ; \mathrm{CDH}+\mathrm{TO} \mathrm{R}^{2}=0.000002, \mathrm{p}=0.99$. 

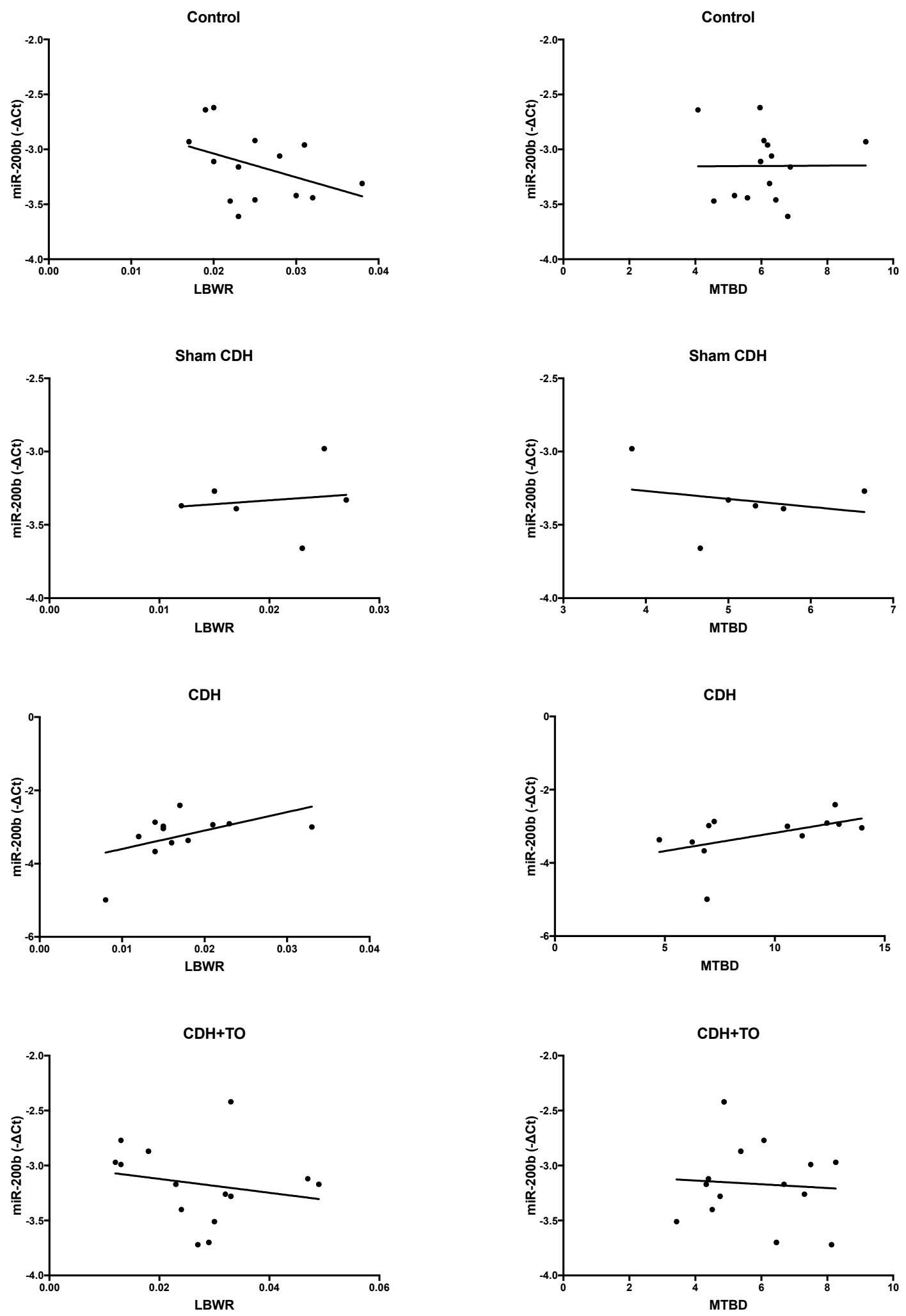

Supplementary Figure 8: Correlation Graphs of miR-200b vs LBWR and miR-200b vs MTBD. miR-200b expression data presented as $-\Delta \mathrm{Ct}$. miR-200b vs LBWR - control $\mathrm{R}^{2}=0.17, \mathrm{p}=0.15$; $\operatorname{sham} \mathrm{CDH} \mathrm{R}^{2}=0.02, \mathrm{p}=0.78$; CDH R ${ }^{2}=0.25, \mathrm{p}=0.1 ; \mathrm{CDH}+\mathrm{TO} \mathrm{R}^{2}=0.04, \mathrm{p}=0.49$. miR-200b vs MTBD - control $\mathrm{R}^{2}=0.00003, \mathrm{p}=0.98$; sham $\mathrm{CDH}$ $\mathrm{R}^{2}=0.06, \mathrm{p}=0.65 ; \mathrm{CDH} \mathrm{R}{ }^{2}=0.25, \mathrm{p}=0.1 ; \mathrm{CDH}+\mathrm{TO} \mathrm{R}^{2}=0.01, \mathrm{p}=0.8$. 

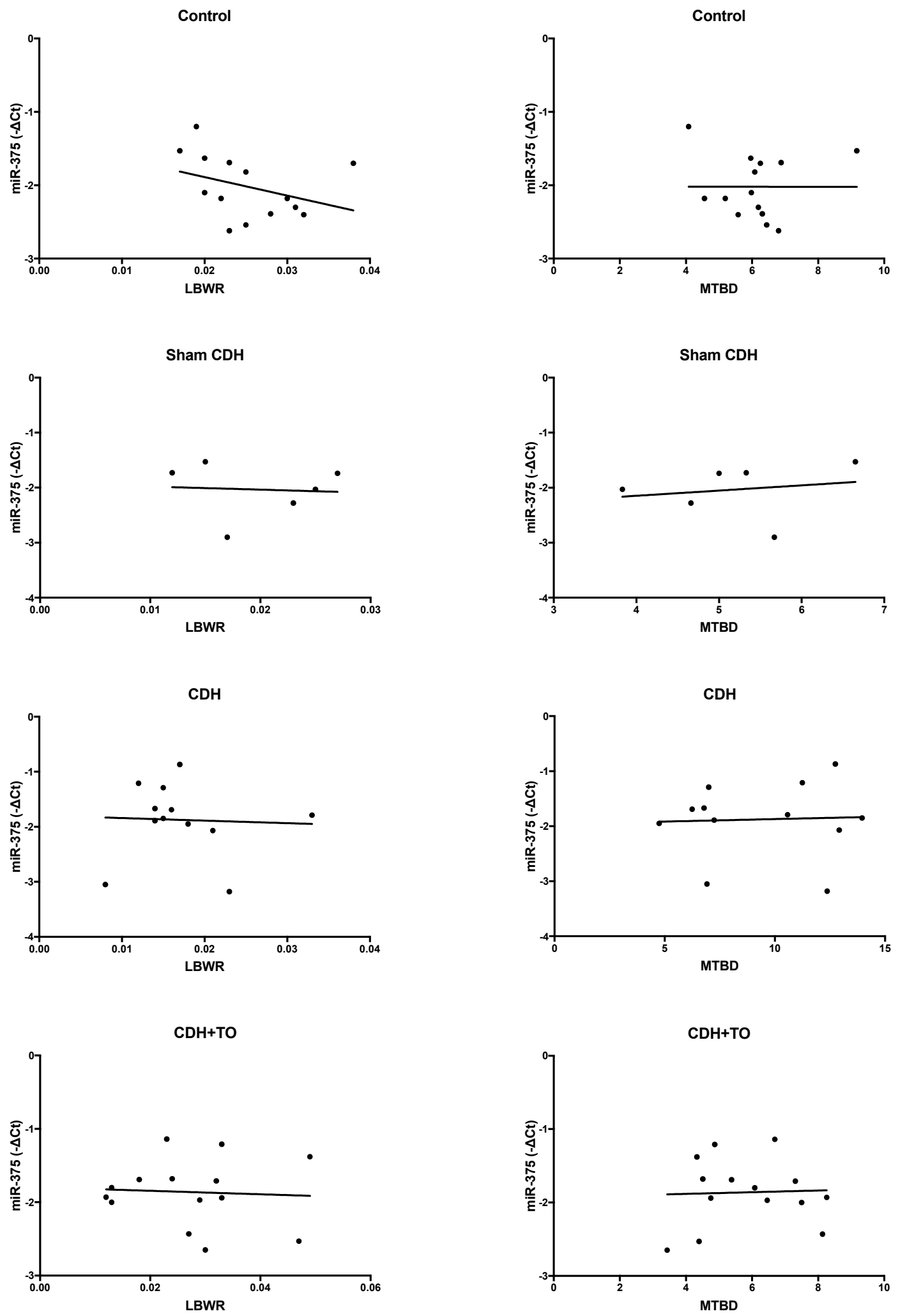

Supplementary Figure 9: Correlation Graphs of miR-375 vs LBWR and miR-375 vs MTBD. miR-375 expression data presented as $-\Delta$ Ct. miR-375 vs LBWR - control $\mathrm{R}^{2}=0.12, \mathrm{p}=0.22$; sham $\mathrm{CDH} \mathrm{R}^{2}=0.005$, $\mathrm{p}=0.9$; $\mathrm{CDH} \mathrm{R}^{2}=0.002, \mathrm{p}=0.89 ; \mathrm{CDH}+\mathrm{TO} \mathrm{R}^{2}=0.004, \mathrm{p}=0.84$. miR-375 vs MTBD - control $\mathrm{R}^{2}=0.0000008, \mathrm{p}=1.00$; sham $\mathrm{CDH} \mathrm{R} \mathrm{R}^{2}=0.03, \mathrm{p}=0.73 ; \mathrm{CDH} \mathrm{R}^{2}=0.002, \mathrm{p}=0.9 ; \mathrm{CDH}+\mathrm{TO} \mathrm{R}^{2}=0.001, \mathrm{p}=0.9$. 


\section{Curriculum Vitae}

Name: Martina Mudri

Post-Secondary Education and Degrees:

General Surgery Residency

2015 - present

Western University

London, ON

Doctor of Medicine

$2011-2015$

University of Saskatchewan

Saskatoon, SK

Certificate in Global Health

$2012-2014$

University of Saskatchewan

Saskatoon, SK

Bachelor of Science Three-Year

$2008-2011$

Anatomy and Cell Biology with Great Distinction

University of Saskatchewan

Saskatoon, SK 


\title{
Publications:
}

Mudri M, Smith SA, Vanderboor C, Davidson J, Regnault TRH, Bütter A. The effects of tracheal occlusion on Wnt signaling in a rabbit model of congenital diaphragmatic hernia. Submitted to the Journal of Pediatric Surgery on July 20, 2018.

Mudri M, Yousef Y, Davidson J, Bütter A, and Emil S. Comparison of perforated appendicitis outcomes at two children's hospitals: The effect of standardization. Submitted to the Canadian Journal of Surgery on June 26, 2018.

Mudri M, Coriolano K, and Bütter A. (2017). Cost analysis of nonoperative management of acute appendicitis in children. Journal of Pediatric Surgery, 52(5), 791-794.

\author{
Abstracts Presented: \\ Oral Presentation: The effects of tracheal occlusion on Wnt signaling in the rabbit model of \\ congenital diaphragmatic hernia \\ Mudri M, Smith SA, Vanderboor C, Davidson J, Regnault TRH, Bütter A \\ Canadian Association of Paediatric Surgeons 50 ${ }^{\text {th }}$ Annual Meeting - September 28, 2018 in \\ Toronto, ON
}

Invited Oral Presentation: The effects of tracheal occlusion on Wnt signaling in the rabbit model of congenital diaphragmatic hernia

Mudri M, Smith SA, Vanderboor C, Davidson J, Regnault TRH, Bütter A

Canadian Surgery Forum 2018 Resident Research Day - September 12, 2018 in St. John's, 
Newfoundland

Invited Oral Presentation: The effects of tracheal occlusion on Wnt signaling in the rabbit model of congenital diaphragmatic hernia

Mudri M, Smith SA, Vanderboor C, Davidson J, Regnault TRH, Bütter A

Dr. Robert Zhong Department of Surgery Research Day - June 15, 2018 in London, ON

Invited Oral Presentation: The effects of tracheal occlusion on Wnt signaling in the rabbit model of congenital diaphragmatic hernia

Mudri M, Smith SA, Vanderboor C, Davidson J, Regnault TRH, Bütter A

$31^{\text {st }}$ Annual Paediatrics Research Day - May 23, 2018 in London, ON

Poster Presentation: Using a surgical rabbit model of congenital diaphragmatic hernia to explore the effects of tracheal occlusion on fetal lung development

Mudri M, Smith SA, Vanderboor C, Davidson J, Regnault TRH, Bütter A

London Health Research Day - May 10, 2018 in London, ON

Oral Presentation: The effects of tracheal occlusion on Wnt signaling in the rabbit model of congenital diaphragmatic hernia

Mudri M, Smith SA, Vanderboor C, Davidson J, Regnault TRH, Bütter A

Division of General Surgery Annual Research Day - May 4, 2018 in London, ON

Oral Presentation: Does fetal tracheal occlusion reverse pulmonary hypoplasia and modify Wnt 
signaling pathway markers in a rabbit model of congenital diaphragmatic hernia?

Mudri M, Smith S, Davidson J, Regnault T, Bütter A

Division of Paediatric Surgery $3^{\text {rd }}$ Annual Research Day - February 12, 2018 in London, ON

Oral Presentation: The management of perforated appendicitis: a tale of two centres

Mudri M, Yousef Y, Davidson J, Bütter A, Emil S

Canadian Association of Paediatric Surgeons 49 ${ }^{\text {th }}$ Annual Meeting - October 5, 2017 in Banff, AB

Oral Presentation: The management of perforated appendicitis: a tale of two centres

Mudri M, Yousef Y, Davidson J, Bütter A, Emil S

Division of General Surgery Annual Research Day - May 5, 2017 in London, ON

Oral Presentation: Cost analysis of non-operative management of acute appendicitis in children

Mudri M, Coriolano K, Bütter A

Canadian Association of Paediatric Surgeons $48^{\text {th }}$ Annual Meeting - September 22, 2016 in Vancouver, BC

Oral Presentation: Cost analysis of non-operative management of acute appendicitis in children Mudri M, Coriolano K, Bütter A

Division of General Surgery Annual Research Day - April 29, 2016 in London, ON

Poster Presentation: Making the Links in the Northern Village of Pinehouse - Dean's Summer Research Day, September 29, 2012 in Saskatoon, SK 


\section{Awards:}

Canadian Association of Paediatric Surgeons First Prize for Best Oral Presentation - 2018

Department of Surgery MSc in Surgery Student Colloquium Presentation Winner - 2018

Best Basic Science Research Award, Division of General Surgery Annual Research Day - 2018

Best Research Presentation, Division of Paediatric Surgery Research Day - 2018

Dean's Summer Research Project Award - 2012

Dr. T. J. Murray Summer Studentship Award - 2011

STM Knights of Columbus First Year Scholarship - 2008

University of Saskatchewan Guaranteed Entrance Scholarship - 2008

University of Saskatchewan Greystone Scholars Society - 2008

Saskatchewan General Proficiency Award - 2008 